Florida International University

FIU Digital Commons

FIU Electronic Theses and Dissertations

University Graduate School

9-16-2009

\title{
The Use of a Computer Graphic Organizer for Persuasive Composition Writing by Hispanic Students with Specific Learning Disabilities
}

Caridad H. Unzueta

Florida International University, drcunzueta@gmail.com

DOI: $10.25148 /$ etd.FI09120819

Follow this and additional works at: https://digitalcommons.fiu.edu/etd

Part of the Bilingual, Multilingual, and Multicultural Education Commons, Curriculum and $\underline{\text { Instruction Commons, Instructional Media Design Commons, Junior High, Intermediate, Middle }}$ $\underline{\text { School Education and Teaching Commons, Other Education Commons, and the Special Education }}$ and Teaching Commons

\section{Recommended Citation}

Unzueta, Caridad H., "The Use of a Computer Graphic Organizer for Persuasive Composition Writing by Hispanic Students with Specific Learning Disabilities" (2009). FIU Electronic Theses and Dissertations. 110.

https://digitalcommons.fiu.edu/etd/110 


\section{FLORIDA INTERNATIONAL UNIVERSITY}

Miami, Florida

THE USE OF A COMPUTER GRAPHIC ORGANIZER FOR PERSUASIVE COMPOSITION WRITING BY HISPANIC STUDENTS WITH SPECIFIC LEARNING DISABILITIES

A dissertation submitted in partial fulfillment of the requirements for the degree of DOCTOR OF EDUCATION

in EXCEPTIONAL STUDENT EDUCATION

by

Caridad H. Unzueta

2009 
To: Interim Dean Marie McDemmond

College of Education

This dissertation, written by Caridad H. Unzueta, and entitled, The Use of a Computer Graphic Organizer for Persuasive Composition Writing by Hispanic Students with Specific Learning Disabilities, having been approved in respect to style and intellectual content, is referred to you for judgment.

We have read this dissertation and recommend that it be approved.

Elizabeth Cramer

Adriana McEachern

Linda Spears-Bunton

Patricia M. Barbetta, Major Professor

Date of Defense: September 16, 2009

The dissertation of Caridad H. Unzueta is approved.

Interim Dean Marie McDemmond

College of Education

Dean George Walker

University Graduate School

Florida International University, 2009 
(C) Copyright 2009 by Caridad H. Unzueta

All rights reserved. 


\section{DEDICATION}

This is dedicated to my family. Thank you for always believing in me. 


\section{ACKNOWLEDGMENTS}

I would like to thank the members of my committee Major Professor Dr. Patricia M. Barbetta, Dr. Elizabeth Cramer, Dr. Adriana McEachern, and Dr. Linda SpearsBunton for their dedication, insights, and support. Without their leadership, this work would not have been possible. Dr. Barbetta, thank you for your countless hours of mentoring that went into this work.

I want to extend a special thanks to Dr. Ann Nevin for first teaching me about single subject design. Her enthusiasm and support has been an inspiration.

Finally, I would like to thank Mortimer Hechavarria, Mayra Constantino, Denise Lam, Olga De Novi, and Javier Unzueta for the valuable input and time they have given to this study. Thank you for your support.

Throughout my doctoral journey at F.I.U., I have met and worked closely with several students, faculty, and staff. I am very grateful for the support I have received from all of them and for the opportunity to learn and share with them. 


\begin{abstract}
OF THE DISSERTATION
THE USE OF A COMPUTER GRAPHIC ORGANIZER FOR PERSUASIVE COMPOSITION WRITING BY HISPANIC STUDENTS WITH SPECIFIC LEARNING DISABILITIES
\end{abstract}

by

Caridad H. Unzueta

Florida International University, 2009

Miami, Florida

Professor Patricia M. Barbetta, Major Professor

Many culturally and linguistically diverse (CLD) students with specific learning disabilities (SLD) struggle with the writing process. Particularly, they have difficulties developing and expanding ideas, organizing and elaborating sentences, and revising and editing their compositions (Graham, Harris, \& Larsen, 2001; Myles, 2002). Computer graphic organizers offer a possible solution to assist them in their writing. This study investigated the effects of a computer graphic organizer on the persuasive writing compositions of Hispanic middle school students with SLD. A multiple baseline design across subjects was used to examine its effects on six dependent variables: number of arguments and supporting details, number and percentage of transferred arguments and supporting details, planning time, writing fluency, syntactical maturity (measured by Tunits, the shortest grammatical sentence without fragments), and overall organization. Data were collected and analyzed throughout baseline and intervention.

Participants were taught persuasive writing and the writing process prior to baseline. During baseline, participants were given a prompt and asked to use paper and 
pencil to plan their compositions. A computer was used for typing and editing. Intervention required participants to use a computer graphic organizer for planning and then a computer for typing and editing. The planning sheets and written composition were printed and analyzed daily along with the time each participant spent on planning.

The use of computer graphic organizers had a positive effect on the planning and persuasive writing compositions. Increases were noted in the number of supporting details planned, percentage of supporting details transferred, planning time, writing fluency, syntactical maturity in number of T-units, and overall organization of the composition. Minimal to negligible increases were noted in the mean number of arguments planned and written. Varying effects were noted in the percent of transferred arguments and there was a decrease in the T-unit mean length.

This study extends the limited literature on the effects of computer graphic organizers as a prewriting strategy for Hispanic students with SLD. In order to fully gauge the potential of this intervention, future research should investigate the use of different features of computer graphic organizer programs, its effects with other writing genres, and different populations. 


\section{TABLE OF CONTENTS}

CHAPTER

PAGE

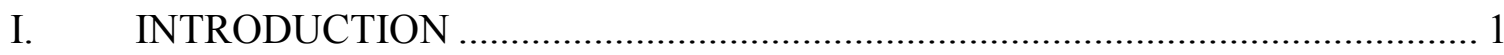

Composition Writing Profiles for Students with SLD and CLD Students .............4

Composition Writing Instructional Strategies for Students with SLD and

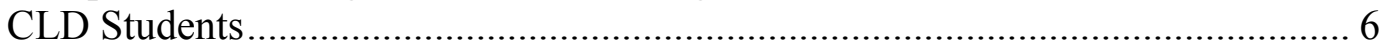

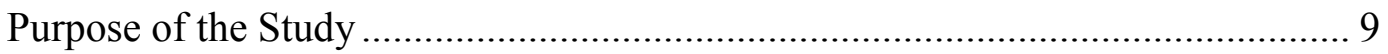

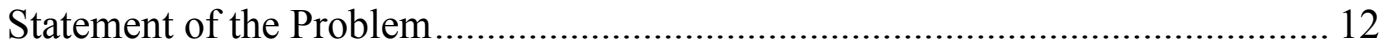

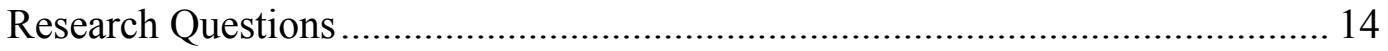

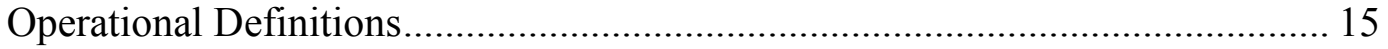

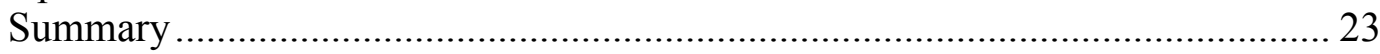

II. LITERATURE REVIEW ................................................................... 26

Writing Abilities During Stages of Writing of Students with SLD and

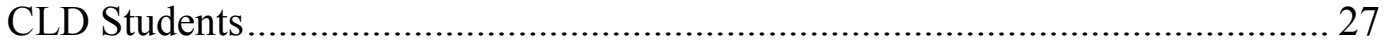

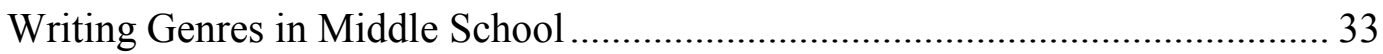

Writing Strategies for Students with Specific Learning Disabilities ................... 34

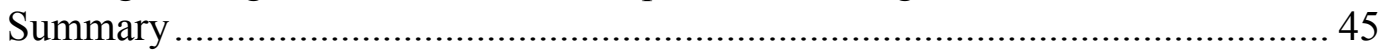

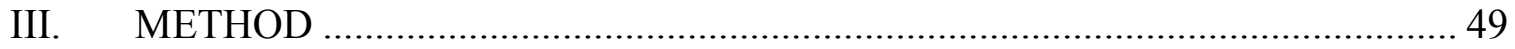

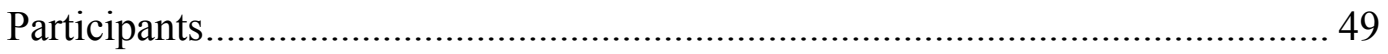

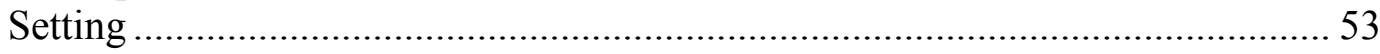

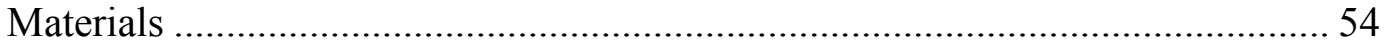

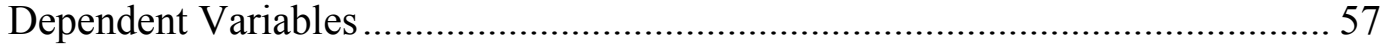

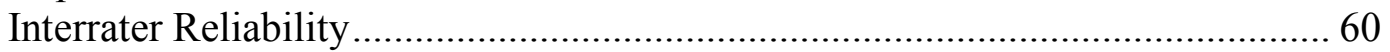

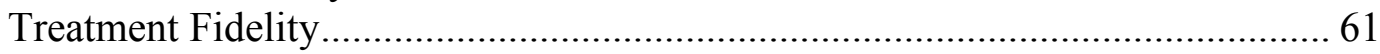

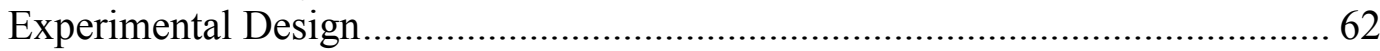

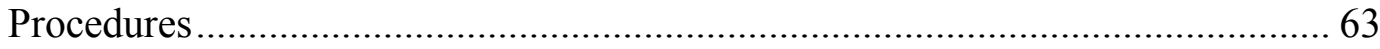

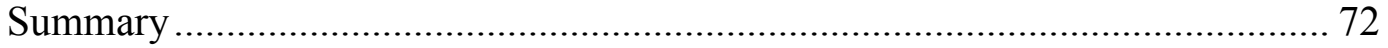

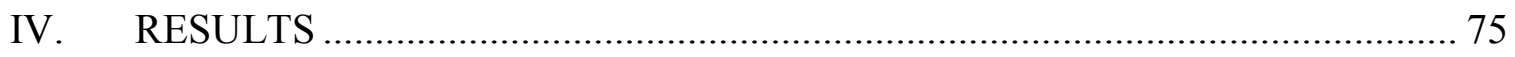

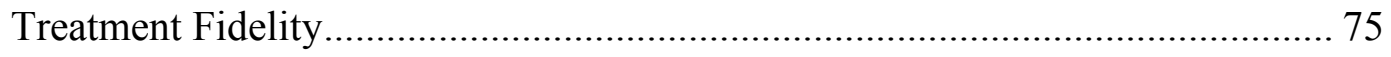

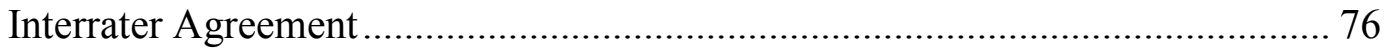

Number of Arguments and Supporting Details .............................................. 76

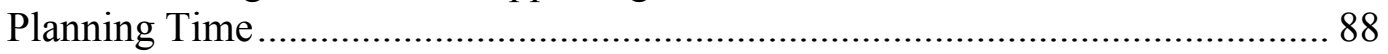

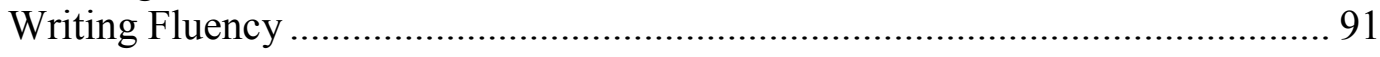

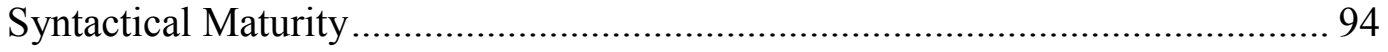

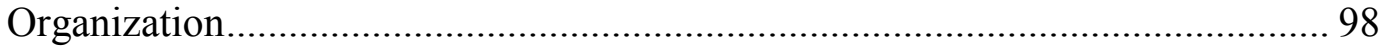

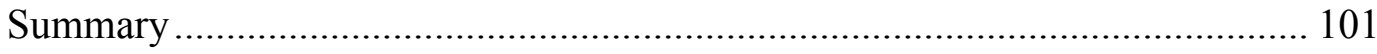

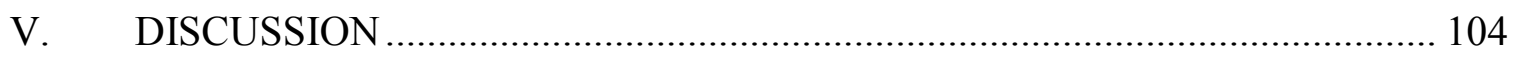

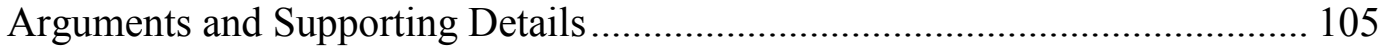

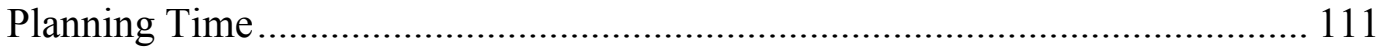


Writing Fluency …............................................................................. 113

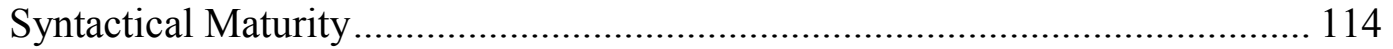

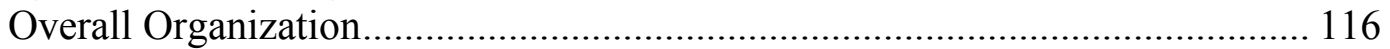

Summary of Results of All Dependent Variables......................................... 118

Implications for Practice .................................................................... 120

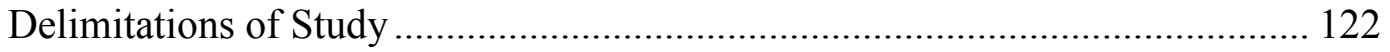

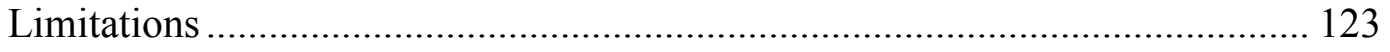

Suggestions for Future Research .............................................................. 123

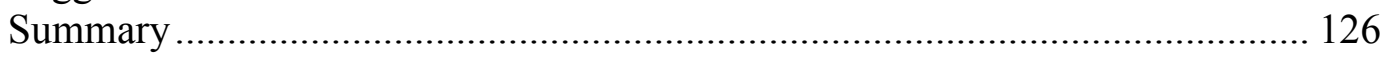

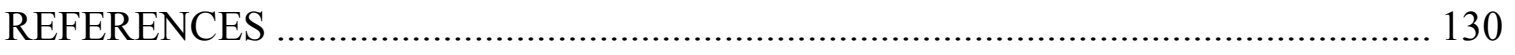

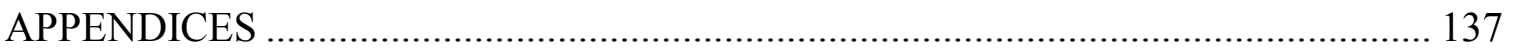

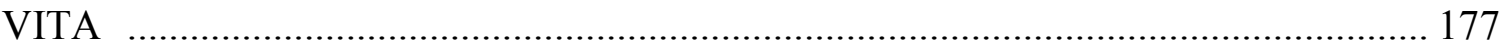




\section{LIST OF TABLES}

TABLE

PAGE

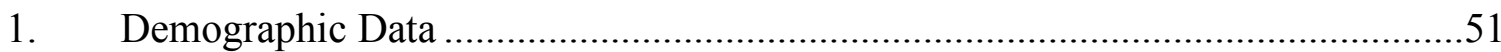

2. Mean Number of Arguments and Supporting Details ........................................81

3. Percentage of Transferred Arguments and Supporting Details ...........................83

4. Mean Number of Minutes Spent in the Planning Stage.....................................90

5. Mean Number of Words Written During Baseline and Intervention ....................93

6. Mean Number of T-units in the Compositions and Mean Length .........................97

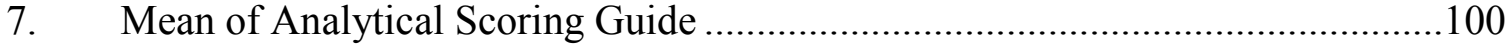




\section{LIST OF FIGURES}

FIGURES

PAGE

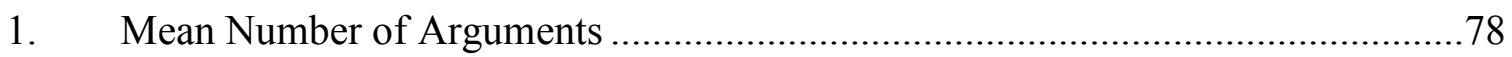

2. Mean Number of Supporting Details ……………...........................................78

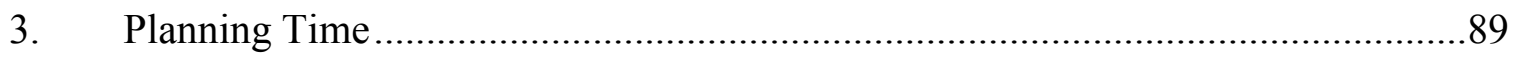

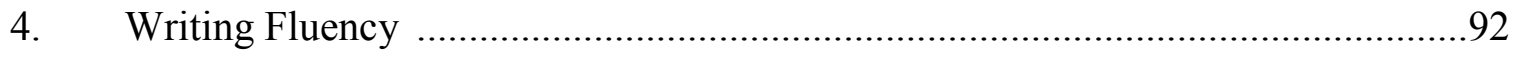

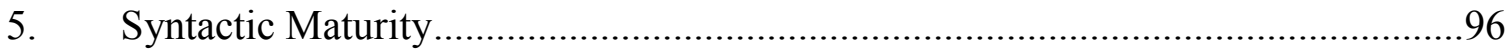

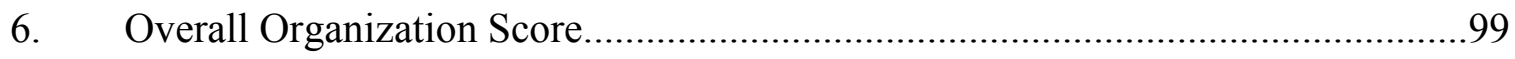




\section{CHAPTER I}

\section{INTRODUCTION}

The ability to write or compose clearly, concisely, and effectively is important to achieve success in today's schools (National Writing Project, 2003). Many students, however, have limited writing abilities and struggle to write compositions that adequately convey their thoughts and ideas. As evidence, the National Assessment of Educational Progress (NAEP) Writing Assessment results show that only $33 \%$ of eighth grade students are scoring at or above the proficient level in writing (Salahu-Din, Persky, \& Miller, 2008). This means that fewer than one in three eighth grade students receive scores at or above the proficient level. The NAEP Writing Assessment measures the formal writing ability of students in the United States across three different writing genres: (a) narrative, (b) expository, and (c) persuasive. Of the eighth graders who completed any of the three NAEP writing genre assessments, the mean score was 156 points out of a possible 300 , which is about 20 points below the minimum proficiency mark (Salahu-Din et al., 2008). In particular, two groups of students show a significant deficiency in writing: students with specific learning disabilities (SLD) and Hispanic students.

Many students with SLD struggle with writing in part because of the nature of their disability (Sitko, Laine, \& Sitko, 2005; Troia, 2003). SLD is the term used to describe a disorder in one or more of the basic psychological processes needed to understand or use language, whether spoken or written, that impairs learning. This disorder may manifest itself as the imperfect ability to listen, think, speak, read, write, 
spell, or perform mathematical calculations (Individuals with Disabilities Education Improvement Act [IDEA], 2004, § 602). In recent years, more than $80 \%$ of the referrals for special education are for suspected SLD, representing a tripling of the number of students labeled SLD in the last 30 years (National Center Educational Statistics [NCES], 2006; U.S. Department of Education, 2002). Although prevalence rates specifically for SLD in written expression are not available, a recent study suggests that problems in written expression for students with SLD are increasing and are in need of attention (Mayes \& Calhoun, 2005).

Similar to the increase in the number of students identified as having SLD, there has been an increase in the number of culturally and linguistically diverse (CLD) students in U.S. classrooms (Kewal Ramani, Gilbertson, Fox, \& Provasnik, 2007). CLD students are those whose backgrounds differ from the background of White students by race, class, culture, ethnicity, and/ or language (Arendale, 2007; Willis, 2000). These students may bring into the classroom a different set of values, expectations, and experiences (Hoover, Klingner, Baca, \& Patton, 2008). Hispanic students represent one of the most rapidly growing populations of CLD students (Caesar, 2005; Gándara, 2008; Williams, 2001). For example, in 1990, Hispanics represented $9 \%$ of the U.S. population (Caesar), while in 2005 they represented 14\% of the whole population (Kewal Ramani et al., 2007). Hispanic students are those whose origins are from Spain or any of the Spanish speaking countries in Central America, South America, or Caribbean Islands (U.S. Census Bureau, 2000).

Hispanic students often have greater problems than non-Hispanic White students in attaining appropriate writing proficiency levels in English (Salahu-Din et al., 2008). 
On the NAEP Writing Assessment, the average White eighth grade student scored 164 of 300 points, while the average Hispanic eighth grade student scored 142 points (Salahu-

Din et al.). The primary reasons for many Hispanic students' low performances in writing are an inability of many of these students to write fluently in English, and a limited ability to use complex sentence structures in English (Myles, 2002).

CLD students who are also classified as SLD often display the writing problems of each group (Monroe \& Troia, 2006), making writing a more difficult task to accomplish. Their disability in written expression hinders their writing abilities and their understanding of the writing process (Monroe \& Troia). Likewise, their lack of command of the language can contribute to their lack of writing fluency and inability to use the writing process effectively (Brice, Miller, \& Brice, 2006; Myles, 2002). CLD students with SLD are at greater risk for academic failure because they have the combined problems of a disability and a linguistic or cultural difference (Hoover et al., 2008).

In summary, writing is a problem for many American students (Salahu-Din et al., 2008). One specific group of students having difficulties with writing is CLD students with SLD. Many CLD students with SLD struggle with writing as they share the writing challenges of both groups (Hoover et al., 2008; Monroe \& Troia, 2006). Hispanic students, the subgroup of CLD students for whom this study was designed, represent one of the most rapidly growing populations of CLD students (Caesar, 2005; Gándara, 2008; Williams, 2001). Consequently, there is a need to address the writing skills of Hispanic students with SLD.

It should be noted that in this study writing refers to composition writing which is composed of having and knowing how to use prior knowledge on topics, writing genres 
and conventions while using the writing process (Scott \& Vitale, 2003). The terms writing and composition are used interchangeably throughout.

\section{Composition Writing Profiles for Students with SLD and CLD Students}

The research on the writing challenges of students with SLD has been well documented (e.g., Englert, Zhao, Dunsmore, Collings, \& Wolbers, 2007; Graham, Harris, \& Larsen, 2001; McCormick, 2003). Many of these same challenges have been attributed to CLD students who struggle with composition writing (Graham, Harris, \& Mason, 2005; Monroe \& Troia, 2006). For those students who are both CLD and have SLD, achieving in academics is not easily attained (Hoover et al., 2008).

Research demonstrates that most students with SLD have difficulty navigating the five stages of the writing process: (a) planning, (b) organization, (c) revising, (d) editing, and (e) publishing (Englert et al., 2007; Graham et al., 2001; Kunka et al., 2007; McCormick, 2003). Many students with SLD lack the ability to develop an idea during the planning stage, expand on it, and express it in written form in an organized manner during the organization stage (Englert et al.; Graham et al., 2001; Monroe \& Troia, 2006). Furthermore, these students fail to view and to use the writing process as a recursive process, in which writers may have to return to any of the stages at any time in their writing to make improvements or corrections (Englert et al.; Wong, 2000). Usually students with SLD do not complete all five stages. In particular, they do not complete the revising and publishing stages (Graham et al., 2001; Wong). In part, this is due to the large number of errors they have in their composition and their inability to expand on their ideas (Wong). 
Many CLD students, such as those who are Hispanic, face similar problems with the writing process as students with SLD (Monroe \& Troia, 2006). When Hispanic students have not mastered the English language, considerable time in the classroom is spent on teaching English language proficiency (listening, speaking, and reading) which leads to a diminished focus on writing and writing development (Hartman \& Tarone, 1999; National Council for Teachers of English [NCTE], 2001). This is one of the reasons that Hispanic students who have not fully mastered the English language have additional challenges with composition writing (Myles, 2002; NCTE). For some Hispanic students, instruction in composition writing is withheld until proficiency in listening, speaking, and reading is achieved (Gándara, Rumberger, Maxwell-Jolly, \& Callahan, 2003). Although proficiency in listening and speaking is often attained quickly, reading fluency and comprehension may take several years or even a lifetime to master (NCTE). Therefore, some Hispanic students receive limited instruction in composition writing because language proficiency requirements have not been met (Gándara et al., 2003). In summation, students with SLD are less likely to understand and to use the writing process effectively than general-education students (Graham et al., 2001). Likewise, many CLD students face similar writing challenges as students with SLD (Monroe \& Troia, 2006), making writing at a proficient level difficult to attain. This would suggest that both groups of students, SLD and CLD, or those with SLD and CLD, would benefit from remedial or additional instruction in the writing process. However, both groups receive less exposure to writing instruction as compared to general-education students (Graham et al., 2001; James, Abbott, \& Greenwood, 2001). Furthermore, the exposure they do receive lacks the depth of instruction received by general-education 
students (Applebee \& Langer, 2006). This reduced exposure most likely contributes to their inability to utilize the process to its fullest potential (James et al., 2001).

Composition Writing Instructional Strategies for Students with SLD and CLD Students

There has been considerable research on effective writing strategies for students with SLD (e.g., De La Paz \& Graham, 2002; Englert et al., 2007; Graham et al., 2005; Sturm \& Rankin-Erickson, 2002). However, there is a need for more research on effective writing strategies for CLD students (August, 2006; Hoover et al., 2008). Furthermore, there exists an even greater need for studies on effective writing strategies for CLD students with SLD as limited research exists (e.g., August; Graham et al., 2005; Graves, Valles, \& Rueda, 2001; Monroe \& Troia, 2006). Nevertheless, experts suggest that effective writing strategies with students with SLD should be considered for CLD students (August; Monroe \& Troia).

Effective writing strategies for students with SLD have focused on teaching these students the writing process and how to use it effectively to improve their writing. Four main strategies recommended for students with SLD are: (a) scaffolding, (b) selfregulated strategy development (SRSD), (c) mnemonics, and (d) graphic organizers. Scaffolding allows students to break the writing process into smaller parts (Englert et al., 2007). SRSD focuses on developing self-regulation of the students' writing to selfmonitor progress (De La Paz \& Graham, 2002). Mnemonic devices refers to the use of a word in which each letter represents a specific task or phrase that assists students in remembering the writing process or specific writing genre formula (De La Paz \& Graham; Graham \& Harris, 2005). The fourth recommended strategy, graphic organizers, was the focus of this study. Graphic organizers are pictorial or graphical ways of 
organizing information and thoughts (DiCecco \& Gleason, 2002; George, Schaff, \& Jeffs, 2005; Kim, Vaughn, Wanzek, \& Wei, 2004).

There are two major methods forms of graphic organizers: handwritten graphic organizer, and computer graphic organizer. Handwritten graphic organizers employ the use of paper and pen while computer graphic organizers use computer software to generate the organizers. Computer graphic organizers provide students with the option of editing and making changes quickly and efficiently without having to erase or start over as would be the case with the handwritten graphic organizers (Anderson-Inman \& Ditson, 1999).

Graphic organizers have been found to be effective in aiding students to attain and retain knowledge across multiple subject areas (Nesbit \& Adesope, 2006). In a pilot study, Boon, Fore, Ayres, and Spencer (2005) noted that graphic organizers helped increase the recall of information with students with mild disabilities in social studies when they used graphic organizers to retain social studies facts over a 1-week period. Asan (2007) found similar results on student achievement when graphic organizers were used as a science review of teacher-taught material. In their synthesis of the graphic organizer research, Kim et al. (2004) found that graphic organizers assisted students with SLD in organizing the information they read and improving their recall of the readings. Hence, graphic organizers helped improve the students' reading comprehension (Kim et al., 2004) which is the ability of the reader to activate prior knowledge and experiences to make sense of text (Randi, Grigorenko, \& Sternberg, 2005). However, Kim et al. also noted that prior studies on graphic organizers and composition writing did not follow a progressive or systematic line of research, possibly leading to the inconsistencies in the 
results and challenges in identifying sources of variability of results. Although graphic organizers have been used extensively with reading comprehension across multiple subjects (e.g., Boon et al., 2005; DiCecco \& Gleason, 2002; Kim et al.; Sitko et al., 2005) there is a need for additional research on graphic organizers to extend the limited research on the use of graphic organizers to improve students' writing.

Only four studies were found that employed the use of computer graphic organizers to improve students' writing (i.e., Blair, Ormsbee, \& Brandes, 2002; Lin, Strickland, Ray, \& Denner, 2004; Lorber, 2004; Sturm \& Rankin-Erickson, 2002). Of these, only two specifically investigated the use of computer graphic organizers with students with disabilities (i.e., Blair et al., 2002; Sturm \& Rankin-Erickson). Lin et al. (2004) investigated the use of handwritten and computer graphic organizers as a prewriting strategy for persuasive writing with 278 eighth grade general-education students. They found that computer graphic organizers increased the number of ideas generated by the students in the planning stage more than with handwritten graphic organizers. Lorber (2004) conducted a study on expository writing with 67 eighth grade general-education students using computer graphic organizers. The researcher found that computer graphic organizers increased the students' ability to organize their ideas and to effectively write compositions. Blair et al. (2002) studied the effects of a computer graphic organizer on the narrative writing of 24 students with mild disabilities. The results of the study revealed that there was only a small improvement in the quality of the students' writing but a notable improvement in the quantity of the students' writing. However, Blair et al.'s study did not provide statistical data in their paper to support these results. 
Sturm and Rankin-Erickson (2002) conducted a study on composition writing across three conditions: (a) writing with no graphic organizer, (b) handwritten graphic organizers, and (c) computer graphic organizers. Of the 27 students who participated, only the 12 scores for the students with SLD were presented. Findings of their study indicated that both handwritten and computer graphic organizers had significant increases in the number of words written, number of main clauses with subordinate clauses (Tunits), and quality of writing as measured by a holistic score. However, increases were also noted in the control group who did not use either type of graphic organizer intervention. These researchers attribute this to the fact that expository writing instruction was taught after the collection of baseline data. Therefore, the control group improvements may be attributable to the writing instruction. In addition, improvements in the experimental group may be attributed both to the writing instruction and the use of graphic organizers.

All four studies demonstrated that computer graphic organizers can be used to improve students' writing and organization. Unfortunately, only two of the four studies involved students with disabilities (i.e., Blair et al., 2002; Sturm \& Rankin-Erickson, 2002), and none of the four studies involved CLD students with SLD.

\section{Purpose of this Study}

Composition writing continues to be a challenge for a significant number of American students. NAEP Writing Assessment, indicated that as many as $66 \%$ of the nation's students scored below the proficiency level (Salahu-Din et al., 2008). Amongst the $66 \%$ writing below proficiency were students with SLD (Salahu-Din et al.). In addition, there exists a writing gap between Hispanic students and non-Hispanic White 
students (Salahu-Din et al.). Therefore, it is likely that Hispanic students with SLD are at a greater disadvantage when it comes to writing.

Of the three writing genres measured by the NAEP Writing Assessment, persuasive writing requires the highest levels of thinking from a student. Persuasive writing requires the student to take a stance and convince his or her audience through logical arguments and supporting evidence that this opinion is the correct one (SalahuDin et al., 2008). This genre of writing is rather challenging for many CLD students with SLD because of their existing difficulties in composition writing and their limited exposure to this form of writing. Only one study was found using persuasive writing with CLD students with SLD (Monroe \& Troia, 2006); however, that study did not involve the use of graphic organizers. Hence, researching methods to improve the quality of the persuasive writing for CLD students with SLD is needed.

A promising approach to support CLD students with SLD with persuasive writing is to use computer graphic organizers. However, limited research exists on the use of computer graphic organizers and composition writing; none were found with Hispanic students who are SLD. In fact, only four prominent studies were identified that involved the use of computer graphic organizers with respect to composition writing and the results of these were equivocal (i.e., Blair et al., 2002; Lin et al., 2004; Lorber, 2004; Sturm \& Rankin-Erickson, 2002). Lin et al. (2004) studied the persuasive writing of 226 general-education students. Although their study demonstrated that computer graphic organizers assist students in the planning stage, the study did not demonstrate improvement in the students' overall writing. Lorber (2004) focused on expository writing with 67 general-education students. The results of Lorber's study indicated that 
students did in fact plan better and write better. Confirmation of Lorber's results still need to be obtained through replication of the study. Blair et al. (2002) focused on narrative writing with 24 seventh and eighth grade students with mild disabilities. As with Lorber, Blair et al.'s study has not been replicated and the results can not be further verified. Sturm and Rankin-Erickson (2002) studied the expository writing of 12 students with SLD. The findings of Sturm and Rankin-Erickson showed increases when using handwritten and computer graphic organizers; however, increases were also found when no graphic organizer was used. According to Sturm and Rankin-Erickson, the inability to determine which strategy was better is in part due to the research method employed. Sturm and Rankin-Erickson suggest implementing a single subject design with graphic organizers as a prewriting strategy. They suggest that this will narrow the focus of the study and will facilitate in determining the effectiveness of graphic organizers as a prewriting strategy. This study utilized a single subject, multiple baseline design.

Both the Blair et al. (2002) and the Sturm and Rankin-Erickson (2002) studies employed the use of computer graphic organizers for the planning phase of writing. Although both studies had similar populations, neither study investigated the use of computer graphic organizers with CLD students or with CLD students with SLD. Both studies recommended more research in the use of computer graphic organizers in writing. This study focused on Hispanic students with SLD.

In sum, this study was guided by the need to improve the composition writing skills of Hispanic students with SLD. Furthermore, it was designed to extend the results of the limited research on the use of computer graphic organizers by Hispanic students with SLD. No study was found that investigated the effects of computer graphic 
organizers on the writing skills of Hispanic students with SLD. Hispanics are the fastest growing subgroup of CLD students in the U.S. (Caesar, 2005; Gándara, 2008; Williams, 2001). Research on effective writing strategies is needed for this growing population of students. This study was conducted to investigate a strategy to improve the persuasive writing skills of Hispanic students with SLD and to expand the limited existing literature.

Statement of the Problem

This study investigated the effects of the computer graphic organizer, Inspiration $^{\mathrm{TM}} 8.0$ (2008), on the persuasive composition writing skills of Hispanic middle school students with SLD. Specifically, the researcher examined the number of arguments and supporting details developed during the planning stage of writing and the number and percentage of these that transferred to the composition during the organization stage. Writing was also assessed in terms of: (a) the total time spent on the planning stage, (b) writing fluency, (c) syntactical maturity, and (d) the overall organization.

This study extended the work of Sturm and Rankin-Erickson (2002) in several ways. Sturm and Rankin-Erickson's study involved 27 students ranging in ability levels. They used a within-subject repeated measures design to determine the effectiveness of three interventions: (a) writing without graphic organizers, (b) handwritten graphic organizers, and (c) computer graphic organizers. Only the scores for the 12 students with SLD were reported. In extension, this study focused on one specific group of students, Hispanic students with SLD. The influence of graphic organizers on the writing skills of Hispanic students with SLD had not been studied. Also, the persuasive writing genre has not been studied with Hispanic students with SLD. Likewise, this study assessed the 
impact of one independent variable, the computer graphic organizer, and implemented it across two stages of the writing process, planning and organization. Sturm and RankinErickson only focused on the planning phase. In comparison to the Sturm and RankinErickson study, in this study, instruction in persuasive writing was taught before the collection of baseline data. Sturm and Rankin-Erickson taught the expository writing after taking baseline. This caused a problem in discriminating between the effects of the expository writing instruction and the use of the graphic organizer intervention on the writing. In this study, teaching the writing strategy prior to baseline avoided this confounding effect. Additionally, to measure the writing quality of the persuasive writing samples, an analytical scoring rubric was employed instead of a holistic scoring rubric. Using an analytical scoring rubric allowed for the focus to be on specific elements of organization in persuasive writing, rather than on the whole composition (Moskal, 2000). In addition, a multiple baseline design across subjects was employed, allowing for individual rather than group performances to be analyzed.

Also, this study was innovative in that two new dependent variables were incorporated that had not been previously measured in other studies: the number of arguments and supporting details found in both the planning and in the written composition, and the number of arguments and supporting details that transferred from the planning to the written composition. Furthermore, the genre for this study was persuasive writing. No research on the use of computer graphic organizers with persuasive writing and Hispanic students with SLD was found. 


\section{Research Questions}

Using the computer graphic organizer software Inspiration ${ }^{\mathrm{TM}} 8.0$ (2008) to assist Hispanic middle school students with SLD in the writing process, the following research questions were investigated:

1. Maintaining writing time as a constant, will Hispanic middle school students with specific learning disabilities plan their persuasive writing more effectively as measured by the mean number of arguments and supporting details generated in the planning and in the written composition, and the mean number and percentage of arguments and supporting details written in the planning stage that then appear in the written composition with or without the use of computer graphic organizers?

2. Allocating as much as 15 minutes for daily planning, how many minutes daily will Hispanic middle school students with specific learning disabilities utilize for planning?

3. Maintaining writing time as a constant, will Hispanic middle school students with specific learning disabilities perform more effectively in persuasive writing as measured by writing fluency and syntactical maturity with or without the use of computer graphic organizers?

4. Maintaining writing time as a constant, will Hispanic middle school students with specific learning disabilities improve their overall organization of persuasive writing as measured by an analytical scoring rubric with or without the use of computer graphic organizers? 


\section{Operational Definitions}

The following section defines certain terms that are frequently used in this study. Infrequently used terms that require definitions are explained as they are introduced. Agreement

Agreement is when the researcher and rater independently score the dependent variables in the same exact manner (Cooper, Heron, \& Heward, 2007). Analytical Scoring Guide

An analytical scoring guide allows for the separate evaluation of each element of the composition (Moskal, 2000). Unlike a holistic scoring guide which scores the composition as whole, the analytical scoring guide divides the composition into different elements of writing. Each element is scored individually and then added up for a total score (Maxwell, 1996). It is assumed that all elements are of equal importance. The mean can then be calculated by dividing the total score by the number or elements in the scoring guide.

\section{Composition}

Composition is the ability to know how to use prior knowledge on topics, writing genres and conventions while using the writing process to create essays (Scott \& Vitale, 2003). In this study, the terms composition and writing are used interchangeably.

\section{Composition Writing}

Composition writing is the formulation of words and sentences following conventional pattern to create essays or compositions. Composition writing requires having prior knowledge of a topic and of writing genre with its rules and writing 
conventions, and combining this with the ability to use the prior knowledge to organize and write (Scott \& Vitale, 2003) using the writing process.

\section{Computer Graphic Organizers}

Computer graphic organizers are graphic organizers created using computer software. Graphic organizers create visual portrayals that allow the user to brainstorm new ideas and connect concepts (DiCecco \& Gleason, 2002). Computers allow users to easily create, revise, and add information to graphic organizers by linking and unlinking concepts with a click of the mouse (Anderson-Inman \& Ditson, 1999).

\section{Culturally and Linguistically Diverse (CLD) Students}

Culturally and linguistically diverse (CLD) students' backgrounds differ from the prevalent White middle or upper class students' by one or more of the following: race, class, culture, ethnicity, and language (Arendale, 2007; Willis, 2000).

\section{CLD students with Specific Learning Disabilities (SLD)}

CLD students with SLD are students who have limitations in the psychological processes needed to understand or use language either spoken or written as well as having a background that differs from the prevalent White middle or upper class students by one or more of the following: race, class, culture, ethnicity, and language. In this specific study, the psychological process examined was written expression.

\section{Disagreement}

Disagreement is when the researcher and the rater have any difference in the scoring of the dependent variables (Cooper et al., 2007). 


\section{Editing}

The editing stage is composed of the proofreading of a composition to check that words are spelled correctly, grammatical errors are taken care of, punctuation and capitalization are correct and good sentence structure is present (Educational Resource Service [EDR], 2004).

\section{Expository Writing}

Expository or informative writing asks the writer to present the reader with information in the form of a message, idea, or instruction. Expository writing requires the use of such skills such as organization, application, and analysis (Wilder \& Mongillo, 2007).

\section{Graphic Organizers}

Graphic organizers are visual representations that portray relationships among key concepts and form a schematic mapping for this information; creating a meaningful diagram that will help the user expand and explain a concept (DiCecco \& Gleason, 2002). These visual portrayals or illustrations assist in the connection of key concepts and in the building of schema. In writing, graphic organizers allow for the brainstorming of new ideas that connect to the main theme of the writing piece, create concept maps relating the new ideas, and outline said ideas to then aid in the writing of the composition.

\section{Handwritten Graphic Organizers}

Handwritten graphic organizers are graphic organizers that employ the use of paper and pencil to create the organizers. The user draws the graphic organizer onto paper. Any changes to the graphic organizer will require the user to erase, cross-out, or develop a new graphic organizer (Anderson-Inman \& Ditson, 1999). 


\section{Hispanic Students}

Hispanic students are those whose origins are from Spain or any of the Spanish speaking countries in Central America, South America, or Caribbean Islands (U.S. Census Bureau, 2000). Origin could be seen as their heritage, nationality, lineage, or country of birth for the student, their parents, or their ancestors before coming to the United States (U.S. Census Bureau).

\section{Interrater Reliability}

Interrater reliability is the percent of agreement between two independent scores. In this study, the two independent raters scored the compositions of the participants and then compared to the scoring of the researcher. In this study, the interrater reliability score was calculated by taking the number of agreements divided by the number of agreements and disagreements and then multiplying it by 100 for each of the dependent measures as defined by Cooper et al., (2007).

IOWA Test of Basic Skills (ITBS)

The ITBS is a yearly test to measure a student's skills and academic achievement in the major content areas (Hoover et al., 2003). For the purposes of this study, the language arts component score was taken from each of the participant's test results to gauge his or her writing skills. The national grade equivalent scores (GE) for total language were recorded for each participant.

\section{Mnemonic}

A mnemonic is a device usually involving an acronym or phrase that assists one in remembering information or steps in a procedure (The Access Center, 2007). 


\section{Multiple Baseline Design Across Subjects Design}

A multiple baseline design across subjects is a type of single subject design. In this design the treatment variable is applied to the same behavior of 2 or more subjects in the same setting (Cooper et al., 2007). With a multiple baseline design, treatment does not have to be withdrawn. A multiple baseline design allows for replication and verification of predictions of behaviors (Cooper et al.). Verification was achieved by comparing the treatment results of the participants.

\section{Narrative Writing}

Narrative writing allows the writer to bring his or her experiences, imagination, and creativity into the writing. It develops creativity, imagination, and thought in the writer (Salahu-Din et al., 2008)

Organization

Organization, or translating, is the logical and sequential structuring of the planning stage of writing into a paragraph or composition to convey a message or an idea to the reader (Rossitto, 2004; Wong, 2000). In this study, the term organization will be used for the second stage of the writing process. Organization will be measured using an analytical scoring guide (see Appendix H).

\section{Persuasive Writing}

Persuasive writing seeks to influence the reader to take some action or bring about change; it is neither completely objective nor wholly emotional (University of Iowa, 2008). It may contain factual information, such as reasons, examples, or comparisons. However, its main purpose is not to inform, but to persuade the reader to take the stance of the writer (Salahu-Din et al., 2008). In this study, persuasive writing will be measured 
by (a) the total number of arguments and supporting details planned and written; (b) the total number and percentage of arguments and supporting details transferred from planning to written composition; (c) the total planning time; (d) the total number of words; (e) the mean number and length of the T-units; and (f) the overall organization score of an analytical scoring guide.

\section{Planning}

Planning is the work a writer does, such as, thinking, brainstorming, or outlining, before he or she begins to actually write (Kunka et al., 2007). In this study, planning will be measured by counting the total amount of minutes spent planning.

\section{Publishing}

Publishing is the fifth stage of the writing process. This is where the writer prepares his or her writing to be shared with an audience (Graham et al., 2001).

Publishing in school could consist of presentations to the class or others, posting of work, or actual submission of work to competitions or magazines (EDR, 2004).

Revision

Revision is the process of making meaningful and thoughtful changes in the organization of the writing and adding statements that need more supports (Wong, 2000). It involves varying sentence structure, changing word choice, clarifying and elaborating on ideas, and removing unnecessary information (EDR, 2004).

Scaffolding

Scaffolding is an instructional technique in which the teacher models a learning strategy and then teaches the strategy in sequential steps to the student (Englert et al., 2007). The student works on each part of the strategy with the teacher providing 
assistance and support as needed until independence is reached (Hammond \& Gibbons, 2001).

\section{Self-Regulation}

Self-regulation is when the student is monitoring his or her own learning and motivation (Arendale, 2007).

\section{Self-Regulated Strategic Planning}

Self-regulated strategic planning (SRSD) is when the student is monitoring his or her own writing and motivation for writing (Graham et al., 2005). Goal setting and selfmonitoring of writing progress are major components of SRSD.

Specific Learning Disabilities (SLD)

Specific Learning Disabilities (SLD) is the term used to describe a disorder in one or more of the basic psychological processes needed to understand or use language, spoken or written. This disorder may manifest itself in the imperfect ability to listen, think, speak, read, write, spell, or do mathematical calculations (IDEA, 2004).

\section{Syntactical Maturity}

Syntactical maturity is the growth in grammatical sentence complexity. It is measured in T-units (Hunt et al., 1968).

\section{Text-to-Speech}

Text-to speech is a feature in most new word processors and software that allows the computer to read aloud all text written by the user.

\section{T-Units}

The T-unit measures the shortest grammatically allowed sentence without creating fragments in between the T-units (Hunt et al., 1968). It contains a main clause, 
subject and a predicate, plus any subordinate clause that is attached to it (Hunt et al.). A slash is used to mark the ending of a T-unit. The total number of T-units in a composition is calculated by counting the total number of slashes drawn in a composition by the rater. The mean length of a T-unit is calculated by the summation of all the words divided by the total number of T-units in the composition.

Wechsler Individual Achievement Test-Second Edition Abbreviated (WIAT-II)

The WIAT-II is an individual test for student achievement. It is composed of three sub-tests that measure a student's reading, mathematics, and writing ability. It is used to screen for deficits and for measuring ability-achievement discrepancies (The Psychological Corporation, 2001). The portion of this test used for this study was the written expression.

White Students

A White student is any student whose parents or ancestral origins come from any of the original peoples of Europe, Middle East, or North Africa. It includes anyone who states that their race is "White" or Irish, German, Italian, Lebanese, Near Eastern, Arab or Polish (U.S. Census Bureau, 2000).

Woodcock-Johnson(r) III Diagnostic Supplement to the Tests of Cognitive Abilities.

The Woodcock-Johnson(r) III is an individual test for student achievement. It is composed of 21 sub-tests that look at a student's abilities. It is used to screen for deficits and for measuring ability-achievement discrepancies (Woodcock, McGrew, Mather, \& Schrank, 2003). The portion of this test used for this study was the written expression. 


\section{Written Expression}

Written expression is the ability to communicate logical, organized thoughts and ideas in written form with minimal spelling and grammatical errors (Miller, 2000).

\section{Writing}

Writing has been widely accepted as a process oriented approach requiring the coordination and integration of the writing process which consists of planning, organization, revising, editing, and publishing (Scott \& Vitale, 2003). It is a recursive process leading to a composition of words and sentences that follow conventional patterns. In this study, it will be used interchangeably with composition writing and composition.

\section{Writing Fluency}

Writing fluency is the ability to write for a length of time fluidly. In this study, writing fluency is defined as the total number of words written (Sturm \& RankinErickson, 2002) during the 40 minute writing session.

\section{Writing Process}

The writing process is a recursive process generally composed of five stages: prewriting or planning, drafting or organization, revising, editing, and publishing (Babin \& Harrison, 1999). In this study, only planning and organization were measured.

\section{Summary}

With over $66 \%$ of eighth grade students writing at or below proficiency levels, composition writing is a problem for a majority of American students (Salahu-Din et al., 2008). Research demonstrates that many students with SLD have difficulty navigating the writing process (Englert et al., 2007; Graham et al., 2001; Kunka et al., 2007; 
McCormick, 2003). Some CLD students have problems similar to students with SLD with the writing process (Monroe \& Troia, 2006). Both groups receive less exposure to the writing process as compared to general-education students (Graham et al., 2001; Hartman \& Tarone, 1999; James, Abbott, Greenwood, 2001). This reduction of writing exposure causes students to have fewer opportunities to use writing and to learn context. Some CLD students with SLD have even more difficulties as they bring into the classroom both sets of problems (Hoover et al., 2008). In an attempt to remedy the writing problems of students with SLD, research has focused on developing appropriate writing strategies for these students. Some experts suggest that the strategies used for students with SLD would also be effective for CLD students and CLD students with SLD because of the similarities in the challenges of writing (August, 2006; Monroe \& Troia).

Four strategies in particular have been found to be highly useful with students with SLD: (a) scaffolding, (b) self-regulated strategy development (SRSD), (c) mnemonics, and (d) graphic organizers (De La Paz \& Graham, 2002; Englert et al., 2007; Harris \& Graham, 1999). This study focused on the fourth strategy, graphic organizers, as they have shown promise in assisting students with SLD with writing (Sitko et al., 2005) and have also been suggested for use with CLD students (August, 2006).

Graphic organizers employ pictorial or graphical methods to organize information and thoughts and help the writer expand and explain a concept, and create clear and concise relationships (DiCecco \& Gleason, 2002; George et al., 2005; Kim et al., 2004). Four prominent studies were found that used computer graphic organizers as a writing strategy (i.e., Blair et al., 2002; Lin et al., 2004; Lorber, 2004; Sturm \& Rankin-Erickson, 2002). Of these, only two were used with students with disabilities (i.e., Blair et al.; 
Sturm \& Rankin-Erickson). Both studies showed improvement in the students' compositions. None of the four studies specifically focused on Hispanic students and only one (Lin et al.) used persuasive writing.

The limited research on computer graphic organizers has shown some positive effects in the compositions of students with disabilities (Blair et al., 2002; Sturm \& Rankin-Erickson, 2002). However, given that no research exists on computer graphic organizers and their use with Hispanic students with SLD, this study was conducted to add to the literature base.

This study used a multiple baseline design across subjects to examine the effects of the computer graphic organizer on the compositions of Hispanic middle school students with SLD. In particular, the study specifically looked at the mean number of arguments and supporting details in the planning and written composition, the mean number and percentage of these arguments and supportive details that were transferred from the planning to the written composition, the amount of time spent on planning, the writing fluency, the syntactical maturity, and the overall organization of the composition. 


\section{CHAPTER II}

\section{LITERATURE REVIEW}

Learning to write clearly and effectively is an important skill for students to obtain success in school and in the workforce (National Writing Project, 2003). Unfortunately, many students struggle with writing (Salahu-Din et al., 2008). In particular, many culturally and linguistically diverse (CLD) students with specific learning disabilities (SLD) are challenged by writing (Monroe \& Troia, 2006). Hispanics, a subgroup of CLD students is the fastest growing group in the U.S. (Caesar, 2005;

Gándara, 2008; Williams, 2001), and SLD is the largest group of students with disabilities (NCES, 2007). Yet, limited research on effective writing strategies for these populations of students has been conducted. Subsequently, this study was designed to identify effective writing strategies for Hispanic middle school students who have SLD. There is an emerging body of literature investigating the effects of the use of computer graphic organizers on writing, which was the intervention approach selected to investigate in this study.

In this chapter, a review of the literature as it relates to this study is presented. Discussed first is the current research of the writing profiles of CLD students with SLD. This is followed by a brief overview of writing genres taught in middle school, the agegroup investigated. A brief review of studies that analyze the different writing strategies used with CLD students with SLD then follows. Finally, provided is a thorough presentation of the research on graphic organizers, specifically, computer graphic organizers, the intervention investigated in this study. 
Writing Abilities During Stages of Writing of Students with SLD and CLD Students Many students with SLD often have difficulties in the five stages of the writing process: planning, organization, revising, editing, and publishing. Problems with the writing process in the first two stages usually hinder students from accomplishing all five stages (Graham et al., 2001). Due to these problems, most research on students with SLD has focused on first two stages of writing, planning and organizing (De la Paz \& Graham, 2002; Monroe \& Troia, 2006). Throughout the writing process, students with SLD struggle with written expression (Englert et al., 2007; Graham et al., 2001; Kunka et al., 2007; McCormick, 2003). Some CLD students experience struggles in writing similar to those of students with SLD (Monroe \& Troia, 2006). It has been noted that many CLD students who have SLD often have more significant academic challenges than those who do not belong to both groups (Hoover et al., 2008). Hence, it is logical that these students would experience the writing problems from both groups of students, and perhaps even more significant writing problems than students categorized in only one of the two groups (Hoover et al., 2008; Monroe \& Troia). Unfortunately, there is limited research on the specific writing problems of CLD students with SLD (Monroe \& Troia). Regardless, at each stage of the writing process, CLD students with SLD experience difficulties (Monroe \& Troia).

Stage One of Writing Process: Planning

Planning, the first stage of writing, is the work a writer does including thinking, brainstorming, talking, or outlining, before he or she begins to actually write (Kunka et al., 2007). During this stage, many students with SLD have demonstrated difficulties developing or expanding an idea, given a writing prompt. The planning stage of the 
writing process is largely dependent on the writer's skills to: (a) draw from prior schema or prior knowledge on a topic, (b) reflect upon these ideas, (c) make connections with the prompt, and (d) make revisions in order to improve or gather new information on that idea (Englert et al., 2007; Graham et al., 2001). Since many students with SLD are fixated on the grammatical and mechanical portions of writing (Graham et al., 2001; Wong, 2000), they are stunted in expressing and generalizing ideas and expanding on subtopics of these ideas (Englert et al.; Graham et al., 2001; Montgomery \& Kahn, 2007). Subsequently, these students rarely spend any time on the planning portion of writing. They seem to write compositions with a brief statement of the first thought that comes to their minds (Englert et al.; Graham et al., 2001). Students with SLD, for the most part, overlook the planning stage and move straight into the writing stage.

Similarly, during the planning stage, some CLD students tend to spend minimal time in the planning of their writing (Monroe \& Troia, 2006). These students do not take sufficient time to properly organize their writing. The formulation of new ideas can be difficult for some CLD students as it requires the student to compose and develop ideas in a language in which proficiency may still be lacking (Myles, 2002). Some CLD students spend more time trying to understand the topic about which they are asked to write than non-CLD students (Myles). The inability of some CLD students to either understand or formulate new ideas in a language in which they may not be proficient often prevents them from properly planning their writing in that language (Myles).

In summary, many students with SLD and CLD students struggle with the first stage of writing, planning. They often lack the skills needed to carefully and thoughtfully plan out their ideas (Englert et al., 2007; Graham et al., 2001, Myles, 2002). Thus, by 
having problems in the first stage of the writing process, many students with SLD and CLD students continue to struggle as they enter the second stage of writing. Stage Two of Writing Process: Organization

During the second stage of the writing process, organization of the writing, many students with SLD have problems structuring a paragraph in a logical, organized fashion (Englert et al., 2007; Graham et al., 2001; Wong, 2000). At this stage, the writer may have to engage in the recursive writing process and go back to the planning stage to generate more ideas to support statements to then return to writing. However, many students with SLD usually write one long, disorganized paragraph with little or no evidence of organization and limited elaborations of ideas (Graham et al., 2001; Montgomery \& Kahn, 2007). The ideas generated by these students often are written in no sequential order, and culminate in a group of disorganized thoughts that ineffectively convey their messages (Englert et al.; Graham et al., 2001). Students with SLD tend to simply write without much organization; thus they migrate into the editing stage without revising their work.

Problems with organization are shown also by some CLD students. For example, some CLD students tend to focus more on vocabulary and obtaining the correct word or spelling rather than on the fluency of their writing (Myles, 2002). The limited knowledge of Standard English vocabulary, syntax, and writing conventions tend to hinder CLD students from establishing fluency in their writing in Standard English (Myles). Unable to properly articulate thoughts in Standard English, many CLD students tend to write at a slower pace and produce shorter pieces with poor fluency in their writing as compared to White middle or upper class students (Myles). 
In summation, many students with SLD and CLD students struggle in achieving fluency in their writing in Standard English. Many students with SLD are unable to organize their text in a logical and sequential format, while CLD students often do not possess the writing conventions needed to create organized text in a logical and sequential manner in Standard English (Englert et al., 2007; Graham et al., 2001, Myles, 2002). These inabilities lead to further problems in the writing process when the revising and editing stages occur.

Stage Three of Writing Process: Revising

In the revising stage of the writing process, many students with SLD tend to not treat the process of writing as a recursive process (Wong, 2000). Instead, they tend to focus on a search for grammatical errors (Graham et al., 2001; Montgomery \& Kahn, 2007; Wong). These students often make minimal changes in their compositions, and rarely restructure or revise their writing (Wong). This inability of many students with SLD to navigate through the writing process and to organize their thoughts affects their ability to make any meaningful changes to their writing (Graham et al., 2001). Therefore the revising stage of the writing process merges with the editing stage for students with SLD.

The revising stage of the writing process also poses many challenges for many CLD students. Many of these students spend little time in this stage (Myles, 2002). Few changes are made in their papers and little restructuring of the actual paper occurs. Because CLD students often have difficulty elaborating on their thoughts in Standard English or organizing their work logically, few in depth revisions are made to their writings (Myles). Many CLD students often look for simple grammatical or spelling 
errors, hence, avoiding revising or restructuring their ideas. Revisions that are made usually focus on grammatical corrections, or editing (Myles), thus showing similar patterns of behavior in the revising stage as students with SLD.

In summary, many students with SLD and CLD students struggle with the revision stage of writing. These students often usually only make minor changes in their compositions (Wong, 2000). For the most part they do not revise their writing. Both students with SLD and CLD students seem to forgo this stage and move straight into the editing, focusing on grammatical corrections (Graham et al., 2001; Montgomery \& Kahn, 2007; Myles, 2002).

\section{Stage Four of Writing Process: Editing}

During the editing stage, students should proofread their work looking specifically for errors in spelling, capitalization, punctuation, and sentence completion (ERS, 2004). Unfortunately, the attempts of students with SLD at fixing grammatical errors are frequently unsuccessful as they struggle to compose sentences with proper syntax and correctly spelled words (Wong, 2000). Students with SLD overemphasize the importance of the syntax and lose the importance of good writing (Graham et al., 2001).

Many CLD students experience similar problems with editing as students with SLD but possibly for different reasons (Monroe \& Troia, 2006). Some CLD students look for simple grammatical or spelling errors because their limited vocabularies do not allow them to use complex sentence structures (Myles, 2002). As with students with SLD, CLD students usually focus on grammatical corrections for the editing (Myles) over emphasizing the importance of the syntax. 
In summary, during the editing stage both students with SLD and CLD students primarily focus on correcting simple grammatical errors (Graham et al., 2001; Monroe \& Troia, 2006; Myles, 2002). Their lack of command of the syntax often limits and hinders them from successfully editing their papers.

Stage Five of Writing Process: Publishing

Publishing is the fifth and final stage of the writing process. In this stage, the final written composition is submitted for publication (EDR, 2004). For most students this stage is the most enjoyable stage, because they get their work presented for everyone to see (EDR). The problem is that both groups of students, those students with SLD and CLD students, rarely make it to this stage (Graham et al., 2001; Wong, 2000). The frustration and problems encountered during the first few stages make this stage rarely attainable.

In summary, during the publishing stage students share their compositions with others. Allowing students to showcase their work brings the writing process to a close. Unfortunately, often both students with SLD and CLD students do not reach this stage (Graham et al., 2001; Wong, 2000). The Five Stages of Writing Process Summary

Many students with SLD and CLD students experience similar problems throughout the writing process. Many students from each group produce compositions that lack evidence of planning, organization, and editing (Monroe \& Troia, 2006). Since many students in both groups experience problems throughout the writing process, many students who are classified as both, SLD and CLD may experience the same or perhaps more significant problems when writing (Monroe \& Troia). Moreover, these writing 
problems are not limited to one specific writing genre, as evidenced by the results of the NAEP Writing Assessment, which assessed students across three writing genres (SalahuDin et al., 2008).

\section{Writing Genres in Middle School}

The NAEP Writing Assessment examines the writing of students across three major writing genres: narrative, expository, and persuasive (Salahu-Din et al., 2008). Each writing genre requires the use of an introduction, the supporting details, and a conclusion. In general, the skills needed for writing in each area are similar. However, each genre has unique requirements that should be taught. The differences among these genres are in the purpose, style, and format of the composition.

The main purpose of narrative writing is for the writer to bring his or her experiences, imagination, and creativity into the writing (Salahu-Din et al., 2008). It is the re-telling of events in sequential order and description of events or places in full detail. This style of writing involves the use of thinking skills such as understanding, application, and analysis (Salahu-Din et al.). It is usually written in the form of a story or narration (Steele, 2007). Examples of this genre include short stories, personal narratives and descriptive compositions.

Expository or informative writing asks the writer to present the reader with information (Steele, 2007). This information could be in the form of a message, idea, or instruction. The expository writing style asks the writer to use skills such as organization, application, and analysis (Wilder \& Mongillo, 2007). Although the writer informs the reader about a specific subject, the writer does not persuade the reader to take a specific side. Rather, the author allows the reader to make his or her own choice on the matter. 
Expository writing is important for middle school students to learn as they are required to use this genre in many different courses (Wong, 2000). Examples of this genre include reports, news articles, and destination guides.

Persuasive writing requires the writer to take a position and convince his or her audience through logical arguments and supporting evidence that the writer's position is the correct stance to take (Salahu-Din et al., 2008). This style of writing requires students to develop and use higher order thinking skills such as analysis, inference, synthesis, and evaluation (Salahu-Din et al.). Because of these required skills, persuasive writing tends to be difficult for students. Examples of persuasive writing include, book reviews, movie reviews, and compositions relating to an opinion on a topic.

The three writing genres have slight variations (Salahu-Din et al., 2008) but for the most part require the same elements. Therefore, researchers have focused on developing general writing strategies. Current research has focused primarily on finding writing strategies for students with SLD. Few studies were located that also incorporated CLD students with SLD.

Writing Strategies for Students with Specific Learning Disabilities In the late 1980s, researchers shifted the focus from studying the problems of students with SLD in writing to finding strategies that would help them improve their writing. Research on writing instruction for students with SLD has led to the development of four major writing strategies: (a) scaffolding, (b) self-regulated strategy development (SRSD), (c) mnemonics, and (d) graphic organizers. These strategies have been found to be effective in improving the writing performance of general-education students and students with SLD alike (De La Paz \& Graham, 2002; DiCecco \& Gleason, 
2002; Englert et al., 2007; Graham et al., 2005; Monroe \& Troia, 2006). Although a few of the studies involved some CLD students with SLD, no study was located that specifically dealt with writing strategies for CLD students with SLD.

The first three writing strategies (scaffolding, self-regulating, and SRSD) will briefly be described. A separate, more-detailed section will be devoted to graphic organizers, as it was the focus of this study.

\section{Scaffolding}

Scaffolding is an instructional method in which the teacher first models a learning strategy and then proceeds to have the students replicate the strategy in small increments (LD Online, 2008). Most of the research investigating the use of scaffolding with students with SLD has been led by Englert and her associates, and this method has generally been found to be effective for improving these students' compositions. In a recent study, Englert et al. (2007) employed scaffolding techniques to break down the writing process for students with SLD, so as to assist them to better organize and compose their compositions. In Englert et al.'s study, the scaffolding consisted of a stepby-step series of prompts, organizers, and questions. At each step, the student would check to see if he or she had covered all the requirements before continuing in the writing. Using a computer scaffolding program, Englert et al. noted an increase of 135\% from pre-test $(M=6.25)$ to post-test $(M=14.05)$ in the students' expository text structure. Specifically, there was an increase in the number of topic sentences and in the number of related support details the students used from the pre-test to the post-test. 


\section{Self-regulated Strategic Development}

The self-regulated strategic development (SRSD) model allows the student to monitor his or her own writing and motivation for writing. Graham and his associates (De La Paz \& Graham, 2002; Graham et al., 2005) studied struggling writers and have designed and conducted a line of research involving the SRSD model. Results of over 20 SRSD studies have shown positive outcomes for students who monitor their own writing and revise it (Harris \& Graham, 1999). In a study, that involved 73 third grade urban students with difficulty in writing, a majority of them being CLD students, Graham et al. (2007) found the SRSD model and mnemonics to be effective tools for students during the planning and writing stages. Students using the SRSD and mnemonics strategies wrote longer and better quality compositions than students who did not use these strategies. Students using the SRSD and mnemonic model increased 2 points on an 8point writing scale from pre-test to post-test.

\section{Mnemonic Devices}

Mnemonic devices in combination with writing instruction have been shown to improve the writings of students with SLD (De La Paz \& Graham, 2002; Graham \& Harris, 2005; Monroe \& Troia, 2006). A mnemonic device is a word or phrase that helps one remember information or steps in a procedure. Monroe and Troia (2006) conducted a study with 12 students, six from general-education and six from special education, where five of the six students in special education were also CLD. Different mnemonics were used to teach writing to the different students. The students made significant gains improving from 0.5 to over 1.5 points on a 6-point scale in each of the five writing quality traits: content, organization, sentence fluency, word choice, and conventions. 


\section{Graphic Organizers and Writing}

Graphic organizers portray visual relationships among key concepts and form schematic mappings for these concepts; creating meaningful diagrams that allow the user to expand and explain concepts (DiCecco \& Gleason, 2002). In writing, graphic organizers help brainstorm new ideas that connect to the main theme of the writing piece, create concept maps relating the new ideas, and outline the ideas to help write a composition. There are two methods in which to create graphic organizers: handwritten and by computer. Limited research has been conducted on the use of either type of graphic organizer for writing.

Research of handwritten graphic organizers. Handwritten graphic organizers employ the use of paper and pencil to create the concept maps. Although there have been several studies regarding reading comprehension and handwritten graphic organizers, there is limited research on the effects on their use with writing (Nesbit \& Adesope, 2006). Three major studies, one of which is dated, were found that involved the use of handwritten graphic organizers and writing (e.g. Capretz, Ricker, \& Sasak, 2003;

DiCecco \& Gleason, 2002; Meyer, 1995). Only one study, DiCecco and Gleason (2002), investigated the effects of handwritten graphic organizers with students with SLD.

Meyer (1995) researched the use of handwritten graphic organizers to facilitate improved writing. Using a pre- and post-test design, Meyer tested the effectiveness of handwritten graphic organizers with the narrative writings of third grade students. Two classes from different schools were asked to write several narrative pieces during a 13week study. One class was held as a control group, receiving all the same information and training, with the exception of the training in handwritten graphic organizers. The 
experimental group was taught to use a handwritten graphic organizer to visualize the relationships among the main ideas and organize their creative writings. Results of the holistic scoring showed that the students in the experimental group (those who used handwritten graphic organizers) improved their writing as measured by the mean gains made from pre-test to post-test in the holistic scoring. Mean gains of the experimental group were 1.33 as compared to the control group's 0.38 .

Capretz et al. (2003) conducted a 16-week study on using handwritten graphic organizers to improve second, third, and fifth grade students' written organization. A preand post-test rubric for writing was designed to score the 65 students' writing samples across four criteria: focus, support, organization, and grammar. Data from anecdotal records, student surveys, parent surveys and teacher surveys were also collected. All students were asked to write one persuasive composition at the beginning of the study and to complete a survey. A rubric was used to score each composition. The 14 weeks that followed were used to teach students how to use graphic organizers, conduct miniwriting workshops, and to have student writing conferences. Instruction in narrative and expository writing were also provided during this time frame. In the final sessions, students were asked to write a second structured persuasive composition and complete the student surveys again. Post-test results showed that organization increased from $68 \%$ (pre-test) to $84 \%$ (post test). Students' focus on the main idea and writing with supporting details increased from pre- to post-test measures from $80 \%$ to $95 \%$ and $70 \%$ to $80 \%$, respectively. Grammar and usage also increased from pre- to post-test measures from $63 \%$ to $72 \%$. In general, the results demonstrated that students using handwritten graphic organizers were able to organize their writing in a more sequential fashion than when 
they did not use handwritten graphic organizers (Capretz et al.). The graphic organizers allowed the students to brainstorm their ideas, clarify them, and organize them to then write cohesive, sequential compositions.

DiCecco and Gleason (2002) researched the effects of using handwritten graphic organizers to investigate the ability of 26 middle school students with SLD to make relational connections in their expository writings. This study involved the use of a preand post-test composition with an experimental and control group. The experimental group received explicit instruction, in addition to instruction on graphic organizers to help organize and apply relational information, while the control group simply received explicit instruction on expository writing for social studies. Handwritten graphic organizers were found to be effective in improving the ability of these students to write more relational statements in their compositions. On the post-test composition using handwritten graphic organizers, the experimental group recalled a mean of 4.33 relational statements as compared to the control group which recalled a mean of 2.54 relational statements in their compositions. This represented a gain of over 3 points for the experimental group from the pre-test composition to the post-test composition and a gain of only 1 point for the control group.

Overall, handwritten graphic organizers have been found to be effective in helping students organize their writing. The results of the three major studies found show that the use of handwritten organizers would be beneficial both in a general-education classroom and with students with SLD (Capretz et al., 2003; DiCecco \& Gleason, 2002; Meyer, 1995). With the increased use of computers in the classroom, computer graphic 
organizers have become an alternative to handwritten graphic organizers. Thus, more recently, some research has been done in this area.

Research of Computer Graphic Organizers. The technological advancements of computers have allowed for the creation of computer graphic organizers. Computer graphic organizers employ the use of computer software programs to develop the diagrams or concept maps. These organizers allow the student to manipulate the information without having to start over again (Sitko et al., 2005). Once the student has designed his or her graphic diagram or concept map, it can easily be changed into an outline where the student can reorganize or expand the items and then transfer it to a word processing program for the student to use as he or she begins to write (Sitko et al.). There are a limited number of studies conducted on the use of computer graphic organizers and writing. In fact, only four studies were found that involved the computer graphic organizers and writing (i.e., Blair et al., 2002; Lin et al., 2004; Lorber, 2004; Sturm \& Rankin-Erickson, 2002). All four studies reviewed below focused on middle school students. Participants in the first two reviewed, Lin et al. (2004) and Lorber, were general-education students. The latter two studies reviewed (i.e., Blair et al., Sturm \& Rankin-Erickson) focused specifically on students with disabilities.

Lin et al. (2004) investigated the use of handwritten and computer graphic organizers as a prewriting strategy for persuasive writing with 226 general-education students. Seven classes served as a control group receiving instruction in handwritten graphic organizers to create persuasive compositions. The other seven classes received instruction and training on Inspiration ${ }^{\mathrm{TM}}$ (2008), a computer graphic organizer, to write their persuasive compositions. Both groups were given identical instruction in writing 
and in planning. Two evaluation rubrics were used in this study, a state developed 5-point scoring rubric and a 3-point concept map rubric developed by Ditson, Kessler, AndersonInman, and Mafit (as cited in Lin et al., 2004). The number of ideas in each student's map was tallied. In comparing the number of ideas generated, students who used computer graphic organizers generated more ideas $(M=12.27)$ than the students who used handwritten graphic organizers $(M=10.26)$. However, when scoring the actual final persuasive pieces, students who used handwritten graphic organizers $(M=3.37)$ seemed to score better than the students who used computer graphic organizers $(M=2.96)$. The researchers attributed this to the possibility that when the students used computer graphic organizers, they spent more of their time planning than writing. Also, the use of the state assessment in this study could have affected the scoring, as little emphasis was placed on the logical development of the persuasive argument (Lin et al., 2004). The researchers stated the need for further investigation with computer graphic organizers and persuasive writing using different writing assessments due to the limitations of the study.

Lorber (2004) conducted a two-trial, pre- and post-test action research study on the use of computer graphic organizers and expository writing with eighth grade generaleducation students. A total of 67 students were divided into three groups: (a) an experimental group, (b) a combination control and then second experimental group, and (c) a second control group. All students were required to write a composition at the beginning of the study. Then the first experimental group received a 5-week intervention training on Inspiration ${ }^{\mathrm{TM}}$ (2008) and creating computer graphic organizers for the planning of their writing. The control group and the first experimental group then wrote a second composition, which was compared. Afterwards, the control group became the 
second experimental group and the third group became the second control group. The second experimental group then received a 5-week intervention training on Inspiration ${ }^{\mathrm{TM}}$. A third composition was written and compared. After the study was completed the second control group received training in Inspiration ${ }^{\mathrm{TM}}$ as well. The items measured in the study were ideas and organization of the compositions, along with student attitudes towards writing and qualitative data. The six-trait analytical writing rubric developed by Spandel (as cited in Lorber 2004) was used along with surveys and personal interviews with 36 randomly selected students. The writing rubric measured: (a) ideas, (b) organization, (c) voice, (d) word choice, (e) sentence fluency, and (f) conventions. Lorber noted increases in the organization and the writings of students who used the computer graphic organizer $(M=5.25)$ as compared to those who were not given the intervention $(M=4.84)$. Lorber also noted increases in the perceptions of student's ability to create ideas when they used computer graphic organizers. Lorber suggested investigation of the other writing genres with computer graphic organizers. Lorber also noted that investigation of computer graphic organizers should be conducted with different types of learners, not just general-education students.

Blair et al. (2002) conducted a study with 24 seventh and eighth grade students with mild disabilities using story webbing and a computer graphic organizer to create narrative writing. The students were divided into two groups, experimental and control for the 4-week study. Pre-tests of writing were collected from all students before any instruction or intervention was provided. The experimental and control group design was used during the first 2 weeks of the study. During these 2 weeks, the experimental group received instruction, first on story webbing and then on the use of Inspiration ${ }^{\mathrm{TM}}$ (2008). 
Inspiration ${ }^{\mathrm{TM}}$ was used to assist in the planning and organizing of the narrative writing. The control group received instruction in writing techniques. At the end of the second week, samples of the students' compositions were collected from both groups, and the control group was then introduced to both story webbing and Inspiration ${ }^{\mathrm{TM}}$. After the use of computer graphic organizers, the researchers noted a modest positive change in attitude toward writing, as well as an increase in the length of student compositions. A small, but positive, growth in the quality of writing was also noted in the students' compositions as stated by the researchers. Actual statistics or measurements of student growth in writing were not presented by the researchers. Blair et al. did not clearly indicate whether computer graphic organizers assisted in improving the students' writing. They stated that a lengthier study would be required to see changes in the students' compositions. The researchers suggest that further research is needed in this topic, and, in particular, the time frame for the study should be increased.

In the final study, Sturm and Rankin-Erickson (2002) used a within-subjects repeated measure to compare eighth grade students' expository writings under three conditions: (a) writing without graphic organizers, (b) handwritten graphic organizers, and (c) computer graphic organizer, Inspiration ${ }^{\mathrm{TM}}$. The study investigated the quality of the writings of 27 students. Results are presented for only the 12 students with SLD. During the first week, all the students wrote two baseline compositions. In the second and third weeks, all the students received instruction, first in handwritten graphic organizers and then in computer graphic organizers. The students were then divided into three groups. For 6 weeks, each group wrote two more compositions under each of the three conditions. Data were collected under each condition for the following dependent 
variables: number of words, syntactic maturity, and holistic writing. When compared to baseline for the number of words written, significant main effects, $F(3,11)=6.8, p<$ 0.01 , were found across all three independent variables. When compared to baseline for the number of T-units written, significant main effects were also noted, $F(11,3)=6.05, p$ $<0.01$, across all three independent variables. For the holistic writing score, a significant main effect, $F(11,3)=7.56, p<0.01$, was found across all three independent variables. The quality of writing was slightly better with the computer graphic organizer $(M=9.06)$ by the third position, the final weeks of the study, than with handwritten graphic organizers $(M=6.56)$ and no graphic organizer $(M=8.63)$ or baseline $(M=4.44)$. However, it was unclear whether the teaching of writing or the graphic organizer caused the improvement in the students' compositions. One possible reason for this may be the lack of differentiation between the writing instruction and the graphic organizers. Effective writing was taught after achieving baseline for all three groups. Hence, the study leaves the question unanswered as to the effect of graphic organizers, either handwritten or computer, on the writing performance of students with SLD. Sturm and Rankin-Erickson suggested single-subject design studies be used to test the effects of graphic organizers as a prewriting strategy and to obtain additional information about specific features of computer graphic organizers that could help improve the writing quality of students with SLD.

In summary, research on computer graphic organizers has demonstrated limited positive outcomes on writing. Lin et al. (2004) found that computer graphic organizers helped increase the number of ideas generated. Lorber (2004) noted improvements in the students' organization and writing when computer graphic organizers were used. Blair et 
al. (2002) found that students with SLD produced longer compositions and their attitudes towards writing also improved. Sturm and Rankin-Erickson (2002) found that computer graphic organizers could improve students' writings. However, in Sturm and RankinErickson's study, the true effects of computer graphic organizers were not clear since the other two independent variables were also found to be effective in the improvement of writing. More research is necessary to determine the effects of computer graphic organizers. Specifically, research is needed regarding the effects of computer graphic organizers on the writing of CLD students with SLD, as no research was found.

\section{Summary}

Many students with SLD have difficulties at each stage of the writing process. In the planning stage, many students with SLD often simply focus on the spelling and syntax (Graham et al., 2001; Wong, 2000). They struggle in formulating their ideas and expanding on the subtopics (Englert et al., 2007; Graham et al., 2001; Montgomery \& Kahn, 2007). During the second stage of the writing process, organization, some students with SLD have problems logically organizing a paragraph in a sequential manner (Englert et al.; Graham et al., 2001; Wong). In the next stage of the writing process, revising, many of these students do not look for ways to improve their compositions, (i.e. improving word choice), but rather search for grammatical errors merging into the fourth stage editing (De la Paz, 1999; Graham et al., 2001; Montgomery \& Kahn, 2007; Wong). Many do not reach the final stage of writing, publishing, due to the problems encountered in the previous stages (Graham et al., 2001; Wong).

Hispanic students are one of the fastest growing CLD groups (Caesar, 2005; Gándara, 2008; Williams, 2001). However, specific research on writing and Hispanic 
students is lacking. The information that is known about Hispanic students comes from the general information on CLD students, many of whom experience challenges similar to those of students with SLD and composition writing (Monroe \& Troia, 2006). In addition, many CLD students have difficulties formulating new ideas in Standard English, as it requires composing and developing ideas in a language in which proficiency may still be lacking (Myles, 2002). In addition, CLD students' limited knowledge of vocabulary, and grammar stop them from gaining fluency in their compositions (Myles). These students do not revise or restructure their compositions. Across all genres of writing for both groups, students with SLD and CLD students, there is a need to improve the writing skills of these students.

The NAEP Writing Assessment examines the writings of students across three major writing genres: narrative, expository, and persuasive (Salahu-Din et al., 2008). The main purpose of narrative writing is for the writer to bring his or her experiences, imagination and creativity into the writing (Salahu-Din et al.). Expository or informative writing asks the writer to present the reader with information (Wilder \& Mongillo, 2007). Persuasive writing requires the writer to take a position and convince his or her audience through logical arguments and supporting evidence that the writer's position is the correct stance to take (Salahu-Din et al.). Each of these writing genres requires minor adjustments to the writing instruction to be taught within a writing strategy.

Research on writing instruction has led to four major writing strategies: (a) scaffolding, (b) self-regulated strategy development, (c) mnemonics, and (d) graphic organizers (De La Paz \& Graham, 2002; DiCecco \& Gleason, 2002; Englert et al., 2007; Graham et al., 2005; Monroe \& Troia, 2006; Sturm \& Rankin-Erickson, 2002). These 
strategies have been found to be effective with general-education students and students with SLD. A few of these have also included a couple of CLD students (Graham et al., 2005; Monroe \& Troia). More studies with CLD students and writing strategies are necessary.

In writing, graphic organizers assist in brainstorming new ideas that connect to the main theme of the writing piece, create concept maps relating the new ideas, and outline the ideas to help write a composition. Three studies were found that involved the use of handwritten graphic organizers and composition writing with students with SLD (i.e., Capretz et al., 2003; DiCecco \& Gleason, 2002; Meyer, 1995). All three were found to be effective in supporting students with SLD with writing. Meyer (1995) researched the use of handwritten graphic organizers to facilitate better writing. Capretz et al. (2003) conducted a study using handwritten graphic organizers to improve students' written organization. DiCecco and Gleason (2002) researched the abilities of students with SLD to relate facts and other information in their writings.

Computer graphic organizers employ the use of computer software programs to develop concept maps. Four studies were found that involved the computer graphic organizers and writing (i.e., Blair et al., 2002; Lin et al., 2004; Lorber, 2004; Sturm \& Rankin-Erickson, 2002). In the study conducted by Lin et al. (2004), the researchers found that the use of handwritten and computer graphic organizers as a prewriting strategy for persuasive writing with general-education students was effective in improving their writing skills. Lorber (2004) conducted a study on computer graphic organizers and writing. Post-tests results of Lorber's study revealed that graphic organizers aided in the improvement of students' expository writing. In the study 
conducted by Blair et al. (2002), the computer graphic organizer resulted in positive effects on the writing of students with mild disabilities. Finally, Sturm and RankinErickson (2002) used a within-subjects repeated measure to compare the student's with SLD expository writing under three conditions: (a) writing without graphic organizers, (b) computer graphic organizers, and (c) handwritten graphic organizers. The researchers noted a slight improvement in student writing towards the end of the study when using the computer graphic organizer.

With the increasing number of Hispanic students and students with SLD, it is important to find strategies that assist them in succeeding academically. Improving the writing skills of Hispanic students with SLD is a major component in achieving academic success (National Writing Project, 2003). Computer graphic organizers have shown promise in their ability to help students plan effectively and organize their writings. However, more research is needed to determine the extent of their effects on the writing of Hispanic students with SLD. There is little research on computer graphic organizers and CLD students SLD. In fact, no study was located that specifically investigated the effects computer graphic organizers on the writings of Hispanic students with SLD. 


\section{CHAPTER III}

\section{METHOD}

This study examined the effects of using computer graphic organizers on the writing produced by Hispanic middle school students with specific learning disabilities (SLD). More specifically, this study investigated the effects of the use of the computer graphic organizer software, Inspiration ${ }^{\mathrm{TM}} 8.0$ (2008), on the persuasive composition writings of Hispanic middle school students with SLD. In this chapter, there is information about the study's participants, setting, materials, dependent measures, general procedures, and experimental design. A summary of the methodology is found at the end of the chapter.

\section{Participants}

The 4 participants (two boys and two girls) were Hispanic middle school students in the researcher's class, grades seven and eight, who were enrolled in a Catholic parochial school with a $96 \%$ Hispanic population, located in an urban community in Miami-Dade County (see Table 1, page 51). Participants, whose ages ranged from 12 to 13, were from a Hispanic family, where Spanish was spoken in the home, and were identified by the school as having a specific learning disability in written expression. In the process of selecting each participant, psychological education evaluations were reviewed for the professional determination of SLD. IDEA (2004) allows the local educational agencies to use either the IQ-discrepancy model or to use scientific researchbased intervention as part of the evaluation process for students suspected of having an SLD. The target school utilized teacher referral along with the psychological education evaluation to identify students with SLD. Additionally, each participant had been referred 
to student services based on prior teacher referrals for writing. Each participant's language performance on the IOWA Test of Basic Skills (ITBS; Hoover et al., 2003) was also reviewed for the participant's ability to use words, vocabulary, spelling, grammar, and language.

In this study, the researcher used teacher nomination in the selection of the participants. This approach is considered an effective method for finding the participants most in need of the intervention by single subject design researchers (Cooper et al., 2007). Finally, an informed written consent form was signed and received from each parent (see Appendix B) and with it, each student also signed an assent form in order for the student to participate (see Appendix C).

Participants were required to have basic computer skills in order to use the intervention software. The computer skills needed to meet the study's eligibility criteria included the ability to use the basic features of Microsoft ${ }$ Word 2003, and the ability to type a 100 word essay in 10 minutes (see Appendix D). A computer skills-assessment checklist was used to assess the potential participants' knowledge and ability to use Microsoft ${ }^{\circledR}$ Word 2007 (see Appendix E). Finally, each participant must have been able to meet after school at least 4 days a week from 3:15 p.m. to 4:15 p.m.

\section{Participant 1}

Arthur (pseudonym) was a 13-year-old Hispanic boy, who was born in Cuba. $\mathrm{He}$ finished ESOL IV in a public school before transferring to the Catholic school. He was considered to be socially bilingual (see Table 1). He was tested and diagnosed in the fourth grade for SLD. The results of the Wechsler Individual Achievement Test Second edition (WAIT-II; The Psychological Corporation, 2001) showed a grade equivalency 
(GE) of a 2.8 and a 25 percentile ranking on the writing sample section. He was placed in the school's special education pull-out program for reading. As an eighth grader, Arthur continued to struggle with reading and writing. He was still in the school's special education program with pull-out services for study skills and in an inclusion setting for reading. Both the reading teacher and the special education teacher co-taught this class. He was referred for this study by the director of pupil services, the special education teacher, and both his reading and English teachers. On his most recent ITBS (Hoover et al., 2003) test, he scored a GE of a 3.5 for total language, suggesting a 4.5 grade level difference.

Table 1

Demographic Data

\begin{tabular}{ccccccccc}
\hline Participant* & Gender & Age & Grade & Ethnicity & IQ Test & GE & Disability & ITBS GE \\
\hline Arthur & M & 13 & 8 & Hispanic & WIAT-II & 2.8 & SLD & 3.5 \\
Carmen & F & 12 & 7 & Hispanic & WIAT-II & 3.0 & SLD & 4.4 \\
Victoria & F & 13 & 8 & Hispanic & WJ- III & 2.8 & SLD & 3.7 \\
Pedro & M & 13 & 7 & Hispanic & WIAT-II & 2.8 & SLD & 2.8 \\
\hline
\end{tabular}

Note. *All participant names are pseudonyms. GE refers to grade equivalent. ITBS is a yearly test to measure a student's skills and academic achievement in the major content areas. The total language grade equivalency score from the ITBS is presented above.

\section{Participant 2}

Carmen (pseudonym) was a 12-year-old Hispanic girl who spoke both English and Spanish at home (see Table 1, above). She was tested in fourth grade and diagnosed with language impairment. On the WIATT-II (The Psychological Corporation, 2001) assessments she scored a GE of a 3.0 in written expression. According to the psychological evaluation, although she scored only one grade level below, her writing 
was "technically accurate but formulaic and minimally expressive" causing the belief that in future years her problems with written expression would become more apparent. She was placed in the school's pull-out program for special education in reading. As a seventh grade student, she was still in the school's special education program with pullout services for study skills and in an inclusion setting for reading. Both the reading teacher and the special education teacher co-taught this class. She was referred for this study by the director of pupil services, the special education teacher, and both her reading and English teachers. On her most recent ITBS (Hoover et al., 2003) test, she scored a GE of a 4.4 for total language, suggesting a 2.6 grade level difference.

\section{Participant 3}

Victoria (pseudonym) was a 13-year-old Hispanic girl who spoke both Spanish and English at home (see Table 1). She was tested in the fourth grade for SLD. On the Woodcock Johnson III (Woodcock, 2003) assessment, Victoria scored a total GE of 2.8 with a 45 percentile rank. Under written expression she scored a GE of 3.7. She was placed in the school's special education pull-out program for reading. As an eighth grade student, she was still in the school's special education program with pull-out services for study skills and in an inclusion setting for reading. Both the reading teacher and the special education teacher co-taught this class. She was referred for this study by the director of pupil services, the special education teacher, and both her reading and English teachers. On her most recent ITBS (Hoover et al., 2003) test, she scored a GE of a 4.7 for total language, suggesting a 3.3 grade level difference. 


\section{Participant 4}

Pedro (pseudonym) was a 13-year-old Hispanic boy. He spoke both English and Spanish at home (see Table 1). He was tested in third grade for specific learning disabilities in written expression. On the WIATT-II (The Psychological Corporation, 2001) assessments, he scored a GE of a 2.8 in written expression with a standard score of 84 which was one standard deviation below the mean. According to the psychological evaluation, he scored in the first quartile for written word fluency. He was placed in the school's pull-out program for special education in reading. As a seventh grade student, he was still in the school's special education program with pull-out services for study skills and in an inclusion setting for reading. Both the reading teacher and the special education teacher co-taught this class. He was referred for this study by the director of pupil services, the special education teacher, and both his reading and English teachers. His most recent ITBS (Hoover et al., 2003) scores reflected a GE of a 2.8 for total language, suggesting a 4.2 grade level difference.

\section{Setting}

The study was conducted in the English classroom of a Catholic parochial school located in Miami-Dade County in South Florida. Four Dell Laptops, all networked and running Microsoft ${ }^{\circledR}$ Windows 2000 and Microsoft ${ }^{\circledR}$ Office 2007 were brought into the classroom. Inspiration ${ }^{\mathrm{TM}} 8.0$ (2008), the intervention software used in the study, was installed in each laptop. An interactive white board was used by the researcher to present the persuasive writing genre. A laser printer was readily available as well. All teaching and student writing was facilitated from this classroom. 
Only the participants, researcher, and, on occasion, an independent observer were present during the research sessions. The participants used the same laptops each day, with one laptop at each corner of the room to minimize distractions. The study sessions were held 4 days a week after school from 3:15 p.m. to 4:15 p.m. for 12 weeks. The participants were instructed to walk independently to the classroom from their homerooms at dismissal time.

\section{Materials}

The following is a description of materials used in the study. Materials included: consent forms, technology assessment forms, writing prompts, treatment fidelity procedure sheets, data logs, interrater agreement and treatment fidelity forms, and computer hardware and software.

\section{Parental Consent Form}

A parental consent form was given to each parent (see Appendix B). The purpose of this form was to establish parental consent for this study. The form provided a concise study description along with its purpose, information regarding the length of the study, and the parental and student participation expectations. Researcher and university contact information was provided on the form.

\section{Student Assent Form}

A student assent form was given to each student after the parent has signed the parental consent form (see Appendix C). The student assent form explained the study to the participating student and the expectations for the student. 


\section{Technology Skills Assessment}

A 100 word pre-written paragraph was given to each potential participant to type (see Appendix D). They were given 10 minutes to complete the task of typing the paragraph using Microsoft ${ }^{\circledR}$ Word 2007. Participants were then asked to make formatting changes in the typed paragraph (e.g., ability to cut and paste, ability to change typeface and type size, ability to realign text) by using the toolbars and menus available in Microsoft ${ }^{\circledR}$ Word 2007. This was given to ascertain that the participant could manipulate the word processing program.

\section{Technology Skills Assessment Checklist}

The technology skills assessment checklist (see Appendix E) was used to determine if each needed skill was attained by the student. The technology skills assessment checklist contained a list of skills pertaining to the usage of Microsoft $₫$ Word 2007 that each participant needed to have to be part of this study.

\section{Paper and Pencils}

Unlined white paper and two sharpened pencils were provided for each participant daily while the participants were in the baseline condition. These were available for the participants to use for their planning during baseline condition.

\section{Writing Prompts}

A writing prompt is a question posed to the participants, which serves as a guide for the composition content. Writing prompts were adapted from a commercially available teachers' resource (Learning Express, 2003) to reflect the ability level of average middle school students (see Appendix F). One English middle school teacher and a special education teacher were asked to rate each prompt as easy or difficult. All 
prompts rated as difficult were rephrased or completely rewritten by the researcher to better reflect the abilities of the participants and then reviewed by the two teachers again. Treatment Fidelity Procedure Sheet and Checklist

The treatment fidelity checklist included the procedures for each phase in the study and the step-by-step daily instructions (see Appendix G). The treatment fidelity checklist was used by the researcher and the independent observers to ascertain that the researcher followed all protocols for this study.

Writing Samples Scoring Procedures Sheet

A procedures sheet for scoring the four dependent variables was used (see Appendices H).

Writing Sample Data Logs

Data logs were kept on each of the four participants. Daily progress was charted on logs and graphs on each of the dependent variables: arguments and supporting details, planning time, writing fluency, syntactical maturity, and organization (see Appendix I) as calculated from the Writing Sample Scoring Sheet (see Appendix H).

Interrater Reliability Form

An Interrater Reliability Form (see Appendix J) was used to compare the writing samples scores obtained from the Writing Sample Scoring Sheet (see Appendix H) by each of two raters and the researcher.

Computer Hardware and Software

Four personal Dell laptops were used in this study. Each laptop was equipped with wireless network capabilities, printing and an external mouse. 
Inspiration $^{\mathrm{TM}} 8.0$. Inspiration ${ }^{\mathrm{TM}} 8.0$ (2008) is a commercially available graphic organizer program that is used to create different types of visual organizers which allows users to visualize ideas, concepts and relationships, and to expand on these ideas in an outline format. In this study, all features of the software were available, however, students were prompted to use specific features.

Persuasive writing graphic organizer template from Inspiration ${ }^{\mathrm{TM}}$ 8.0. This template is available on Inspiration ${ }^{\mathrm{TM}} 8.0$ (2008). It assists users in planning and organizing their persuasive compositions. Modifications to this template were made by the researcher to resemble the mnemonic TREE: tell your position, give at least three reasons, end it, and examine the writing (see Appendix K; Graham \& Harris, 2005).

Microsoft ${ }^{\circledR}$ Word 2007. Microsoft ${ }^{\circledR}$ Word 2007, a commercially available word processing program, was used to create, edit, and save documents. In this study, all features of the software were available for participants to use though they were not prompted to use the features.

SanDisk 2.0 gigabyte (thumb drive). A SanDisk 2.0 gigabyte (thumb drive) was used as a portable memory storage device to transfer all of the participants' writings and graphic organizers from the individual computers to the researcher's computer.

\section{Dependent Variables}

At the end of each session, each participant's writing sample was printed and transferred from each computer to the researcher's thumb drive. Each participant's composition and planning notes (whether written or on computer) were analyzed for six writing elements: (a) number of arguments and supporting details for each argument developed, (b) number and percentage of arguments and supporting details generated in 
planning that transferred to the composition; (c) the total number of minutes spent on planning; (d) writing fluency as measured by the total number of words written; (e) syntactical maturity as measured by the number and length of T-units; and (f) overall organization score as measured by the Analytical Scoring Guide (see Appendix H). Arguments and Supporting Details

In persuasive writing, the writer attempts to persuade the reader into accepting or believing a specific position or premise. This is accomplished through the presentation of arguments with supporting details for the arguments. Arguments are defined as a series of statements that establish a position to the premise (Andrews, 1995). An argument is composed of supporting details that provide logical support or rationale to the argument. Supporting details are defined as the number of statements containing facts, logical support, or examples that support the writer's arguments and point of view (Steele, 2007). The total number of arguments and the total number of supporting details per argument in the planning and in the composition were counted and recorded in the Writing Sample Scoring Sheet (see Appendix H). The total number and percentage of arguments and supporting details that transferred from the planning to the written composition were also recorded.

\section{Total Time Spent in Planning Stage}

The total number of minutes spent on the planning stage was recorded on the Writing Sample Scoring Sheet (see Appendix H) for each participant. The maximum allowed planning time was 15 minutes. As the participant was ready to move into the writing stage, he or she raised his or her hand to inform the researcher. Participants were informed when 15 minutes had elapsed and asked to move on. 


\section{Writing Fluency}

Writing fluency is defined as the total number of words written during the writing session (see Appendix H). All words produced including garbled, and unrecognizable words were included in the summation.

\section{Syntactical Maturity}

Syntactic maturity was measured using Hunt et al.'s (1968) minimal terminable unit (T-unit). The T-unit measures the shortest grammatically-allowed sentence without creating fragments in between the T-units (Hunt et al.). It contains a main clause, subject and a predicate, plus any subordinate clause that is attached to it that could not stand alone (Hunt et al.). A backward slash was drawn to separate T-units. The number and length of T-units per writing sample were tallied upon completion of the session and recorded in the Writing Sample Scoring Sheet (see Appendix H). The number of T-units was determined by counting all of the slashes drawn on the composition. The length of the T-unit was determined by the total number of words that form a T-unit without excluding a fragment. The mean length of a T-unit was determined by adding all of the words in the composition and dividing by the number of T-units in the composition.

\section{Overall Organization}

Overall organization was measured using an analytic scoring guide (see Appendix H). Analytic scoring guides are criterion specific rubrics allowing for evaluation of precise information without having to evaluate other aspects of writing (Moskal, 2000). This scoring guide allowed for certain components of organization to be analyzed individually as well as holistically, rather than allowing any other criterion such as grammar, to interfere with the rating of the writing sample. The participants' 
compositions were scored daily using an analytical scoring guide created by Monroe and Troia (2006) for organization and recorded in the Writing and Scoring Sample Sheet (see Appendix H). Monroe and Troia based the scoring guide from writing trait model developed by Spandel. This model has been employed in writing for the past 15 years (Monroe \& Troia, 2006). The scoring guide divided the scoring into the following subcategories: premise/argument/content, organization, sentence fluency, word choice, and conventions. The rater read each composition and rated each on a scale of 1 to 6 , with 1 being a poor composition and 6 being an exemplary composition for each section. A total organization score was then obtained by the calculating the average.

\section{Interrater Reliability}

Interobserver reliability or interrater reliability refers to the degree to which two or more independent observers or raters agree after observing or scoring the same events (Cooper et al., 2007). In this study, the term used was interrater reliability as permanent products were measured, and it referred to the degree in which two independent raters scored the compositions of the participants. In this study, two trained raters collected interrater reliability data on all dependent variables on approximately $31 \%$ of the sessions under baseline and intervention conditions. This percentage was determined based on current practice and recommendations in behavioral research which states that interrater reliability data should be collected on at least $25 \%$ of all sessions (Cooper et al., 2007). The raters were middle school teachers who taught at the site school. The raters were selected by the researcher based on availability and their experience with the target population. 
Training of the independent raters was provided by the researcher and lasted approximately 2 hours. The training session began with a verbal explanation of each dependent variable and examples of how to score each. A written handout defining each dependent variable was also provided. Following, the raters were given three sample compositions to score and rate using the Writing Sample Scoring Sheet (see Appendix H). The researcher and the raters then compared their independent scores with each other. Both reviewed the criterion and continued practicing on the sample compositions until at least $90 \%$ agreement was obtained for each dependent measure. At this point, the independent raters were considered trained. By training the raters in the same method of scoring, reliability of the results was increased (Copper et al., 2007).

Throughout the study, $31 \%$ of the compositions were randomly selected across different sessions to be scored by the independent raters. This was done to obtain a representative sample of the compositions to be scored (Cooper et al., 2007). The interrater reliability score was calculated by dividing the number of agreements by the total number of agreements and disagreements and then multiplying it by 100 for each of the dependent measures (Cooper et al.). Interrater reliability data was collected during baseline, and intervention. A minimum interrater reliability of $90 \%$ was to be obtained for each dependent variable in each writing sample compared. When $90 \%$ agreement was not reached, a re-training session occurred.

\section{Treatment Fidelity}

Treatment fidelity refers to the extent to which the independent measures are carried out as planned by the researcher (Cooper et al., 2007). In order to establish treatment fidelity, a treatment fidelity checklist (see Appendix G) was used daily by the 
researcher. This served as a measure to ascertain that procedures were carried out as planned.

The independent observers used for the interrater reliability were also trained to collect treatment fidelity data. The observers were trained to use the Treatment Fidelity Procedure Sheet and Checklist (see Appendix G) in the training session before the beginning of the study. Training was provided in the same session of the interrater reliability. During this session, the raters were given a copy of the Treatment Fidelity Procedure Sheet and Checklist. The independent observers were asked to observe the researcher as she executed the steps of the Treatment Fidelity Procedure Sheet and Checklist during a session with a student who was not in the study. Upon completing the checklist, the raters and researcher compared checklists and calculated the interobserver agreement percentage. Training continued until 90\% agreement in the checklists was obtained. This percentage was determined based on current research practices in applied behavior analysis (Cooper et al., 2007).

After the training, the observers randomly observed $31 \%$ of the writing sessions during baseline and intervention, and assessed the sessions using the Treatment Fidelity Procedure Sheet and Checklist (see Appendix G). Data were collected and recorded from each of the two conditions: baseline and intervention.

\section{Experimental Design}

A single subject, multiple baseline design across subjects was employed using 4 participants. A multiple baseline design was selected for several reasons. First, treatment does not have to be withdrawn in a multiple baseline design (Cooper et al., 2007). Withdrawing treatment in this project would not only be unethical, but nearly impossible, 
seeing as one cannot withdraw what has been learned (Cooper et al.). This study entailed the teaching of a writing strategy through the use of technology. Once the strategy is learned it can not be unlearned.

Second, a multiple baseline design allows for replication and verification of predictions of behaviors (Cooper et al., 2007). Verification is not determined directly, but inferred through the lack of change in the untreated subjects or behaviors. In other words, verification was achieved by comparing the treatment results of the first participant to the second participant, who has not received the treatment yet, and so on with other participants.

Finally, a multiple baseline design is easy for teachers to apply and mirrors how educators would normally employ change for their students (Cooper et al., 2007). Data collected were presented in tables and graphical form. The visual inspection of the graphs allowed for observation of experimental control and the effects of the intervention on the dependent variables. The ability for educators to implement the use of this writing strategy is crucial to this study. Hence, the model for this study was one that educators could model and adapt for their students with SLD.

\section{Procedures}

The following section describes the procedures that were used to conduct this study. Although some of this information was provided previously, additional detailed explanations are also provided in this section. The pre-study procedures section describes the preparation that took place prior to the start of the study, including obtaining parental consent, student technology skills assessment, selection of writing prompts, training of raters, and the teaching of persuasive writing and the writing process. The research site 
preparation section describes how the classroom was prepared daily prior to the start of each writing session. Finally, the general study procedures section has descriptions of the baseline and treatment conditions.

\section{Pre-study Procedure}

The following procedures were implemented prior to the beginning of the study. Explanations of participants and consent forms will first be presented. This will be followed by an explanation of the technology assessment. Procedures for the training of the independent raters will then be stated.

Selection of participants and consent and assent forms. As previously stated, four participants were selected from the available pool of students identified by the school as having an SLD in written expression. Letters were sent home inviting parents of potential participants to individually meet with the researcher. At this meeting, the researcher explained the purpose, requirements, and time commitments of the study. Each parent was asked to sign a consent form if he or she agreed to have his or her child participate in the study (see Appendix B). Additionally, each student was required to sign an assent form consenting to being part of the study (see Appendix C).

Technology assessment. Participants were asked to type a 100 word essay provided for them (see Appendix D) using Microsoft ${ }^{\circ}$ Word 2007. This assessment was conducted in the classroom. The researcher assessed the participants' abilities to use the basic functions of Microsoft ${ }^{\circledR}$ Word 2007 using a checklist (see Appendix E). Once the student was able to accomplish the items in the checklist with at least $90 \%$ accuracy, the student was considered proficient and ready to begin the study. 
Selection of writing prompts. Writing prompts were adapted from a commercially available teacher's resource (Learning Express, 2003) and reflected the ability level of average middle school students (see Appendix F). Two teachers, an English middle school teacher and a special education teacher, rated the difficulty of each prompt as either easy or difficult. Only the prompts rated as easy were maintained in this study. Each chosen prompt was typed and numbered (see Appendix F). A random generation of numbers using Excel was created to select the prompts.

Training of independent raters. Two independent raters were trained to measure and rate the participants' compositions for (a) number of arguments and supporting details for each argument developed in planning and composition; (b) number and percentage of arguments and supporting details generated in planning that transferred to the composition; (c) total planning time; (d) writing fluency; (e) syntactical maturity; and (f) overall organization. At this training the independent raters were also trained for treatment fidelity. Training was conducted by the researcher and was done in the one session. During the training, the raters were provided with verbal and written instructions on the scoring procedures sheets for each dependent variable (see Appendix H). Practice using these forms was provided in the form of sample compositions previously rated as excellent, average, and poor by the Iowa Writing Assessment (Hoover et al., 1995).

First the raters were trained on counting the number of arguments and supporting details in the planning stage and in the composition. Arguments are defined as a set of ordered statements or supporting details that establish a position to the premise (Andrews, 1995). Supporting details are statements containing facts, logical support, or examples that support the writer's arguments. The raters were taught to look for these 
statements in the planning sheets and record the number of supporting details found per argument and the number of arguments on the Writing Sample Scoring Sheet (see Appendix H). Then the raters were taught to look for the supporting details found per argument and the total number of arguments in the composition. The raters also recorded the number of arguments and supporting details that were present in the planning that then transferred to the composition. Both numbers were recorded on the Writing Sample Scoring Sheet.

The Writing Sample Scoring Sheet (see Appendix H) had a section for the recording of the minutes spent on planning. The total number of minutes spent by each participant was provided to the raters by the researcher. These numbers were used to track the amount of actual writing time of each participant.

Next, the raters were taught how to calculate the writing fluency. Writing fluency is the total number of words found in the composition. The raters were taught to count all of the words, including garbled and misspelled words. This number was then recorded in the Writing Sample Scoring Sheet (see Appendix H).

Following this, the raters were trained in scoring the syntactical maturity of the composition. Syntactical maturity was calculated by counting the number of T-units in the composition and calculating the mean length of the T-units. As the raters located the end of a T-unit, they marked it with a slash. The raters then counted all of the slashes and recorded the number on the Writing Sample Scoring Sheet (see Appendix H). The total number of words in each T-unit was summed and recorded on the Writing Sample Scoring Sheet. The mean number of words in each T-unit was calculated by dividing the total number of words in the composition by the total number or T-units. The total 
number of words in each T-unit was also tallied, averaged, and recorded on the Writing Sample Scoring Sheet.

Finally the raters were taught how to score the composition using the AnalyticTrait scoring guide developed by Monroe and Troia (2006). This guide contained five different traits: premise/argument, organization, sentence fluency, word choice, and conventions. The raters learned the differences in the scoring numbers and practiced scoring on different prewritten and scored compositions provided by the Iowa Writing Assessment (Hoover et al., 1995) that used a similar scoring rubric as the one chosen for this study.

The scores of the raters and the researcher were then compared and calculated for interrater reliability. The interrater reliability score was calculated as stated in Cooper et al. (2007) by taking the number of agreements divided by the number of agreements and disagreements and then multiplying it by 100 for each of the dependent measures. All dependent measures are of equal importance. A minimum interrater reliability of $90 \%$ was to be obtained for each dependent measure on each composition compared. If at any point throughout the study, $90 \%$ agreement was not reached, a re-training session occurred. One re-training session occurred in the study. When necessary, clarification on the scoring procedures was made. The interrater reliability scores were recorded in the Interrater Reliability Form (see Appendix J).

Training was also provided for treatment fidelity. The same raters used for scoring the compositions were trained to gather treatment fidelity using the Treatment Fidelity Procedure Sheet and Checklist (see Appendix G). First the raters read through the Treatment Fidelity Procedure Sheet and Checklist. The Treatment Fidelity Procedure 
Sheet and Checklist listed all of the steps the researcher took and said at each step of the study. This checklist was used by the raters as the researcher began each session of the study. As the steps were taken, the raters placed a checkmark next to the step. The steps were divided by sections: general procedures, persuasive writing instruction, baseline and intervention procedures, and intervention training of Inspiration ${ }^{\mathrm{TM}} 8.0$ (2008). Only the sections covered in the session were checked off that day, not every section occurred every day. At the end of the sessions observed by the independent rater, both the checklists of the researcher and rater were compared for interrater reliability. A minimum interrater reliability of $90 \%$ was to be obtained for each session. If $90 \%$ agreement was not reached, a re-training session occurred.

Teaching of persuasive writing strategies. During the first two sessions, participants were taught part of the writing process (planning, organizing, and editing) using persuasive writing. Each part of the writing process was explained using examples and non-examples. Persuasive writing was introduced and explained in these sessions using a PowerPoint presentation (see Appendix L). Handouts including all information covered were provided to the participants. All elements and characteristics of persuasive writing were explained using the mnemonic TREE: tell your position, give at least three reasons, end it, and examine the writing (Graham \& Harris, 2005). As part of the instruction, the researcher presented two examples of persuasive compositions. At the completion of the lesson, the students were asked to identify the parts of a persuasive composition using a sample composition. They were also asked to locate the arguments and the supporting details. This assessment was scored to ascertain that the participants understood the components of persuasive writing (see Appendix M). Being able to locate 
the writer's position, the three main arguments, and at least one supporting detail for each argument was sufficient criteria for understanding the basic components of persuasive writing. Afterwards they were given a sample prompt and asked to write a persuasive composition, using the mnemonic TREE to guide them in their writing. Then, they were asked to score the composition using the same scoring guide that was used with their writing (see Appendix H). Attaining a minimum score of a 2 out of a 6 by the participant was sufficient to state that the participant was able to write a persuasive composition. A score of 2 stated that the participant held sufficient knowledge of what was expected and could write the compositions. Scores of 3 or above meant the participant held a good understanding of the material and did not need a new writing strategy.

\section{General Study Procedures}

In this section, the general daily instructions for each portion of the study are described. The general daily procedures are listed first. Then, the baseline procedures are presented, followed by the intervention training. Lastly, the intervention procedures are stated.

General daily procedures. Each study session, the laptop computers were distributed and set up before the participants arrived. Microsoft ${ }^{\circledR}$ Word 2007 was launched and ready to use by the participants. A printed copy of the writing prompt was placed next to each laptop, and ready for the participant's use.

After being dismissed by their homeroom teachers at 3:15 p.m., the participants arrived independently at the classroom, where they were given 5 minutes to eat a snack (juice and chips provided by the researcher) and then asked to sit in front of their designated laptop. After the participants were seated in front of their computers, the 
researcher read to them the scripted directions located on the Treatment Fidelity

Procedure Sheet and Checklist (see Appendix G) and then read the writing prompt for the session. The researcher then instructed the participants that they had 15 minutes for planning, 20 minutes for writing, and 5 minutes for editing. The researcher prompted the participants at each interval. These time constraints were selected to adhere to the general format of most standardized tests. If the participant did not need all of the time allotted, he or she moved on to the next stage. However, the participant needed to inform the researcher that he or she was moving to the next stage by raising his or her hand. The recorded the total time spent in the planning stage and in the writing and researcher editing combined.

Baseline. Laptops were turned on and opened to Microsoft ${ }^{\circledR}$ Word 2007. A writing prompt, selected at random, was printed and placed next to each laptop before the participants arrived. Two sheets of white unlined paper and two pencils were also placed next to the computers. These were available for the participants to use during the planning stage. Any ideas or prewriting that the participant needed to do was done on these sheets. The participants arrived and were seated behind their assigned laptop. The researcher began the session by following the steps outlined on the Treatment Fidelity Procedure Sheet and Checklist (see Appendix G). Baseline procedures in the checklist included reminding participants of the three stages of writing and of the principle parts of a persuasive composition using the mnemonic TREE. The writing prompt was read out loud to the participants. General questions were answered and then the participants were asked to begin writing their compositions. 
Intervention training. When it was determined that a participant was to move into the intervention condition (based on visual inspection of the data), an individualized Inspiration $^{\mathrm{TM}} 8.0$ (2008) training session was conducted with that participant. Individualized training took place during the researcher's planning time in the library. The training session consisted of: teaching the participant how to create to a main idea cluster, expand it, create supporting clusters, and finally link main idea clusters and supporting clusters. A persuasive writing graphic organizer template, designed by the makers of Inspiration ${ }^{\mathrm{TM}} 8.0$, and modified by the researcher, was shown and taught to the participants (see Appendix K). This template consisted of different clusters that assisted the participants in planning their compositions. The participants were taught how to add or delete clusters as needed. Next, the outline program in Inspiration ${ }^{\mathrm{TM}} 8.0$ was taught so that the participants could organize their thoughts. Participants then learned how to transfer their outlines to Microsoft ${ }^{\circledR}$ Word 2007 and manipulate it to delete the outline headers, leaving the participants with their compositions in paragraph form. Once the participant became familiar and comfortable with the program, the participant was given a writing prompt and asked to use the program to plan and begin writing the composition using Inspiration ${ }^{\mathrm{TM}} 8.0$.

Intervention. After being trained in using Inspiration ${ }^{\mathrm{TM}} 8.0$ (2008), each participant began the intervention phase. Prompts were randomly selected and provided for the participants as previously described. The researcher continued to read instructions from the Treatment Fidelity Procedure Sheet and Checklist (see Appendix G). Instructions for both baseline and intervention participants were read as some participants were still on baseline. At this point, participants trained on Inspiration ${ }^{\mathrm{TM}} 8.0$ were 
instructed to do all planning on this program while the rest continued to plan on paper. The participants were reminded of the mnemonic TREE and of the basic features of persuasive writing. The writing prompt was read out loud to all participants. General questions were answered and then the participants were asked to start writing. Data were collected and recorded on each of the dependent variables for all participants including those still on baseline. The independent rater analyzed the data for verification purposes as previously described. The collection of data continued until all participants had moved through baseline and into the intervention stage.

\section{Summary}

This study examined the effects computer graphic organizers on the persuasive composition writing of Hispanic middle school students with SLD who have deficits in written expression. The research questions focused on (a) whether or not the computer graphic organizers had an effect on the total number of arguments and supporting details written during the planning and in the written composition, and (b) the total number and percentage of arguments and supporting details written that transferred from the planning to the composition; (c) the total time spent on the planning stage; (d) total number of written words during the writing session; (e) total number and mean length of T-units; and (f) the overall organization of the composition.

The participants were 4 Hispanic middle school students (two boys and two girls) enrolled in a Catholic school in an urban community. The participants were nominated by the teacher/ researcher and had a deficiency in written expression. The study was conducted in the middle school's English classroom using four Dell Laptops, all networked and running Microsoft ${ }^{\circledR}$ Windows 2000 and Microsoft ${ }^{\circledR}$ Office 2007 with an 
external mouse available for use. The materials included parental consent form, technology assessments, writing prompts, treatment fidelity procedure sheets, writing sample scoring sheets and data log sheets, and interrater reliability forms.

Data on five dependent measures were collected in this study. The total number of arguments and supporting details generated through the planning phase and writing phase, along with the total number and percentage of arguments and supporting details that transferred from the planning stage to the composition were calculated. Next, the total time spent on the planning stage was recorded. The total number of words written per session was recorded to obtain the writing fluency. The number of T-units and the mean length were also measured to obtain a syntactical maturity measurement, and finally the total organization score was calculated through the use of an analytical scoring rubric. The study collected data on the computer graphic organizer's effect on the participants' compositions from baseline through intervention. Interrater agreement and treatment fidelity data were collected and reported as well.

A single subject, multiple baseline design across subjects was used in this investigation. A multiple baseline design was selected for three main reasons. First, treatment will not have to be withdrawn. Second, multiple baseline design allows for replication and verification of predictions of behaviors. Finally, multiple baseline designs are easy for educators to implement. They follow how educators would normally implement change for their students. The ability for educators to implement the use of this writing strategy was crucial to this study, as providing assistance to all students was the general goal. 
A steady state of writing fluency was first maintained before the first participant began the intervention. Upon reaching steady state in intervention stage of the first participant, the intervention was then applied to the second participant, and so on. Data were collected and graphed daily. Visual analysis of the data points were conducted daily. Verification occurred when the data points began to change at predictable times as each participant received the intervention. It was assumed that if baseline behaviors changed as intervention was applied then a functional relation was observed.

Pre-study procedures included: obtaining parental consent forms, training of the independent raters on all forms and procedures, and selecting of writing prompts. Additionally, the participants were given a technology assessment to gauge their computer skills and received instruction on persuasive writing. The classroom and laptops were checked and prepared daily before students arrived for the study. General daily procedures included the reading of the writing prompt and instructions, as listed in the procedural guide.

Upon obtaining steady state with a participant, the intervention phase began with said participant after training in the use of Inspiration ${ }^{\mathrm{TM}} 8.0$ (2008). Inspiration ${ }^{\mathrm{TM}} 8.0$ instruction was given to each participant on an individual basis. After successful completion of an assessment on using the computer graphic organizer, the participant started using the computer graphic organizer, and data collection on the intervention phase began. Treatment fidelity was maintained by having the independent raters review and rate the compositions. 


\section{CHAPTER IV}

\section{RESULTS}

This chapter presents the findings of a multiple baseline design across subjects study to examine the effects of the computer graphic organizer on the persuasive composition writings of Hispanic middle school students with specific learning disabilities (SLD). In particular, the study was specifically designed to answer the research questions by measuring in baseline and intervention the number of arguments and supporting details in the planning and written composition, number and percentage of these arguments and supportive details that transferred from planning to written composition, total amount of time spent planning, total number of words, syntactical maturity, and overall organization of persuasive composition.

The chapter begins by presenting the treatment fidelity and interobserver agreement (IOA) data. Following this, the results of each participant's and the group's performance on each dependent measure is presented. Finally, a summary of results follows.

\section{Treatment Fidelity}

Treatment fidelity data were collected by the researcher and the two independent observers to ascertain that all procedures were followed as designed. Each day the researcher used the Treatment Fidelity Procedure Sheet and Checklist (see Appendix G) to make certain that the procedures were followed and the researcher's data indicated that the procedures were indeed followed $100 \%$ of the time. The independent observers collected data on 10 of the 32 sessions or $31 \%$ of the sessions across baseline and 
intervention. According to the data from the independent observers and the researcher, procedures were followed $100 \%$ of the time.

\section{Interrater Agreement}

Interrater agreement data were collected by the researcher and the two trained raters for 32 of 113 compositions or $28 \%$ of all compositions. The mean interrater agreement for arguments and supporting details was $92.19 \%$ (range $75-100)$. The mean interrater agreement for writing fluency was $99.40 \%$ (range 93-100). The mean interrater agreement for syntax was $96.90 \%$ (range $77-100)$. The mean interrater agreement for overall organization was $90.00 \%$ (range $75-100)$.

\section{Number of Arguments and Supporting Details}

This study was conducted, partially, to determine if the computer-graphic organizer intervention, Inspiration ${ }^{\mathrm{TM}} 8.0$ (2008), would have an impact on the number of arguments and supporting details written in the composition. The number of arguments and supporting details were counted during the planning stage and in the written composition. The arguments and supporting details were then inspected to determine the number and percentage that transferred from the planning to the composition. Data were collected during baseline and intervention.

In this section, an explanation of the figures and tables relating to the measurement of arguments and supporting details is given. This is followed by a narrative description of each participant's results as they pertain to the arguments and supporting detail. In each of the narratives, the data for planning are given first, followed by data collected during written composition. The data for the transferred number of 
arguments and supporting detail are then presented. After the narratives of the participants are presented, the group results are described.

Figure 1 and Figure 2 depict the mean number of arguments and supporting

details written by participants during planning and in the written composition during baseline and intervention conditions. It further shows the mean number of arguments and supporting details that transferred from planning to the written composition during baseline and planning and written composition during intervention. Table 2 shows participants' mean number of arguments and supporting details written in the planning and composition and the mean number of arguments and supporting details that transferred from planning to written composition during baseline and intervention. Table 3 shows the percentage of arguments and supporting details that transferred during baseline and intervention conditions.

Arthur

From planning during baseline with paper and pencil to planning during intervention with the computer graphic organizer, Arthur had a minimal increase in his mean number of arguments and had a greater increase in his mean number of supporting details. During baseline planning, Arthur wrote a mean of 2.50 arguments (range 2-3) and 2.25 supporting details (range $0-4$ ). During intervention planning, he wrote a mean of 2.95 arguments (range 2-4) and 6.82 supporting details (range 4-9) in the planning stage. This represents a mean increase of 0.45 arguments and 4.57 supporting details in the planning from a baseline to intervention (see Table 2; Figure 1; Figure 2). 


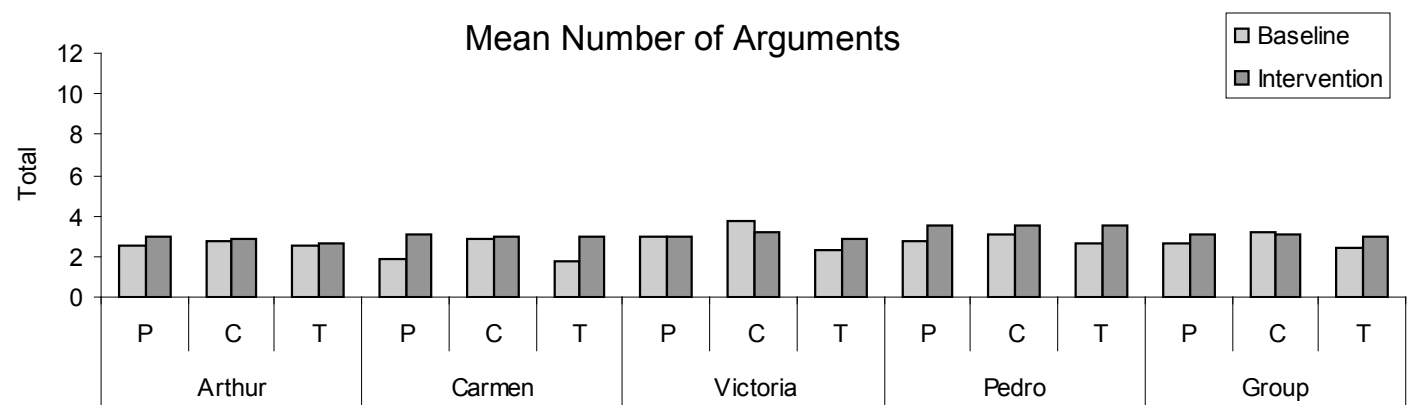

Figure 1: Mean number of arguments for each participant and the group across baseline and intervention. The planning stage is represented by "P" and written composition is represented by "C." The "T" refers to the number of arguments that transferred from planning to the composition.

From baseline compositions to intervention composition, Arthur had an increase in his mean number of arguments, and a greater increase in the mean number of supporting details. In baseline compositions, Arthur wrote a mean of 2.75 arguments (range 2-3) and 2.75 supporting details (range 2-4). During intervention, he wrote a mean of 2.91 arguments (range 2-4) and 7.36 supporting details (range 5-11). This represents a mean increase of 0.16 arguments and 4.61 supporting details in the compositions from a baseline to intervention (see Table 2; Figure 1; Figure 2).

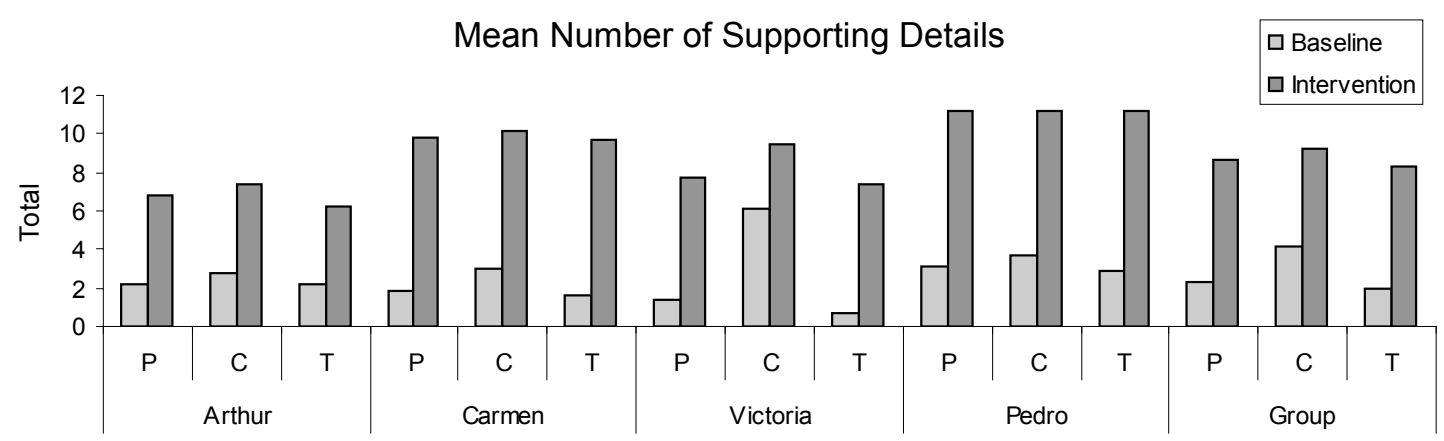

Figure 2: Mean number of supporting details for each participant and the group across baseline and intervention. The planning stage is represented by "P" and written composition is represented by "C." The " $T$ " refers to the number of supporting details that transferred from planning to the composition.

The number of arguments and supporting details that transferred from planning to the written composition during baseline, and the number and percentage that transferred 
from planning to written composition during intervention were compared. In intervention, Arthur had an increase in the mean number of transferred arguments and a greater increase in the mean number of transferred supporting details. Between baseline planning and compositions, Arthur transferred a mean of 2.50 arguments (range 2-3) and a mean of 2.25 supporting details (range $0-4$ ). Between intervention planning and compositions, Arthur transferred a mean of 2.68 arguments (range 1-3) and a mean 6.18 supporting details (range 4-8). This represents a mean increase of 0.18 arguments and 3.93 supporting details in the compositions from a baseline to intervention (see Table 2; Figure 1; Figure 2).

The overall percentages of arguments and supporting details that transferred from planning to written composition during baseline and intervention conditions were compared to each other (see Table 3). Throughout all 4 baseline sessions, Arthur developed a total of 10 arguments with 10 arguments or $100 \%$ transferring to the written composition and a total of 9 supporting details with 9 or $100 \%$ transferring to the written composition. Throughout all 22 intervention sessions, Arthur developed 65 arguments with a total of 59 arguments or $91 \%$ transferring to the written composition, and a total of 150 supporting details with 136 or $91 \%$ transferring to the written composition. This represents $9 \%$ fewer arguments and supporting details being transferred during intervention than baseline. However, it represents a greater mean number of arguments and supporting details.

\section{Carmen}

From planning during baseline with paper and pencil to planning during intervention with the computer graphic organizer, Carmen had an increase in her mean 
number of arguments and a greater increase in her mean number of supporting details. During baseline planning, Carmen wrote a mean of 1.89 arguments (range 1-3) and 1.89 supporting details (range 0-6). During intervention planning, she wrote a mean of 3.05 arguments (range 3-4) and 9.85 supporting details (range 8-16) in the planning stage. This represents a mean increase of 1.16 arguments and 7.96 supporting details in the planning from a baseline to intervention (see Table 2; Figure 1; Figure 2).

From baseline compositions to intervention composition, Carmen had a minimal increase in her mean number of arguments and a greater increase in the mean number of supporting details. In baseline compositions, Carmen wrote a mean of 2.89 arguments (range 2-3) and 3.00 supporting details (range 1-7). During intervention, she wrote a mean of 3.00 arguments (range 3 ) and 10.15 supporting details (range 8-13). This represents a mean increase of 0.11 arguments and 7.15 supporting details in the compositions from a baseline to intervention (see Table 2; Figure 1; Figure 2).

The number of arguments and supporting details that transferred from planning to the written composition during baseline, and the number that transferred from planning to written composition during intervention were compared. In intervention, Carmen had an increase in the mean number of transferred arguments and a greater increase in the mean number of transferred supporting details. Between baseline planning and compositions, Carmen transferred a mean of 1.78 arguments (range 1-3) and a mean of 1.67 supporting details (range 0-6). Between intervention planning and compositions, Carmen transferred a mean of 3.00 arguments (range 3 ) and a mean 9.70 supporting details (range 8-16). This represents a mean increase of 1.22 arguments and 8.03 supporting details in the compositions from a baseline to intervention (see Table 2; Figure 1; Figure 2). 
Table 2

Mean Number of Arguments and Supporting Details

\begin{tabular}{|c|c|c|c|c|c|c|c|c|c|c|c|c|}
\hline \multirow[b]{3}{*}{ Participant } & \multicolumn{6}{|c|}{ Baseline } & \multicolumn{6}{|c|}{ Inspiration ${ }^{\mathrm{TM}}$ Intervention } \\
\hline & \multicolumn{3}{|c|}{ Arguments } & \multicolumn{3}{|c|}{ Supporting Details } & \multicolumn{3}{|c|}{ Arguments } & \multicolumn{3}{|c|}{ Supporting Details } \\
\hline & $\mathrm{P}$ & C & $\mathrm{T}$ & $\mathrm{P}$ & C & $\mathrm{T}$ & $\mathrm{P}$ & $\mathrm{C}$ & $\mathrm{T}$ & $\mathrm{P}$ & C & $\mathrm{T}$ \\
\hline \multirow[t]{2}{*}{ Arthur } & 2.50 & 2.75 & 2.50 & 2.25 & 2.75 & 2.25 & 2.95 & 2.91 & 2.68 & 6.82 & 7.36 & 6.18 \\
\hline & $(2-3)$ & $(2-3)$ & $(2-3)$ & $(0-4)$ & $(2-4)$ & $(0-4)$ & $(2-4)$ & $(2-4)$ & $(1-3)$ & $(4-9)$ & $(5-11)$ & $(4-8)$ \\
\hline \multirow[t]{2}{*}{ Carmen } & 1.89 & 2.89 & 1.78 & 1.89 & 3.00 & 1.67 & 3.05 & 3.00 & 3.00 & 9.85 & 10.15 & 9.70 \\
\hline & $(1-3)$ & $(2-3)$ & $(1-3)$ & $(0-6)$ & $(1-7)$ & $(0-6)$ & $(3-4)$ & (3-3) & $(3-3)$ & $(8-16)$ & $(8-13)$ & $(8-16)$ \\
\hline \multirow[t]{2}{*}{ Victoria } & 3.00 & 3.71 & 2.36 & 1.36 & 6.07 & 0.71 & 2.92 & 3.15 & 2.85 & 7.69 & 9.46 & 7.38 \\
\hline & $(2-5)$ & $(3-6)$ & $(0-5)$ & $(0-6)$ & $(4-11)$ & $(0-3)$ & $(2-3)$ & $(3-4)$ & $(1-3)$ & $(4-11)$ & $(7-14)$ & $(6-9)$ \\
\hline \multirow[t]{2}{*}{ Pedro } & 2.75 & 3.05 & 2.65 & 3.10 & 3.70 & 2.90 & 3.50 & 3.50 & 3.50 & 11.20 & 11.20 & 11.20 \\
\hline & $(1-4)$ & $(1-4)$ & $(0-4)$ & $(0-7)$ & $(1-8)$ & $(0-6)$ & $(2-4)$ & $(2-4)$ & $(2-4)$ & $(6-12)$ & $(6-12)$ & $(6-12)$ \\
\hline \multirow[t]{2}{*}{ Group } & 2.64 & 3.19 & 2.38 & 2.28 & 4.19 & 1.98 & 3.06 & 3.08 & 2.94 & 8.60 & 9.23 & 8.27 \\
\hline & $(1-6)$ & $(1-7)$ & $(0-6)$ & $(0-7)$ & $(1-11)$ & $(0-6)$ & $(2-4)$ & $(2-4)$ & $(1-4)$ & $(4-16)$ & $(4-16)$ & $(4-16)$ \\
\hline
\end{tabular}

Note. Top numbers indicate mean number at each phase. The bottom rows of numbers represent the range of numbers of arguments or supporting details. $\mathrm{P}$ is the abbreviation for Planning. $\mathrm{C}$ is the abbreviation for Composition. $\mathrm{T}$ is the abbreviation for Transfer.

The overall percentages of arguments and supporting details that transferred from planning to written composition during baseline and intervention conditions were compared to each other (see Table 3). Throughout all 9 baseline sessions, Carmen developed a total of 17 arguments with 16 arguments or $94 \%$ transferring to the written composition, and a total of 17 supporting details with 15 or $88 \%$ transferring to the written composition. Throughout all 20 intervention sessions, Carmen developed 61 arguments with a total of 60 arguments or $98 \%$ transferring to the written composition, and a total of 197 supporting details with 194 or $96 \%$ transferring to the written 
composition. This represents $4 \%$ more arguments and $8 \%$ more supporting details being transferred during intervention than baseline.

\section{Victoria}

From planning during baseline with paper and pencil to planning during intervention with the computer graphic organizer, Victoria had a minimal decrease in her mean number of arguments but a noteworthy increase in her mean number of supporting details. During baseline planning, Victoria wrote a mean of 3.00 arguments (range 2-5) and 1.36 supporting details (range $0-6$ ). During intervention planning, she wrote a mean of 2.92 arguments (range 2-3) and 7.69 supporting details (range 4-11) in the planning stage. This represents a mean decrease of 0.08 arguments and a mean increase in 6.33 supporting details in the planning from a baseline to intervention (see Table 2; Figure 1; Figure 2).

From baseline compositions to intervention composition, Victoria had a slight decrease in her mean number of arguments and a noteworthy increase in her mean number of supporting details. In baseline compositions, Victoria wrote a mean of 3.71 arguments (range 3-6) and 6.07 supporting details (range 4-11). During intervention, she wrote a mean of 3.15 arguments (range 3-4) and 9.46 supporting details (range 7-14). This represents a mean decrease of 0.56 arguments and a mean increase of 3.39 supporting details in the compositions from a baseline to intervention (see Table 2;

Figure 1; Figure 2).

The number of arguments and supporting details that transferred from planning to the written composition during baseline, and the number that transferred from planning to written composition during intervention were compared. Victoria had an increase in the 
Table 3

Percentage of Transferred Arguments and Supporting Details

\begin{tabular}{|c|c|c|c|c|c|c|c|c|}
\hline \multirow[b]{2}{*}{ Participants } & \multicolumn{4}{|c|}{ Arguments } & \multicolumn{4}{|c|}{ Supporting Details } \\
\hline & $\begin{array}{c}\text { No. of } \\
\text { Sessions }\end{array}$ & Baseline & $\begin{array}{c}\text { No. of } \\
\text { Sessions }\end{array}$ & $\begin{array}{l}\text { Inspiration } \\
\text { Intervention }\end{array}$ & $\begin{array}{c}\text { No. of } \\
\text { Sessions }\end{array}$ & Baseline & $\begin{array}{c}\text { No. of } \\
\text { Sessions }\end{array}$ & $\begin{array}{l}\text { Inspiration } \\
\text { Intervention }\end{array}$ \\
\hline \multirow[t]{2}{*}{ Arthur } & 4 & $100 \%$ & 22 & $91 \%$ & 4 & $100 \%$ & 22 & $91 \%$ \\
\hline & & $10 / 10$ & & $59 / 65$ & & $9 / 9$ & & $136 / 150$ \\
\hline \multirow[t]{2}{*}{ Carmen } & 9 & $94 \%$ & 20 & $98 \%$ & 9 & $88 \%$ & 20 & $98 \%$ \\
\hline & & $16 / 17$ & & $60 / 61$ & & $15 / 17$ & & $194 / 197$ \\
\hline \multirow[t]{2}{*}{ Victoria } & 14 & $79 \%$ & 13 & $97 \%$ & 14 & $53 \%$ & 13 & $96 \%$ \\
\hline & & $33 / 42$ & & $37 / 38$ & & $10 / 19$ & & $96 / 100$ \\
\hline \multirow[t]{2}{*}{ Pedro } & 20 & $96 \%$ & 10 & $100 \%$ & 20 & $94 \%$ & 10 & $100 \%$ \\
\hline & & $53 / 55$ & & $35 / 35$ & & $58 / 62$ & & $112 / 112$ \\
\hline \multirow[t]{2}{*}{ Group } & 47 & $90 \%$ & 65 & $96 \%$ & 47 & $86 \%$ & 65 & $96 \%$ \\
\hline & & $112 / 124$ & & 191/199 & & $92 / 107$ & & $538 / 559$ \\
\hline
\end{tabular}

Note. Top numbers indicate the number of sessions spent in each condition and the percent of arguments and supporting details transferred. The Group number of sessions indicate the total number of sessions for all participants under each condition, not the number of sessions the researcher conducted. The bottom row represents the numbers that were transferred out of the total possible from planning to composition. 
mean number of transferred arguments and a noteworthy increase in the mean number of transferred supporting details. Between baseline planning and compositions, Victoria transferred a mean of 2.36 arguments (range $0-5$ ) and a mean of 0.71 supporting details (range 0-6). Between intervention planning and compositions, Victoria transferred a mean of 2.85 arguments (range 1-3) and a mean 7.38 supporting details (range 8-16). This represents a mean increase of 0.49 arguments and a mean increase of 6.67 supporting details in the compositions from a baseline to intervention (see Table 2; Figure 1; Figure 2).

The overall percentages of arguments and supporting details that transferred from planning to written composition during baseline and intervention conditions were compared to each other (see Table 3). Throughout all 14 baseline sessions, Victoria developed a total of 42 arguments with 33 arguments or $79 \%$ transferring to the written composition, and a total of 19 supporting details with 10 or $53 \%$ transferring to the written composition. Throughout all 13 intervention sessions, Victoria developed 38 arguments with a total of 37 arguments or $97 \%$ transferring to the written composition, and a total of 100 supporting details with 96 or $96 \%$ transferring to the written composition. This represents $18 \%$ more arguments and $43 \%$ more supporting details being transferred during intervention than baseline.

Pedro

From planning during baseline with paper and pencil to planning during intervention with the computer graphic organizer, Pedro had increase in his mean number of arguments and a greater increase in his mean number of supporting details. During baseline planning, Pedro wrote mean of 2.75 arguments (range 1-4) and 3.10 supporting 
details (range 0-7). During intervention planning, he wrote a mean of 3.50 arguments (range 2-4) and 11.20 supporting details (range 6-12) in the planning stage. This represents a mean increase of 0.75 arguments and 8.10 supporting details in the planning from a baseline to intervention (see Table 2; Figure 1; Figure 2).

From baseline compositions to intervention composition, Pedro had an increase in his mean number of arguments and a greater increase in his mean number of supporting details. In baseline compositions, Pedro wrote a mean of 3.05 arguments (range 1-4) and 3.70 supporting details (range 1-8). During intervention, he wrote a mean of 3.50 arguments (range 2-4) and 11.20 supporting details (range 6-12). This represents a mean increase of 0.45 arguments and 7.50 supporting details in the compositions from a baseline to intervention (see Table 2; Figure 1; Figure 2).

The number of arguments and supporting details that transferred from planning to the written composition during baseline, and the number that transferred from planning to written composition during intervention were compared. In intervention, Pedro had an increase in the mean number of transferred arguments and a greater increase in the mean number of transferred supporting details. Between baseline planning and compositions, Pedro transferred a mean of 2.65 arguments (range $0-4$ ) and a mean of 2.90 supporting details (range 0-4). Between intervention planning and compositions, Pedro transferred a mean of 3.50 arguments (range 2-4) and a mean of 11.20 supporting details (range 6-12). This represents a mean increase of 0.85 arguments and 8.30 supporting details in the compositions from a baseline to intervention (see Table 2; Figure 1; Figure 2).

The overall percentages of arguments and supporting details that transferred from planning to written composition during baseline and intervention conditions were 
compared to each other (see Table 3). Throughout all 20 baseline sessions, Pedro developed a total of 55 arguments with 53 arguments or $96 \%$ transferring to the written composition and a total of 35 supporting details with 35 or $100 \%$ transferring to the written composition. Throughout all 11 intervention sessions, Pedro developed 62 arguments with a total of 58 arguments or $94 \%$ transferring to the written composition and a total of 112 supporting details with 112 or $100 \%$ transferring to the written composition. This represents $2 \%$ less arguments and the same percentage of supporting details being transferred during intervention than baseline. However, it represents a greater mean number of arguments and supporting details.

\section{Group}

From planning during baseline with paper and pencil to planning during intervention with the computer graphic organizer, the participants had an overall slight increase in their mean number of arguments and a greater increase in the mean number of supporting details. During baseline planning, the participants wrote a mean of 2.64 arguments (range 1-6) and 2.28 supporting details (range 0-7). During intervention planning, they wrote a mean of 3.06 arguments (range 2-4) and 8.60 supporting details (range 4-12) in the planning stage. This represents a mean increase of 0.42 arguments and 6.32 supporting details in the planning from a baseline to intervention (see Table 2; Figure 1; Figure 2).

From baseline compositions to intervention composition, the participants had a slight decrease (nearly the same performance) in their mean number of arguments and a greater increase in the mean number of supporting details. In baseline compositions, the participants wrote mean of 3.19 arguments (range 1-7) and 4.19 supporting details (range 
1-11). During intervention, they wrote a mean of 3.08 arguments (range 2-4) and 9.23 supporting details (range 4-16). This represents a mean decrease of 0.11 arguments but a mean increase of 5.04 supporting details in the compositions from a baseline to intervention (see Table 2; Figure 1; Figure 2).

The number of arguments and supporting details that transferred from planning to the written composition during baseline, and the number that transferred from planning to written composition during intervention were compared. Participants had an increase in the mean number of transferred arguments and a greater increase in the mean number of transferred supporting details. Between baseline planning and compositions, the participants transferred a mean of 2.38 arguments (range 0-6) and a mean of 1.98 supporting details (range 0-6). Between intervention planning and compositions, they transferred a mean of 2.94 arguments (range 1-4) and a mean 8.27 supporting details (range 4-16). This represents a mean increase of 0.56 arguments and 6.29 supporting details in the compositions from a baseline to intervention (see Table 2; Figure 1; Figure 2).

The overall percentage of arguments and supporting details that transferred from planning to written composition during baseline and intervention conditions were compared to each other (see Table 3). Throughout all 47 baseline sessions, the participants developed a total of 124 arguments with 112 arguments or $90 \%$ transferring to the written composition and a total of 107 supporting details with 92 or $86 \%$ transferring to the written composition. Throughout all 65 intervention sessions, the participants developed 199 arguments with a total of 191 arguments or $96 \%$ transferring to the written composition, and a total of 559 supporting details with 538 or $96 \%$ 
transferring to the written composition. This represents $6 \%$ more arguments and $9 \%$ more supporting details being transferred during intervention than baseline.

\section{Planning Time}

This study was conducted, in part, to determine if the intervention, Inspiration ${ }^{\mathrm{TM}}$ 8.0 (2008), would have an impact on the number of planning minutes spent by the participants. The number of planning minutes spent each day in baseline and intervention was recorded and graphed in Figure 3. Also, the mean number of planning minutes per participant and the group during baseline and during intervention is presented in Table 4. Arthur

From baseline to intervention, Arthur greatly increased his total number of minutes planning. During baseline, Arthur spent a mean of 5.50 minutes in the planning stage (range 4-8). During intervention, he spent a mean of 13.50 minutes in the planning stage (range 8-19). This represents an overall increase of 8.00 planning minutes from baseline to intervention (see Table 4; Figure 3).

\section{Carmen}

From baseline to intervention, Carmen greatly increased her total number of minutes planning. During baseline, Carmen spent a mean of 4.22 minutes in the planning stage (range 4-8). During intervention, she spent a mean of 13.75 minutes in the planning stage (range 8-19). This represents an overall increase of 9.53 planning minutes from baseline to intervention (see Table 4; Figure 3).

\section{Victoria}

From baseline to intervention, Victoria greatly increased her total number of minutes planning. During baseline, Victoria spent a mean of 5.50 minutes in the planning stage 
Planning Time
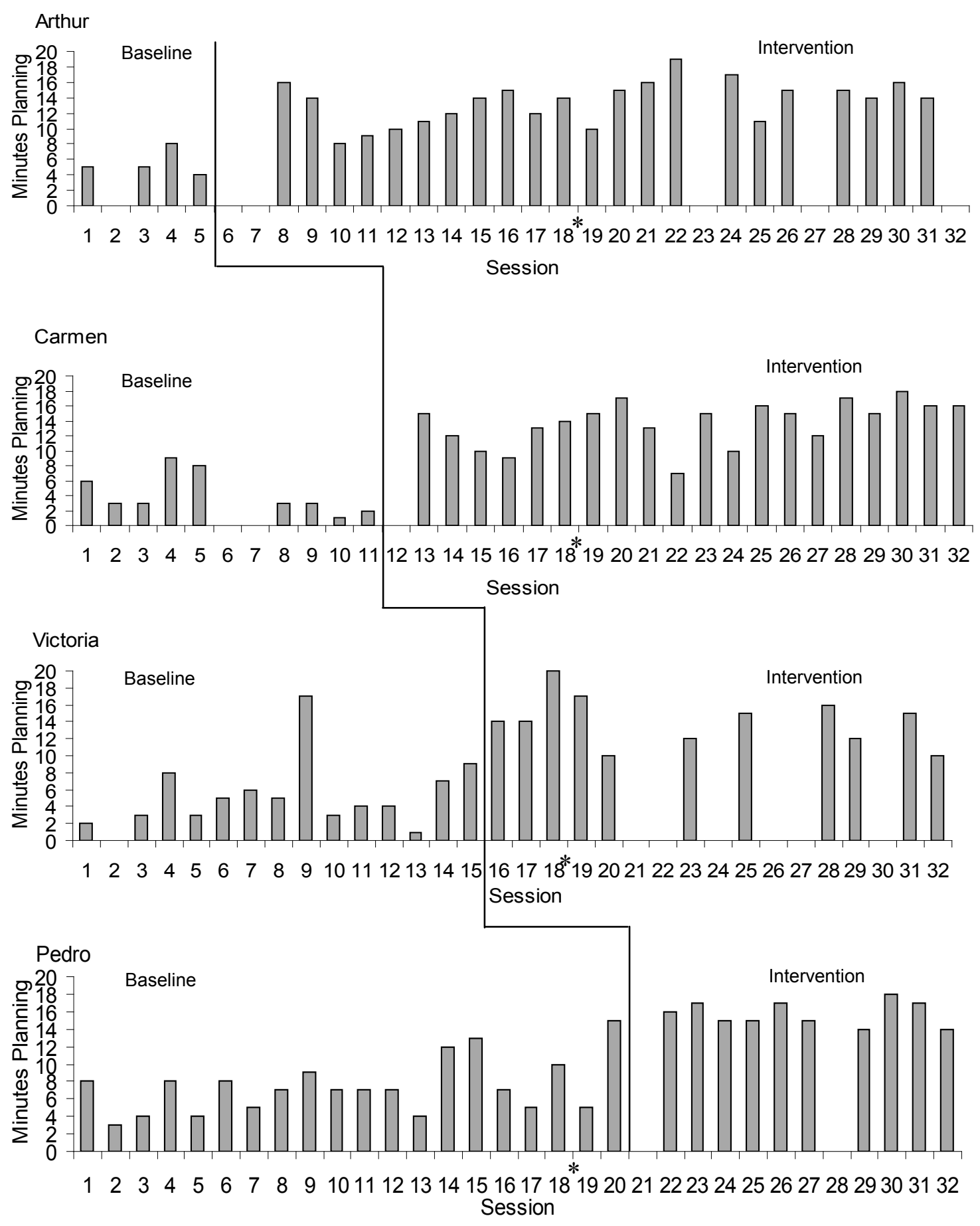

Figure 3. The Number of Minutes Spent on Planning. Note “*” indicates a 10 day break in study due to school holiday. Other breaks in data paths within conditions represent a participant's absence. 
Table 4

Mean Number of Minutes Spent in the Planning Stage

\begin{tabular}{lcc}
\hline \multirow{2}{*}{ Participants } & \multicolumn{2}{c}{ Planning Time } \\
\cline { 2 - 3 } Arthur & Baseline & Intervention \\
& 5.50 & 13.50 \\
Carmen & $(4-8)$ & $(8-19)$ \\
& 4.22 & 13.75 \\
Victoria & $(1-9)$ & $(7-18)$ \\
& 5.50 & 14.00 \\
Pedro & $(2-17)$ & $(12-20)$ \\
& 7.40 & 15.80 \\
Group & $(3-13)$ & $(14-18)$ \\
& 6.10 & 14.00 \\
\hline
\end{tabular}

Note. Top numbers indicate mean number at each phase. The bottom rows of numbers represent the range of number of minutes spent in the planning stage.

(range 4-8). During intervention, she spent a mean of 14.00 minutes in the planning stage (range 8-19). This represents an overall increase of 8.50 planning minutes from baseline to intervention (see Table 4; Figure 3).

Pedro

From baseline to intervention, Pedro greatly increased his total number of minutes planning. During baseline, Pedro spent a mean of 7.40 minutes in the planning stage (range 4-8). During intervention, he spent a mean of 15.80 minutes in the planning stage (range 8-19). This represents an overall increase of 8.40 planning minutes from baseline to intervention (see Table 4; Figure 3).

\section{Group}

From baseline to intervention, the participants greatly increased their total number of minutes planning. During baseline, the participants spent a mean of 6.10 minutes in the 
planning stage (range 1-17). During intervention, they spent a mean of 14.00 minutes in the planning stage (range 7-20). This represents an overall increase of 7.50 planning minutes from baseline to intervention (see Table 4; Figure 3).

\section{Writing Fluency}

This study was conducted, in part, to determine if the intervention, Inspiration ${ }^{\mathrm{TM}}$ 8.0 (2008), would have an impact on the participants' writing fluency. To measure fluency, the total number of words written in the composition daily during a 40-minute writing session by each participant was recorded. Data on writing fluency are presented in the form of total number of words written daily in each composition. Figure 4 depicts the total number of words written daily in each composition during the 40 minute writing sessions by the participants. Table 5 gives the mean and range of number of words written daily by each participant and the group during baseline and intervention. Arthur

From baseline to intervention, Arthur greatly increased his writing fluency. During baseline, Arthur wrote a mean of 84.5 words per composition per session (range 75-94). During intervention, his total number of words increased to a mean of 210.2 words composition per session (range 152-345). Overall, Arthur increased his mean number of words composition per session by 125.7 (see Table 5; Figure 4).

\section{Carmen}

From baseline to intervention, Carmen greatly increased her writing fluency. During baseline, Carmen wrote a mean of 146.2 words per composition per session (range 109-192). During intervention, her total number of words increased to a mean of 

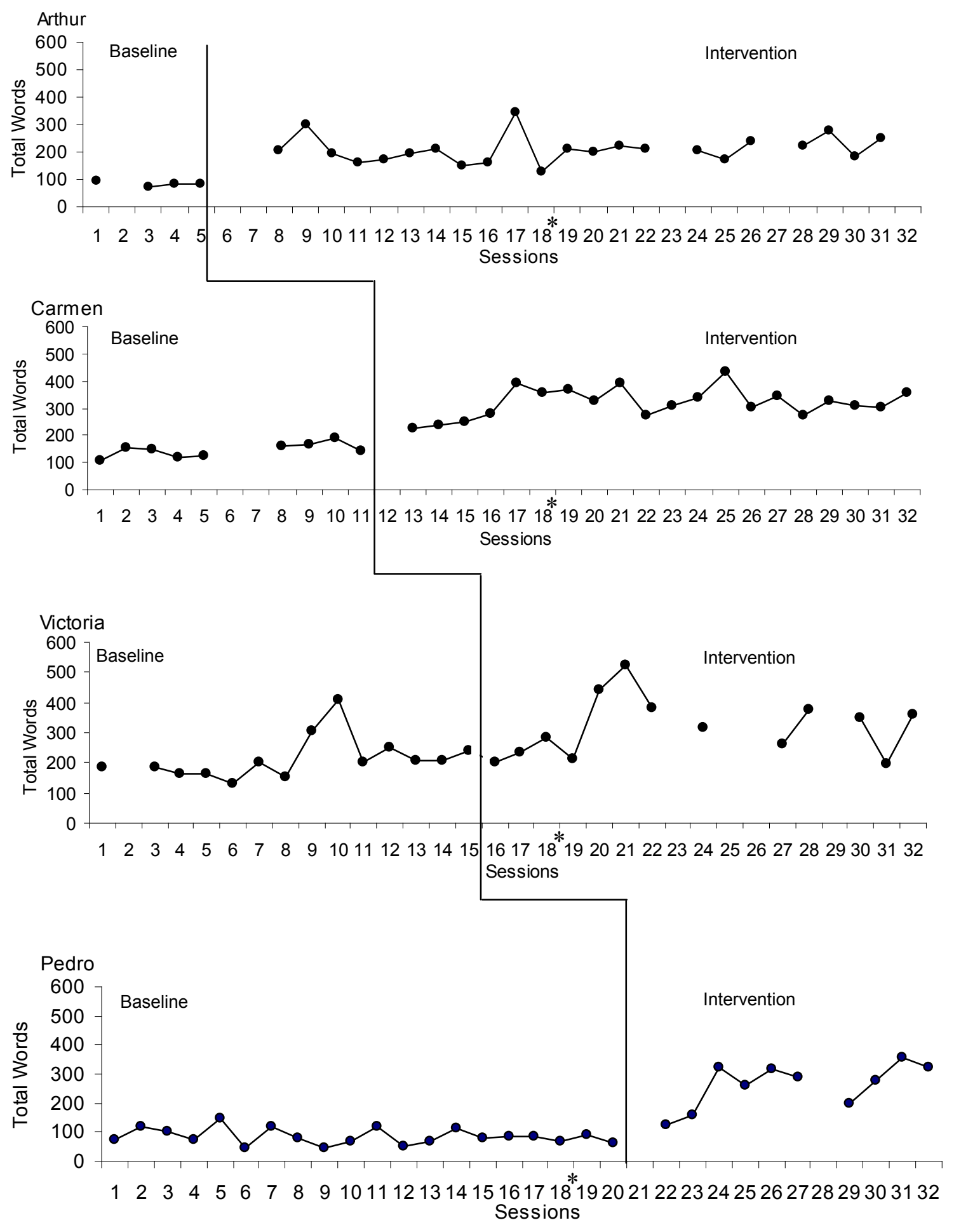

Figure 4. Total number of words written each session. Note “*” indicates a 10 day break in study due to school holiday. Other breaks in data paths within conditions represent a participant's absence. 
Table 5

Mean Number of Words Written During Baseline and Intervention

\begin{tabular}{ccc}
\hline & \multicolumn{2}{c}{ Mean Number of Words } \\
\cline { 2 - 3 } Participant & Baseline & Intervention \\
\hline Arthur & 84.5 & 210.2 \\
& $(75-94)$ & $(130-345)$ \\
Carmen & 146.2 & 319.2 \\
& $(109-192)$ & $(223-431)$ \\
Victoria & 215.0 & 319.0 \\
& $(130-408)$ & $(199-526)$ \\
Pedro & 85.3 & 263.2 \\
& $(48-146)$ & $(127-357)$ \\
Group & 135.5 & 273.6 \\
& $(46-408)$ & $(127-526)$ \\
\hline
\end{tabular}

Note. Top numbers indicate mean number of words written. The bottom rows of numbers represent the range of number of words written.

319.2 words composition per session (range 223-431). Overall, Carmen increased her mean number of words composition per session by 233 (see Table 5; Figure 4).

\section{Victoria}

From baseline to intervention, Victoria greatly increased her writing fluency. During baseline, Victoria wrote a mean of 215 words per composition per session (range 130-408). During intervention, her total number of words increased to a mean of 319 words composition per session (range 199-526). Overall, Victoria increased her mean number of words composition per session by 104 (see Table 5; Figure 4). Pedro

From baseline to intervention, Pedro greatly increased his writing fluency. During baseline, Pedro wrote a mean of 85.3 words per composition per session (range 46-121). During intervention, his total number of words increased to a mean of 263.2 words 
composition per session (range 127-357). Overall, Pedro increased his mean number of words composition per session by 177.9 (see Table 5; Figure 4).

\section{Group}

From baseline to intervention, the participants greatly increased their writing fluency. During baseline, the participants wrote a mean of 135.5 words per composition per session (range 46-121). During intervention, their total number of words increased to a mean of 273.6 words composition per session (range 127-526). Overall, the participants increased their mean number of words composition per session by 138.1 (see Table 5; Figure 4).

\section{Syntactical Maturity}

This study was conducted, partially, to determine if the intervention, Inspiration ${ }^{\mathrm{TM}}$ 8.0 (2008), would have an impact on syntactic maturity. Syntactic maturity was measured using Hunt et al.'s (1968) minimal terminable unit (T-unit). A T-unit is the shortest grammatically-allowed sentence without creating fragments in between the T-units (Hunt et al., 1968). A T-unit contains a main clause, subject and a predicate, plus any subordinate clause that is attached to it that could not stand alone (Hunt et al.). Total number of T-units were counted and recorded. In addition, the length of each T-unit was recorded, and the T-unit mean length was calculated in each condition. Data on the syntactical maturity are presented in the form of mean number and length of T-units in written compositions during baseline and intervention. Figure 5 depicts the daily number of T-units written by the participants and Table 6 shows the participants' mean number of T-units and the mean length of the T-units in baseline and intervention. 
Arthur

Arthur's total number of T-units greatly increased from baseline to intervention. During baseline, Arthur's compositions had a mean of 7.75 T-units (range 6-9). After intervention, his compositions had a mean 17.41 T-units (range 12-31). This is an overall increase of 9.66 T-units (see Table 6; Figure 5). With respect to mean length of T-units, Arthur had a minimal increase from baseline to intervention. During baseline, Arthur's mean T-unit length was 11.20 (range 9.2-11.3). During intervention, his mean T-unit length was 12.00 (range 8.0-14.1). This is an increase of 0.80 words per T-unit (see Table $6)$.

\section{Carmen}

Carmen's total number of T-units greatly increased from baseline to intervention. During baseline, Carmen's compositions had a mean of 11.56 T-units (range 5-16). After intervention, her compositions had a mean of 28.65 T-units (range 21-46). This is an overall increase of 17.09 T-units (see Table 6; Figure 5). With respect to mean length of T-units, Carmen had a decrease from baseline to intervention. During baseline, Carmen's mean T-unit length was 13.60 (range 9.3-21.8). During intervention, her mean T-unit length was 11.40 (range 6.9-15.3). This is a decrease of 2.20 words per T-unit (see Table $6)$.

\section{Victoria}

Victoria's total number of T-units increased from baseline to intervention. During baseline, Victoria's compositions had a mean of 16.50 T-units (range 8-28). After intervention, her compositions had a mean of 22.07 T-units (range 13-34). This is an overall increase of 5.57 T-units (see Table 6; Figure 5). With respect to mean length of 


\section{Syntactic Maturity}
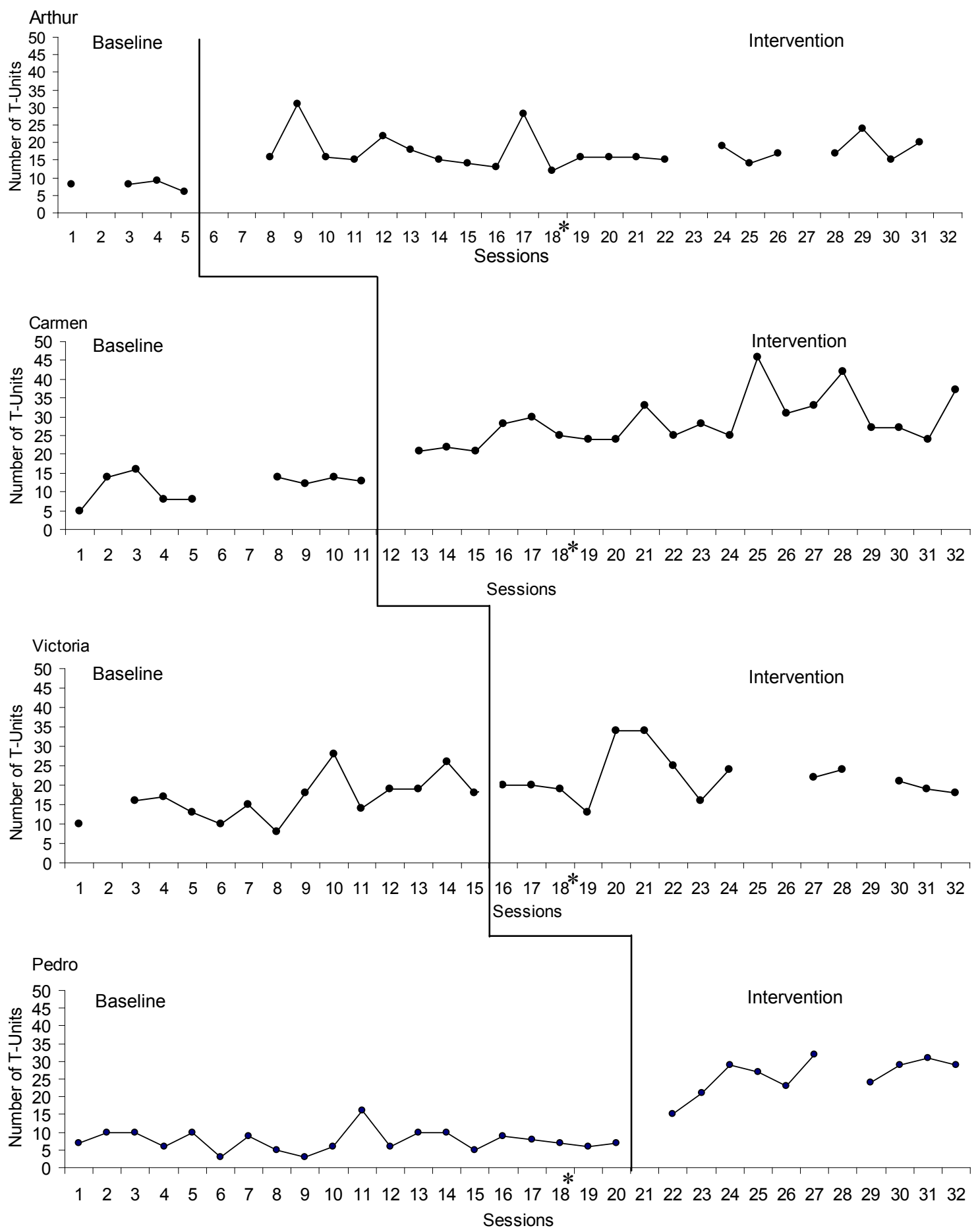

Figure 5. Syntactic Maturity as measured by the total number of T-units in the composition. Note "*" indicates a 10 day break in study due to school holiday. Other breaks in data paths within conditions represent a participant's absence.

T-units, Victoria had a minimal decrease from baseline to intervention. During baseline,

Victoria's mean T-unit length was 14.00 (range 10.4-19.0). During intervention, her 
mean T-unit length was 13.90 (range 10.1-20.0). This is a decrease of 0.10 words per Tunit (see Table 6).

Table 6

Mean Number of T-units in the Compositions and Mean Length

\begin{tabular}{|c|c|c|c|c|}
\hline \multirow[b]{3}{*}{ Participant } & \multicolumn{4}{|c|}{ Mean Length and Number of T-units } \\
\hline & \multicolumn{2}{|c|}{ Baseline } & \multicolumn{2}{|c|}{ Intervention } \\
\hline & Number & Length & Number & Length \\
\hline \multirow[t]{2}{*}{ Arthur } & 7.75 & 11.20 & 17.41 & 12.00 \\
\hline & $(6-9)$ & $(9.2-11.3)$ & $(12-31)$ & $(8.0-14.1)$ \\
\hline \multirow[t]{2}{*}{ Carmen } & 11.56 & 13.60 & 28.65 & 11.40 \\
\hline & $(5-16)$ & $(9.3-21.8)$ & $(21-46)$ & $(6.9-15.3)$ \\
\hline \multirow[t]{2}{*}{ Victoria } & 16.50 & 14.00 & 22.07 & 13.90 \\
\hline & $(8-28)$ & $(10.4-19.0)$ & $(13-34)$ & $(10.1-20.0)$ \\
\hline \multirow[t]{2}{*}{ Pedro } & 7.65 & 11.80 & 26.00 & 10.20 \\
\hline & $(3-16)$ & $(6.8-16.2)$ & $(15-32)$ & $(7.7-13.9)$ \\
\hline \multirow[t]{2}{*}{ Group } & 11.00 & 12.70 & 23.20 & 11.90 \\
\hline & $(3-28)$ & $(6.8-21.8)$ & $(12-46)$ & $(6.9-20.0)$ \\
\hline
\end{tabular}

Note. Top numbers indicate mean number at each phase. The bottom rows of numbers represent the range of number of T-units written.

Pedro

Pedro's total number of T-units greatly increased from baseline to intervention. During baseline, Pedro's compositions had a mean of 7.65 T-units (range 3-16). After intervention, his compositions had a mean 26.00 T-units (range 15-32). This is an overall increase of 19.35 T-units (see Table 6; Figure 5).With respect to mean length of T-units, Pedro had a decrease from baseline to intervention. During baseline, Pedro's mean T-unit 
length was 11.80 (range 6.8-16.2). During intervention, his mean T-unit length was 10.20 (range 7.7-13.9). This is a decrease of 1.60 words per T-unit (see Table 6).

\section{Group}

The participants' total number of T-units greatly increased from baseline to intervention. During baseline, the participants' compositions had a mean of 11.00 T-units (range 3-28). After intervention, their compositions had a mean 23.20 T-units (range 1246). This is an overall increase of $12.20 \mathrm{~T}$-units (see Table 6; Figure 5). With respect to mean length of T-units, the participants had a decrease from baseline to intervention. During baseline, the participants' mean T-unit length was 12.70 (range 6.8-21.8). During intervention, their mean T-unit length was 11.90 (range 6.9-20.0). This is a decrease of 0.80 words per T-unit (see Table 6).

\section{Organization}

This study was conducted, in part, to determine if the intervention, Inspiration ${ }^{\mathrm{TM}}$ 8.0 (2008), would have an impact on the organization of the compositions written by the participants. The total overall organization score of each composition was calculated by averaging the five components of the analytical rubric: premise/arguments, organization, sentence fluency, word choice, and conventions. Each component was scored using a range of 1 to 6 , with 1 being poor and 6 being excellent. Data are presented in the form of daily scores. Figure 6 depicts the participants' daily overall mean score of the analytical scoring rubric during baseline and intervention. Table 7 presents the mean score from the analytical scoring rubric for each participant and the group during baseline and intervention. 

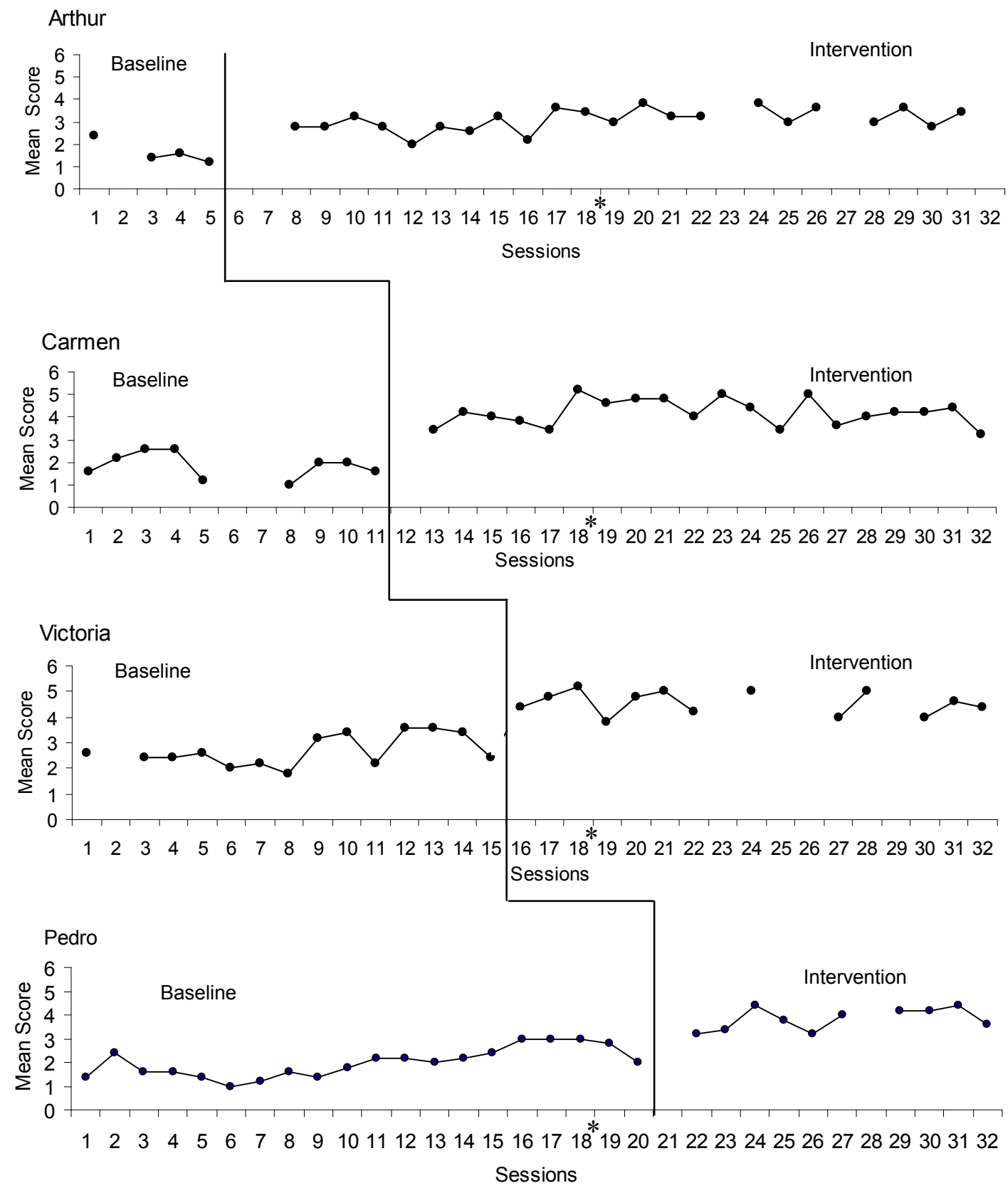

Figure 6. Mean Overall Daily Scores of the Analytical Scoring Rubric as measured by the mean score of all components of the Analytical Scoring rubric.

Note "**" indicates a 10 day break in study due to school holiday. Other breaks in data paths within conditions represent a participant's absence. 
Arthur

During baseline, Arthur's mean overall organization score was 1.65 (range 1.202.40). During intervention, his score was 3.08 (range 2.00-3.80). This represents a slight increase of 0.68 points in his overall organization score (see Figure 6; Table 7).

Carmen

During baseline, Carmen's mean overall organization score was 1.87 (range 1.20 -2.40). During intervention, her score was 4.18 (range 3.20-5.20). This represents an increase of 2.31 points in her overall organization score (see Figure 6; Table 7).

\section{Victoria}

During baseline, Victoria's mean overall organization score was 2.70 (range 1.803.60). During intervention, her score was 4.55 (range 3.80-5.20). This represents an increase of 1.85 points in her overall organization score (see Figure 6; Table 7).

Table 7

Mean of Analytical Scoring Guide

\begin{tabular}{ccc}
\hline \multirow{2}{*}{ Participants } & \multicolumn{2}{c}{ Mean Total Score } \\
\cline { 2 - 3 } Arthur & Baseline & Intervention \\
& 1.65 & 3.08 \\
Carmen & $(1.20-2.40)$ & $(2.00-3.80)$ \\
& 1.87 & 4.18 \\
Victoria & $(1.20-2.60)$ & $(3.20-5.20)$ \\
& 2.70 & 4.55 \\
Pedro & $(1.80-3.60)$ & $(3.80-5.20)$ \\
& 2.01 & 3.84 \\
Group & $(1.00-3.00)$ & $(3.20-4.40)$ \\
& 2.16 & 3.83 \\
& $(1.00-3.60)$ & $(2.00-5.20)$
\end{tabular}

Note. Top numbers indicate mean score of the analytical scoring guide. The bottom rows of numbers represent the range of number of words written. 
Pedro

During baseline, Pedro’s mean overall organization score was 2.01 (range 1.003.00). During intervention, his score was 3.84 (range 3.20-4.40). This represents an increase of 1.83 points in his overall organization score (see Figure 6; Table 7).

Group

During baseline, the participants' mean overall organization score was 2.16 (range 1.00-3.60). During intervention, their score was 3.83 (range 2.00-5.20). This represents an increase of 1.67 points in their overall organization score (see Figure 6; Table 7).

\section{Summary}

This study was designed to investigate the effects of using a computer graphic organizer to improve Hispanic middle school students' with SLD persuasive written compositions. In particular, the study measured the number of arguments and supporting details that were in both planning and in written compositions, number and percentage of arguments and supporting details that transferred from the planning to the written composition, amount of time spent planning daily, number of words written daily, syntactical maturity, and overall organization of the persuasive composition.

The results of this study indicate that the intervention assisted all participants in increasing their mean number of supporting details and 3 of the 4 participants in increasing their mean number of planned arguments. One participant had a slight decrease in the mean number of arguments planned from baseline to intervention. However, her mean number of supporting details did increase from baseline to intervention. The intervention also resulted in all participants increasing their mean number of supporting details written in their compositions and 3 of the 4 participants 
increasing their mean number of arguments. She had a decrease in the mean number of arguments written in the composition from baseline to intervention. However, her mean number of supporting details did show an increase. All participants showed an increase in the mean number arguments and supporting details transferred from the planning to the written composition. A greater percentage of arguments were transferred by 3 of the 4 participants. A greater or equal percentage of supporting details were transferred by all participants.

The results demonstrated that all participants had an increase in the amount of time they spent on planning during intervention. The mean number of minutes spent on planning more than doubled for all participants during intervention.

The participants' writing fluency also increased from baseline to intervention levels. The mean number of words written during intervention more than doubled for 3 of the 4 participants. For the other participant, her mean number of words increased by approximately 100 words per session.

The syntactical maturity of the participants' written composition was measured by the number of T-units and length of T-units written in the composition. The mean number of T-units increased for all participants during intervention. The T-unit group mean doubled during intervention. However, the mean length of the T-unit did not increase. In fact, there was a decrease from baseline to intervention in the mean length for 3 of the 4 participants.

The participants' written compositions were analyzed for organization using an analytical scoring guide. The results show that the participants improved their overall 
organizational of the composition. The mean score of the participants increased over 1 point on the 6-point scale. 


\section{CHAPTER V \\ DISCUSSION}

This chapter presents a discussion of the results of this study. First presented is a brief overview of the study followed by a summary of the results with respect to relevant literature in graphic organizers and composition writing and CLD students with specific learning disabilities (SLD). Lastly, the study's delimitations, limitations, implications for practice, and suggestions for future research are presented.

This study examined the effects of a computer graphic organizer on the persuasive writing composition of Hispanic middle school students with SLD. In particular, the study sought to answer the research questions by measuring multiple dependent variables including: (a) number of arguments and supporting details in the planning and writing stages; (b) number and percentage of these arguments and supportive details transferred from planning to the written compositions; (c) amount of time spent on planning; (d) writing fluency; (e) syntactical maturity; and (f) overall composition organization. Data were collected and analyzed on a total of 113 persuasive writing compositions in 32 session dates with 4 participants across the dependent variables. Of these 113 compositions, 47 were collected during baseline and 66 during intervention.

Despite slight differences in the outcome of the individual participants, overall the results of this study demonstrated that the use of the computer graphic organizer had positive effects on the participant's compositions as measured by the dependent variables. Increases in the mean scores across the following dependent variables were evident: (a) supporting details and transfer of supporting details, (b) planning, (c) writing fluency, (d) 
syntactical maturity, and (e) overall organization. Negligible differences were noted across all participants for the number and percentage of arguments planned, written, and transferred. A complete analysis of the results for each dependent variable, along with connections and comparisons to the existing relevant literature follows. Generally, the results of this study support the findings of relevant literature and offer advancements to the current literature.

\section{Arguments and Supporting Details}

Data on the number of arguments and supporting details written by the participants were analyzed. Presented first is an analysis of the number and percentage of arguments planned and written by the participants and the group in baseline and intervention conditions. Also, there is an analysis of the number of arguments written during planning that were transferred to the written composition. This is followed by a similar analysis of the supporting details planned, written, and percent transferred. Finally, this section ends with a discussion the results related to arguments and supporting details as they relate to the relevant literature.

\section{Arguments}

Overall, the results of this study showed negligible differences in the number of arguments planned, written, and transferred with variation among individual participants. During planning, Carmen had the most substantial increase from baseline to intervention in the mean number of arguments with a mean increase of 1.16. Arthur and Pedro had slight increases from baseline to intervention of 0.45 and 0.75 arguments, respectively. Victoria had a slight decrease of 0.08 in her mean number of arguments from baseline to intervention. 
On the written composition, overall there were negligible differences between mean number of arguments in baseline and intervention written compositions. Arthur, Carmen, and Pedro increased by $0.16,0.11$, and 0.45 arguments respectfully. Victoria had a slight decrease of 0.56 fewer mean number of arguments written in intervention than in baseline.

With respect to the mean number of arguments that transferred from planning to the written compositions, Arthur, Carmen, Victoria, and Pedro slightly increased their mean by $0.18,1.22,0.49$, and 0.85 respectfully. When analyzing the percentage of the total number of arguments by students that transferred between conditions, there was variability. Arthur transferred 9\% fewer arguments, whereas, Carmen and Pedro, transferred $4 \%$ more from baseline to intervention. Yet, Victoria transferred $18 \%$ more arguments from baseline to intervention. Although there was a decrease of $9 \%$ for Arthur, it should be noted that only 10 of 10 arguments were transferred during the 4 days of baseline, or a mean of 2.5 per day. Throughout the 22 intervention sessions, Arthur wrote 65 arguments with 59 or $91 \%$ transferring to the written composition or a mean of 2.9 per day. Subsequently, in actuality even though the percentage of transferred arguments was lower, Arthur did transfer more arguments during intervention than in baseline. A possible explanation to this decrease is the limited number of data baseline data points used to calculate the percentage of arguments.

\section{Supporting Details}

The results of this study demonstrated substantial increases with respect to the number of supporting details planned, written, and transferred. In the planning stage, all participants either doubled or tripled their number of supporting details from baseline to 
intervention. Arthur, Carmen, Victoria, and Pedro increased their mean number of supporting details per planning session by $4.57,7.96,6.33$, and 8.10 respectively.

Similar to the planning stage, the differences between baseline and intervention in the mean number of supporting details in the written composition were much greater. All participants increased from baseline to intervention by either doubling or tripling their mean number of supporting details in written compositions. Arthur, Carmen, Victoria, and Pedro had increases of 4.61, 7.15, 3.39, and 7.50, respectfully.

Also, the analysis of mean number of supporting details that transferred from baseline to intervention demonstrated a substantial growth. All participants either doubled or tripled their mean number of transferred supporting details from baseline to intervention. Arthur, Carmen, Victoria, and Pedro had increases of 3.93, 8.03, 8.99, and 8.30 respectfully. This is a percentage decrease of $9 \%$ for Arthur's number of supporting details, but an increase of $10 \%, 43 \%$, and $6 \%$ for Carmen, Victoria, and Pedro, respectively. Although there was a percentage decrease of $9 \%$ for Arthur, it should be noted that only 9 of 9 supporting details were transferred during the 4 days of baseline or 2.25 per day. Throughout his 22 intervention sessions, Arthur wrote a total of 150 supporting details with 136 or $91 \%$ transferring to the written composition or 6.2 per day. Subsequently, in actuality even though the percentage of transferred arguments was lower, Arthur did transfer more supporting details during intervention than in baseline.

\section{Arguments and Supporting Details and the Literature}

Persuasive writing requires the writer to take a position and convince his or her audience through logical arguments and evidence that the writer's position is the correct stance to take (Salahu-Din et al., 2008), and to then provide evidence in the form of 
supporting details for these arguments. Supporting details are statements containing facts, logical support, or examples that support the writer's arguments and point of view (Steele, 2007).

A common format for persuasive compositions is to have the five-paragraph structure, which includes the introduction or premise, three arguments with a minimum of three supporting details each, and a conclusion (Baker \& Brizee, 2007; Driscoll, 2007). Many students with SLD have problems expressing and generalizing ideas and then expanding on subtopics of these ideas in their compositions (Englert et al., 2007; Graham et al., 2001; Montgomery \& Kahn, 2007). Also, the formulation of new ideas can be challenging for some CLD students, as it requires them to compose and develop ideas in a language in which proficiency may still be lacking (Myles, 2002).

The results of this study do not support the use of the computer graphic organizer for increasing the number of arguments written by students. However, as the common format for persuasive writing is to have 3 arguments (Baker \& Brizee, 2007; Driscoll, 2007), the participants did meet this basic standard. The group mean during intervention was 3.06 arguments planned and 3.08 arguments written.

Conversely, the results of this study, although preliminary, do suggest that using a computer graphic organizer could assist Hispanic students with SLD in creating substantially more supporting details to convince their audiences of their positions as evidenced by the group's 9\% gain in number supporting details transferred. During baseline, the group was writing a mean of 1.98 supporting details. After intervention, as a group the participants were writing a mean of 8.27 supporting details per composition. This was approximately one supporting detail less than the specifications for the common 
five paragraph essay (Baker \& Brizee, 2007; Driscoll, 2007). The gains made by the group with the use of the computer graphic organizer demonstrate the potential effectiveness of this intervention as a strategy for improving writing amongst other learners.

The results of this study support the research of Lin et al. (2004) with generaleducation students using the same computer graphic organizer to improve persuasive writing. Although Lin et al. did not separate the students' persuasive composition by arguments and supporting details or measure the distinct number of ideas created in the composition, they did note that more ideas were produced in planning when students used computer graphic organizer as opposed to handwritten graphic organizers. Students who used the computer graphic organizer in Lin et al.'s study were found to have a mean of 12.27 ideas as opposed to students who used the handwritten graphic organizer who had a mean of 10.26 ideas.

The results of this study demonstrated that as with Lin et al.'s study more supporting details were written with computer graphic organizers. In distinguishing between arguments and supporting details, this study provided a more specific analysis of the participants' performances. These results extend the finding of Lin et al. in that participants used were Hispanic students with SLD and daily progress was measured as opposed to general-education students and a pre- and post-test assessment. Also, by collecting repeated measures of the dependent variables (as is required by the single subject design used), it allowed for the measurement of the students' growth as they progressed through the study rather than measuring performances at only one or two time 
intervals. This allowed the researcher to view changes as they occurred and to determine the immediate and consistent impact of the computer graphic organizer intervention.

The results of this study support the qualitative findings of Lorber (2004), in which the teachers perceived an increase in the number of ideas some general-education students developed after using computer graphic organizers. This study extends the work of Lorber in that a quantitative value was determined for the number of arguments and supportive details written as opposed to Lorber's qualitative findings of the perceptions of increase in the number of ideas written. However, Lorber noted a perceived decrease by the teachers in the number of ideas generated by low-achieving students. The results of this study found that Hispanic students with SLD were able to produce substantially more supporting details using the computer graphic organizer. Therefore, the results of this study contradict the perceptions of the teachers in Lorber's study who perceived a decrease in the number of ideas by low-achieving students, which included students with SLD.

In summary, this study's results demonstrated that using computer graphic organizers with Hispanic students with SLD had negligible results for the number of arguments written, but substantially increased the number of supporting details written in their compositions. Previously, only one study examined the number of ideas written by students in persuasive writing, and no study had collected data on arguments and supporting details separately. Therefore, these results extend the current literature by offering specific information on the effects of computer graphic organizers in producing more supporting details during the planning stage of writing and in written compositions. 
Because only 4 subjects were used in this study, the results should be viewed as preliminary.

\section{Planning Time}

Upon analysis of the time spent on planning each composition, it became apparent that all 4 participants greatly increased their mean planning time per writing session. From baseline to intervention, Arthur, Carmen, Victoria, and Pedro increased their mean planning time by $8.00,9.53,8.50$, and 8.0 minutes, respectfully. This represents a doubling and tripling of minutes spent planning.

Planning is the work a writer does including prewriting, brainstorming, talking, or outlining, before he or she begins to actually write (Kunka et al., 2007). It is dependent on the writer's skills to connect with the topic, understand it, be able to make inferences, and gather new information (Englert et al., 2007; Graham et al., 2001). Skilled writers spend a considerable amount of time planning their compositions (De La Paz \& Graham, 2002). However, many students with SLD often spend little time planning their compositions (De La Paz \& Graham). Similarly, some CLD students tend to spend minimal time in planning (Monroe \& Troia, 2006). The results of this study show that the use of computer graphic organizers can increase the planning time of Hispanic students with SLD; the participants substantially increased the amount of time they spent planning. These results mirror what is expected in good writing, that, in general, more planning is likely to produce more thoughtful, better writing (Graham et al., 2001).

The results of this study partially support the findings of Lin et al. (2002). Lin et al. compared handwritten graphic organizers to computer graphic organizers. The group of students who used the computer graphic organizer spent 4.2 minutes more on planning 
than the group who used handwritten graphic organizers. Both groups, handwritten and computer graphic organizers, in Lin et al.'s study spent a considerable amount of time on planning, 21.5 and 25.7 minutes respectively. The results of this current study support the increase Lin et al. found in the planning time using the computer graphic organizer. However, it should be noted that this current study compared the computer graphic organizer to baseline not to another intervention.

Additionally, the results of this study support the qualitative findings of Blair et al. (2002), in which few students spent any time on planning before being given the computer graphic organizer to plan and write their narrative compositions. According to Blair et al., one student increased his planning time with the use of a computer graphic organizer from 0 minutes to 4 minutes spent planning. Other students were noted to have increased their planning time in a similar fashion, however no data were available. The current study supports the findings of Blair et al., in that increases in the planning time were found using computer graphic organizers. However, the current study was unable to validate the findings of Blair et al., because the Blair et al. study does not provide sufficient quantitative data to make appropriate comparisons. Blair et al.'s results indicated general increases in the planning time.

In summary, the results demonstrated that using computer graphic organizers with Hispanic students with SLD increased the amount of time spent on planning. This study adds to the existing literature base by adding measurable results of the effects of computer graphic organizers on the planning time spent by students. 


\section{Writing Fluency}

Upon analysis of the participants' writing fluency, it appears that all participants greatly increased the mean number of words written per session. From baseline to intervention, Arthur, Carmen, Victoria, and Pedro increased the mean number of words written by $125.7,233,104$, and 177.9 across the 40 -minute writing sessions, respectively.

A written composition requires an adequate number of words to properly convey an idea (Kasper-Ferguson \& Moxley, 2002). Generally, students with SLD tend to write shorter compositions, not allowing them to fully express their ideas (Englert et al., 2007, Wong, 2000). Likewise, many CLD students tend to produce shorter compositions with poor fluency (Myles 2002). The results of this study demonstrated that with the use of computer graphic organizer, Hispanic students with SLD were able to substantially increase their mean number of words.

The results of this study in part support the results of Sturm and Rankin-Erickson (2002). Sturm and Rankin-Erickson had significant main effects for the number of words written by the 12 participants, $F(11,3)=6.05, p<0.01$, across all three interventions: (a) writing without graphic organizers, (b) handwritten graphic organizers, and (c) computer graphic organizer. Due to the methodology employed, Sturm and Rankin-Erickson were unable to determine which intervention was more effective. This current study reduced the confounding effects of Sturm and Rankin-Erickson's study by teaching persuasive writing before collecting baseline data. In this study, the use of computer graphic organizers increased the number of words written. For 3 of the 4 participants the increase was visible almost immediately after beginning the intervention, and the fourth participant showed gains after a few days. Consequently, the results of both studies 
showed gains in writing fluency. However, this study directly demonstrated that the intervention had a measurable effect on the gains. Additionally, the results of this study support the findings of Blair et al (2002). Blair et al. noted an increase in the length of each subsequent composition with the use of the computer graphic organizer.

In summary, the results of this study demonstrated that using computer graphic organizers with Hispanic students with SLD increased the writing fluency of the participants. This study extends to the existing literature by removing the confounding effects of Sturm and Rankin-Erickson (2002) study and by providing quantitative data to support the findings of Blair et al. (2002).

\section{Syntactical Maturity}

Overall, the use of computer graphic organizers resulted in substantial improvements for all 4 participants in the syntactic maturity of their written compositions, as measured by number of T-units. Arthur, Carmen, Victoria, and Pedro increased their mean number of T-units per writing session by $9.66,17.09,5.57$, and 19.35 respectively. With respect to the mean T-unit length, 1 participant had a negligible increase and another, a negligible decrease in the mean length of T-units between baseline and intervention. Specifically, Arthur increased his mean length by 0.80 words per T-unit and Victoria decreased her T-unit mean length by 0.10 . Carmen and Pedro had greater decreases in the mean length of their T-units by 2.20 and 1.60 , respectively. However, it should be noted again that all had substantial increases in the mean number of T-units written.

The ability to elaborate on an idea is important for a writer to convey his or her message adequately. This skill often is limited for CLD students with SLD to perform 
(Englert et al.; Graham et al., 2001; Montgomery \& Kahn, 2007; Myles, 2002).

Measuring and counting T-units is one method employed to measure a writer's ability to expand and elaborate on ideas (Sturm \& Rankin-Erickson, 2002). The results of this study demonstrated that by using computer graphic organizers, the participants were able to substantially increase their mean number of T-units. However, the mean length of the T-units did not result in any improvements with the use of computer graphic organizers.

The results of this study partially support the findings of Sturm and RankinErickson (2002). Again, Sturm and Rankin-Erickson found significant effects in the number of T-units, $F(11,3)=6.05, p<0.01$, across each of three interventions: (a) writing without graphic organizers, (b) handwritten graphic organizers, and (c) computer graphic organizer. This current study reduced the confounding effects of Sturm and Rankin-Erickson's study by teaching persuasive writing before collecting baseline data. The current study demonstrated an increase in the number of T-units produced immediately after the implementation of graphic organizers in 3 of its 4 participants. The fourth participant showed increases after the fourth intervention session. Consequently, the results of both studies showed gains in syntactical maturity. However, this study directly demonstrated that the intervention had a measurable effect on the gains.

The results of this current study support the findings of Sturm and RankinErickson in which they found no significant increase in the length of the T-units written by the students $F(11,3)=0.65, p<0.59$. The current study had negligible to decreasing results for the mean length of the T-units. Thus, the use of computer graphic organizers did not assist in increasing the length of the T-units written. 
In summary, the results demonstrated that using computer graphic organizers to improve the compositions of Hispanic students with SLD partially increased the syntactical maturity. Syntactical maturity has two components, the number of T-units and the mean length of T-units. The results of this study demonstrated increases in the participants' number of T-units but negligible to decreasing results were found for the mean length of the T-units, which supports the findings of Sturm and Rankin-Erickson (2002).

This study extends the existing literature on the syntactical maturity of students using computer graphic organizers. Only one other study, Sturm and Rankin-Erickson, examined syntactical maturity of students using computer graphic organizers, therefore these results should be viewed as preliminary

\section{Overall Organization}

The results on the analytical scoring guide used to measure the quality of the overall organization of the written compositions, demonstrates a general increase to varying degrees for all 4 participants. On a 6-point scale, Arthur, Carmen, Victoria, and Pedro increased by a mean of $0.68,2.31,1.85$, and 1.83 points, respectively. Although Arthur's increase was not as substantial as the other participants, he did improve his score from a 2.40 on the scoring guide to a 3.08. Considering that the scoring guide is on a 6point scale, this much of a change on the position of the scale, although minimal, means improvement.

Organization is the logical and sequential structuring of the planning stage of writing into a composition to convey a message or an idea (Rossitto, 2004; Wong, 2000). Unfortunately, the ideas generated by CLD students with SLD often are written in no 
logical order, and culminate in a group of disorganized thoughts that ineffectively convey their messages (Englert et al., 2007; Graham et al., 2001; Monroe \& Troia, 2006). The results of this study demonstrated that with the use of computer graphic organizers, the participants increased their organizational score.

The results of this study support the findings of Sturm and Rankin-Erickson (2002) who found that the holistic score of students' compositions created with a computer graphic organizer were higher than the students' baseline composition, where the students were asked to write an expository composition, without prior explanations. Also, the results of this study support the findings of Lorber (2004) who found that general-education students using the computer graphic organizer did perform significantly better on holistic scoring of their compositions $F(4,79)=2.49, p=.05$. In summary, the results suggest that using computer graphic organizers with Hispanic students with SLD increases the organization of the written compositions. However, both Lorber (2004) and Sturm and Rankin-Erickson (2002) employed different holistic scoring guides with computer graphic organizers. This current study used an analytical scoring guide in an effort to focus more on the organizational components and remove other variables from affecting the scoring. Since all three employed different scoring guides, the results of the current study should be interpreted as preliminary. All three studies revealed an increase in the scoring of the composition. This might suggest that computer graphic organizers will assist students in better organizing their compositions, regardless of the scoring method employed. 


\section{Summary of Results of All Dependent Variables}

This study examined the effects of computer graphic organizers on persuasive writing compositions of Hispanic students with SLD. The following dependent variables were studied: (a) number of arguments and supporting details; (b) number and percentage of transferred arguments and supporting details; (c) amount of time spent in planning; (d) writing fluency; (e) syntactical maturity; and (f) overall organization. Previously, four studies were found that used computer graphic organizers as a writing strategy to improve student compositions (i.e., Blair et al., 2002; Lin et al., 2004; Lorber, 2004; Sturm \& Rankin-Erickson, 2002). Of these, only two were used with students with disabilities (i.e., Blair et al.; Sturm \& Rankin-Erickson). Both of these two studies showed improvement in the students' compositions. None of the four studies specifically focused on Hispanic students, and only one study (Lin et al.) used persuasive writing.

Of the dependent variables investigated in this study, when computer graphic organizers were introduced as the intervention, substantial improvements were demonstrated in several dependent variables. There were increases for all 4 participants in the number of supporting details developed during planning and that appeared in the written compositions. Overall, an increased percentage of supporting details developed in the planning transferred to the written compositions. Also, there were increases in the number of minutes spent planning, writing fluency, number of T-units created, and overall organization of the written compositions.

Limited increases were found with the number of arguments, and percentage of transferred arguments, and the length of T-units. There were negligible results found for the number of arguments planned and written. This could be due to the planning template 
being designed for three arguments and participants were required to modify the template to add additional arguments. Varying results across the 4 participants were noted for the number of arguments transferred from planning to the written composition. With respect to the mean length of the T-units, no substantial growth was noted, rather a decrease was noted for 3 of the participants. This may be because the participants spent more time planning and organizing their compositions during intervention than in baseline which may have resulted in more concisely written thoughts, thus shorter T-units.

When comparing the results where clear increases were shown for the dependent variables (e.g., number of supporting details, percentage of supporting details transferred, planning time, writing fluency, number of T-units, and overall organization), this study supports or enhances the results of the four previously mentioned studies (i.e., Blair et al., 2002; Lin et al., 2004; Lorber, 2004; Sturm \& Rankin-Erickson, 2002). This study supports and extends the findings of Lin et al. (2004) and Lorber (2004) in which increases were found with the number of ideas written using computer graphic organizer. Also, this study further supports the studies of Blair et al. (2002), and Lin et al. in which increases were noted in the planning time. Furthermore, it supports and extends the findings of Blair et al. and Sturm \& Rankin-Erickson in which increases in the total number of words written were observed. In addition, the data of overall organization also supported the findings of Sturm \& Rankin-Erickson and Lorber.

Where there were limited increases, the dependent variables were either not investigated in previous studies or had similar results. The dependent variables number of arguments and transfer of arguments had limited results in this study and were not directly studied by any other found previous research. Similar results were found for the 
mean length of T-units by Sturm and Rankin-Erickson (2002) in that no increases were noted by the participants.

These results broaden the existing literature in that the dependent variables that clearly demonstrate success further enhance the literature. The dependent variables that had limited success support previous research.

\section{Implications for Practice}

The results of this study have important implications for classroom practice.

Overall, the computer graphic organizer used in this study was effective in improving the persuasive composition writing performances of Hispanic students with SLD. Educators should consider implementing the use of computer graphic organizers in the classroom with individual students or small groups after they teach the persuasive writing genre and possibly others as well. The schools should provide the students with access to desktops or laptops and allow them to plan using Inspiration ${ }^{\mathrm{TM}} 8.0$ (2008). A viable solution to providing students with the needed equipment is to use Minis. A Mini, short for mini notebook, is a laptop computer with a 10.1 inch screen or smaller (Martin, 2008). It has the same capabilities, storage, and speed of regular laptop in a compact size with a lower price (Martin, 2008). They are becoming more affordable and are more than capable of sustaining computer graphic organizers.

When first using Inspiration ${ }^{\text {TM}} 8.0$ (2008) in the classroom, one might consider using a ready-made template as was done in this study. As the students get more familiar with the program, it may be ideal to allow them to create their own organizers. This, however, was not done in this study in order to maintain better control of the study's variables. Students should be instructed in how to complete the planning utilizing 
Inspiration ${ }^{\mathrm{TM}}$ 8.0. However, limiting the amount of time the students spend on writing may hinder the student's writing. Writing is a recursive and cumulative process (Englert et al., 2007; Wong, 2000), and although this study did stipulate a time limit on the planning, limiting the planning in a classroom setting may hinder student writing. At the completion of the planning, the student should be instructed to use the outline mode feature of Inspiration ${ }^{\mathrm{TM}} 8.0$ (2008) to change the ideas into complete sentences. In this study, the participants were asked to not only change the thoughts into sentences, but to rearrange the order of the thoughts if needed. In outline mode, the participants were able to revise their paragraph structure and insure that all of their supporting details were in order. Although this study did not ask the participants to check for spelling or grammar, in the outline mode there are features that would enable the user to do so. This would further enhance the students' writing. Students with trouble formulating complete sentences or choosing appropriate words could use the text-tospeech option in Inspiration ${ }^{\mathrm{TM}}$ 8.0. This feature would read back the sentence or words to students. They could then decide if they chose the correct words. Following this, the student could transfer the outline into a word processor to finalize the composition. As evidenced by the results of this study, gains are visible across most of the dependent variables. The use of Inspiration 8.0 $0^{\mathrm{TM}}$ (2008) with persuasive writing was effective in increasing the number of supporting details used, the planning time, writing fluency, syntactical maturity, and the overall organization of the compositions. However, it did not increase the number of arguments written by the participants. This may have been due to the design of the template used for this study. A ready-made template adapted from Inspiration ${ }^{\mathrm{TM}} 8.0$ was used to assist the participants with their planning. 
This template only allowed space for three arguments. Educators wanting students to develop more arguments should revisit the results of this study and possibly make adaptations to the template or not use one. Instead, they could have students make their own template and evaluate its effectiveness.

Previous research has suggested that CLD students with SLD may benefit from use of computer graphic organizers (August, 2006; Monroe \& Troia, 2006; Sitko et al., 2005). The current study used the writing strategy, the computer graphic organizer, which resulted in an increase in the number of supporting details, planning time, number of words, T-units, and an improvement in the overall organization of the composition. This study's results further demonstrate the need for structured research based interventions to be used with Hispanic students with SLD in writing compositions.

\section{Delimitations of Study}

This study had certain built in exclusions. The participants of this study were in middle school and had a psychological educational evaluation stating that they had a deficiency in written expression. Furthermore, all participants came from a household where a second language, Spanish was spoken. This study focused on Hispanic students with SLD. Only two parts of the writing process were investigated in this study, planning and organization, and only one writing genre was used, persuasive writing. Although in writing it is common at times to share ideas, participants were not given a choice on topics to write and were not allowed to share ideas. Moreover writing a final draft often occurs over several days. However, participants in this study wrote on each given prompt for only one class session. Finally, due to the nature of single subject design, the study 
was limited to a small number of participants. Due to these limitations, additional research will be needed for further generalization of findings.

\section{Limitations}

The study commenced in the final trimester of the school which caused several study limitations. The study had to be scheduled around the school's 10-day spring break, causing a lapse in a period of time when the data could be collected. Final exams for the eighth graders caused an earlier than expected end to the study. End of the year events and meetings limited the number of days the participants were available.

Second, there is a lack of psychometric support for the Analytical Scoring Guide used in this study (see Appendix H). Although the scoring guide implemented in this study was used in another study (i.e., Monroe \& Troia, 2006), there exists no measure to determine its validity as a scoring guide.

Finally, another limitation that could have affected the participants' performance is the familiarity with the researcher. As their regular English teacher and the researcher was the same person, this could have influenced the performance of the participants.

\section{Suggestions for Future Research}

The results of this study recommend several areas for future research. The characteristics of the population used for this study were limited to Hispanic students with SLD, solely. Participants of other demographics should be considered in future research such as English language learners, other culturally and linguistically diverse (CLD) populations, and/or students in elementary school or high school. Inspiration ${ }^{\mathrm{TM}}$ 8.0 (2008) offers a word prediction utility along with a text-to-speech option which might be beneficial for English language learners or other CLD populations. Additionally, the 
use of this graphic organizer should be investigated in whole-class settings.

Future research should include the different writing genres with computer graphic organizers. This study focused on one particular genre, persuasive writing. Warranted is future research on the effects of computer graphic organizers on narrative and expository writing. Additionally, an analysis of class work done by participants while in the study would prove useful in determining the extent to which the effects of the intervention are transferred to other writing assignments in the classroom.

This study focused on the use of one specific computer graphic organizer, Inspiration TM 8.0 (2008). Although all features of the program were presented to the participants and available, only one template was used throughout the study. Future research should consider allowing students to create their own graphic organizers and/or use other templates, without suggesting minimal standards that might have inadvertently limited the number of arguments created. Also, Inspiration ${ }^{\mathrm{TM}} 8.0$ (2008) has the option of allowing text-to-speech, along with most new operating systems. Future research should include the use of this feature during planning. In addition, there are other commerciallyavailable computer graphic organizer programs that have varying features. Future research should investigate the effectiveness of these other programs.

Future research is needed to validate the findings of this study's use of planning time, writing fluency, and overall organization using an analytical scoring guide. Replication of this study is needed with an addition of a maintenance feature. An increase in the length of the study is also needed to note if participants maintain any improvements developed. In addition, no previous studies focused on the number of arguments and supporting details or on the percentage of transferred arguments and 
supporting details created using a computer graphic organizer. This may be due to the fact that these are higher order skills that require greater cognitive investments from the students. Future research may want to examine how computer graphic organizers could be used to promote greater number of arguments, possibly yielding more complex arguments. Finally, most state exams require that students use paper and pen to write their essays. Further research is needed to assess whether writing practice with computer graphic organizers can lead to the development and effective use of handwritten graphic organizers during assessments.

In conclusion, this study investigated the effects of computer graphic organizers and persuasive writing on Hispanic students with SLD. No known previous study has expressly studied the effects of this intervention with Hispanic students with SLD. Clearly, there is a need for additional research. The population and size for this study was limited by design, and, therefore, limits the ability to generalize the findings to all demographics. Additional research should focus on English language learners and other CLD students with SLD. Although this study focused on Hispanic middle school students with SLD, future studies may wish to examine this particular population at the elementary and high school levels. Extensions to this study may also include the use of different features of the computer graphic organizer, different graphic organizers, or even the combination of the graphic organizer and text-to-speech to work through more stages of writing. Further research may be warranted to expand the limitations of this study and to validate the findings by exploring how computer graphic organizers can be used to expand thinking and the depth of the writing content. 


\section{Summary}

The results of this study demonstrated that the use of computer graphic organizers had positive effects on the written compositions of Hispanic students with SLD. Increases in the number of supporting details, percentage of supporting details transferred, planning time, writing fluency, number of T-units created, and overall organization of the composition were noted.

Participants were taught persuasive writing and the writing process prior to the collection of data. During baseline, participants were asked to use paper and pencil during the planning of a persuasive composition on a given prompt. The intervention required the participants to use a computer graphic organizer to plan their writing composition. The planning sheets and written composition were printed and analyzed daily. Data were collected across baseline and intervention on the number of arguments and supporting details each participant wrote during planning and in the composition. Data were also collected on the number and percentage of arguments and supporting details that appeared in planning that transferred to the written compositions. Additionally, data were collected on the number of minutes the participants spent on planning, total number of words written, total number and mean length of T-units, and the overall organization of the composition.

Across all six dependent variables, increases were noted to varying degree. Results of this study demonstrate a substantial increase in the number of supporting details written in the planning and composition. Similarly, a group increase of $9 \%$ was noted for supporting details transferred. In planning, results indicate that the participants doubled or tripled the amount of minutes they spent on writing almost immediately after 
implementation of the intervention. Similarly, results in the writing fluency indicate that all participants increased substantially the total number of words they wrote in their composition after intervention. The results of syntactical maturity demonstrate that the number of T-units increased after intervention for all participants. Likewise, the results of the overall organization show increases in the total organizational score for all participants as measured by the analytical scoring guide.

With regards to the number of arguments, the percentage of transferred arguments, and the mean length of the T-unit, results were either negligible or varying. Negligible results were obtained for the number of arguments planned or written in the composition when comparing baseline and intervention performances. When analyzing the percentage of transferred arguments, the participants had varying results. Finally, negligible to decreasing results were obtained for the mean length of the T-unit for all participants.

This study provides evidence for the use of computer graphic organizers as a strategy to assist Hispanic students with SLD in their written compositions. Since this study was conducted with only seventh and eighth grade Hispanic students with SLD, generalizations of the results can only be made about this specific population. This study extends the limited research on computer graphic organizers and writing with Hispanic students with SLD by demonstrating the effects of computer graphic organizers on the writings of this particular group of students. Furthermore, this study extends the literature by adding information on the analysis of the different variables investigated. It enriches the literature by providing information on the number of supporting details created by using the computer graphic organizer, which has not been studied. Furthermore, it 
increases the literature base on the use of computer graphic organizers to increase the number of supporting details written by Hispanic students with SLD. The study extends the existing literature by adding measurable results to the effects of computer graphic organizers on the amount of time these students spend planning. Additionally, this study removed the confounding effects of previous studies by adding quantifiable data to the effects of the intervention on the writing fluency and syntactical maturity of Hispanic students with SLD. Finally, the study supports the existing literature on the use of computer graphic organizers to improve the overall organization of the composition.

Recent literature suggests that CLD students with SLD may benefit from the use of computer graphic organizers due to the ability of graphic organizers to pictorially and visually represent information in an organized manner (e.g., August, 2006; Monroe \& Troia, 2006; Sitko et al., 2005). The computer graphic organizer used in this study was effective in improving the persuasive writing compositions of Hispanic students with SLD. Educators should consider the use of this writing strategy when working with this population and persuasive writing.

Several delimitations and limitations to the study should be recognized. Due to the nature of single subject design, this study was limited to a small number of participants. The population used for this study was specifically chosen to be Hispanic middle school students with SLD. Subsequently, the results are limited to this population of students. The time of the year in which the study occurred brought several days off from school, meetings, early dismissals, and graduation of the participants which presented some study limitations. The participants were not given the option to choose their writing prompts which may have affected the study's outcome. Finally, the 
familiarity of the researcher to the participants may have had some effects on the participants' performances.

Future research should investigate the effects of computer graphic organizers on the writing compositions of different populations of learners. Furthermore, future research should consider investigating the use of different components of the graphic organizer program, different computer graphic programs, and the effects of graphic organizers with other genres of writing. 


\section{REFERENCES}

Anderson-Inman, L., \& Ditson, L. (1999). Computer-based concept mapping: A tool for negotiating meaning. Learning \& Leading with Technology, 26(8), 6-13.

Andrews, R. (1995). Teaching and learning argument. London: Cassell Education.

Applebee, A. N., \& Langer, J. A. (2006). The state of writing instruction in America's schools: What existing data tell us. Albany, NY: Center on English Learning and Achievement. (ERIC Document Reproduction Service No. ED494608)

Arendale, D. R. (2007, Fall). A glossary of developmental education and learning assistance terms. Journal of College Reading and Learning, 38(1). Retrieved August 12, 2008, from http://findarticles.com/p/articles/mi_hb3247/is_1_38/ai_n29390778

Asan, A. (2007). Concept mapping in science class: A case study of fifth grade students. Educational Technology \& Society, 10(1), 186-195.

August, D. (2006, February 26). Findings from the national literacy panel on language minority children and youth and implications for classroom practice. PowerPoint presentation. Center for Applied Linguistics. Retrieved July 8, 2008, from http://sa.ncsu.edu/esl/documents/5-31-07NorthCarolina.ppt

Babin, E., \& Harrison, K. (1999). Contemporary composition studies: A guide to theorists and terms. Westport, CT: Greenwood Press.

Baker, J. R., \& Brizee, A. (2007). The argumentative essay. The Owl at Purdue. Retrieved July 7, 2009, from http://owl.english.purdue.edu/owl/resource/685/05/

Blair, R. B., Ormsbee, C., \& Brandes, J. (2002, March). Using writing strategies and visual thinking software to enhance the written performance of students with mild disabilities. In No child left behind: The vital role of rural schools, $22^{\text {nd }}$ Annual National Conference Proceedings of the American Council on Rural Special Education (ACRES). Reno, Nevada: ERIC Clearinghouse on Disabilities and Gifted Education. (ERIC Document Reproduction Service No. ED463125)

Boon, R. T., Fore, C., III, Ayres, K., \& Spencer, V. G. (2005). The effects of cognitive organizers to facilitate content-area learning for students with mild disabilities: A pilot study. Journal of Instructional Psychology, 32(2), 101-117.

Bradley-Johnson, S., \& Lesiak, J. (1989). Problems in written expression: Assessment and remediation. New York: The Guilford Press. 
Brice, A. E., Miller, K. J., \& Brice, R. G. (2006). Language in the English as a second language and general education classrooms: A tutorial. Communication Disorders Quarterly, 27(4), 240-247.

Caesar, L. G. (2005). Testing the tests: An investigation into the effectiveness of alternative assessment methods for bilingual language-impaired children. The Hilltop Review, 1, 41-51. Retrieved June 22, 2008, from http://www.wmich.edu/gsac/Hilltop\%20Pages/PDF\%20Hilltop\%20Review\%20ar chive/HilltopReviewVol1Complete.pdf

Capretz, K., Ricker, B., \& Sasak, A. (2003). Improving organizational skills through the use of graphic organizers. Chicago, IL: Saint Xavier University and SkyLight Professional Development. (ERIC Document Reproduction Service No. ED473056)

Cooper, J. O., Heron, T. E., \& Heward, W. L. (2007). Applied behavior analysis (2 ${ }^{\text {nd }}$ ed.). Upper Saddle River, NJ: Pearson Education.

De La Paz, S. (1999). Teaching writing strategies and self-regulation procedures to middle school students with learning disabilities. Focus on Exceptional Children, 31(5), 1-16.

De La Paz, S., \& Graham, S. (2002). Explicitly teaching strategies, skills and knowledge: Writing instruction in middle school classrooms. Journal of Educational Psychology, 94(4), 687-698.

DiCecco, V. M., \& Gleason, M. M. (2002). Using graphic organizers to attain relational knowledge from expository text. Journal of Learning Disabilities, 35(4), 306-320.

Driscoll, D. L. (2007). Paragraphing (length consistency). The Owl at Purdue. Retrieved July 7, 2009, from http://owl.english.purdue.edu/owl/resource/606/02/

Educational Research Service (EDR). (2004). Writing across the curriculum to increase student learning in middle and high school. Arlington, VA: Author.

Englert, C. S., Zhao, Y., Dunsmore, K., Collings, N. Y., \& Wolbers, K. (2007). Scaffolding the writing of students with disabilities through procedural facilitation: Using an internet-based technology to improve performance. Learning Disability Quarterly, 30(1), 9-29.

Gándara, P. (2008). The crisis in the education of Latino students. National Education Association Research Visiting Scholars Series, 1(a). Retrieved June 30, 2008, from http://www.nea.org/achievement/gandara08.html 
Gándara, P., Rumberger, R., Maxwell-Jolly, J., \& Callahan, R., (2003, October). English learners in California schools: Unequal resources, unequal outcomes. Education Policy Analysis Archives, 11(36). Retrieved July 4, 2008, from http://epaa.asu.edu/epaa/v11n36/

George, C., Schaff, J. I., \& Jeffs, T. (2005). Physical access in today's schools: Empowerment through assistive technology. In D. Edyburn, K. Higgins, \& R. Boone (Eds.), Handbook of special education technology research and practice (pp. 355-377). Whitefish Bay, WI: Knowledge by Design.

Graham, S., \& Harris, K. R. (2005). Improving the writing performance of young struggling writers: Theoretical and programmatic research from the center on accelerating student learning. The Journal of Special Education, 39(1), 19-33.

Graham, S., Harris, K. R., \& Larsen, L. (2001). Prevention and intervention of writing difficulties for students with learning disabilities. Learning Disabilities Research \& Practice 16(2), 74-84.

Graham, S., Harris, K. R., \& Mason, L. (2005). Improving the writing performance, knowledge, and self-efficacy of struggling writers: The effects of self-regulated strategy development. Contemporary Educational Psychology, 30(2), 207-241.

Graves, A., Valles, G., \& Rueda, R. (2001). Variations in interactive writing instruction: A study in four bilingual special education settings. CIERA. Retrieved September 28, 2008, from http://www.ciera.org/libray/archive/2000-09/art-online-00-09.html

Hammond, J., \& Gibbons, P. (2001). What is scaffolding? In J. Hammond (Ed.). Scaffolding: Teaching and learning in language and literacy education (pp. 1 14) Sydney, Australia: Primary English Teaching Association. (ERIC Document Reproduction Service No. ED456447)

Harris, K. R., \& Graham, S. (1999). Programmatic intervention research: Illustrations from the evolution of self-regulated strategy development. Learning Disability Quarterly, 22(4), 251-262.

Hartman, B., \& Tarone, E. (1999). Preparation for college writing: Teachers talk about writing instruction for southeast Asian American students in secondary school. L. Harklau, K. M. Losey, \& M. Siegal (Eds.). Generation 1.5 meets college composition: Issues in the teaching of writing to U.S.-Educated learners of ESL (pp. 99 - 118). Mahwah, NJ: Lawrence Erlbaum Associates.

Hoover, H. D., Dunbar, S. B., Frisbie, D. A., Oberley, K.R.; Ordman, V. L., Naylor, R.J., Bray, G.B., Lewis, J. C., Qualis, A. L. (2003) Iowa tests of basic skills, forms A and $B$. Rolling Meadows, IL: The Riverside Publishing Company. 
Hoover, H. D., Hieronymus, D. A., Frisbie, D. A., Dunbar, S. B., Feldt, L. S., Forsyth, R. A., et al. (1995). Iowa writing assessment: Manual for scoring and interpretation. Rolling Meadows, IL: The Riverside Publishing Company.

Hoover, J. J., Klingner, J. K., Baca, L. M., \& Patton, J. M. (2008). Methods for teaching culturally and linguistically diverse exceptional learners. Upper Saddle River, NJ: Pearson Education.

Hunt, K., Morenberg, M., Pope, M., Richardson, J., Rogers, A., Smith, W. L., et al. (1968). An instrument to measure syntactic maturity, preliminary version. (Report No. BR-6-2253). Tallahassee, FL: Florida State University. (ERIC Document Reproduction Service No. ED020926)

Individuals with Disabilities Education Improvement Act (IDEA) of 2004, Pub. L. No. 108-446, 118 Stat. 2658 (2004).

Inspiration $^{\mathrm{TM}}$ (Version 8.0) [Computer software]. Beaverton, OR: Inspiration Software.

James, L. A., Abbott, M., \& Greenwood, C. R. (2001). How Adam became a writer: Winning writing strategies for low-achieving students. TEACHING Exceptional Children, 33(3), 30-37.

Kasper-Ferguson, S., \& Moxley, R. A. (2002). Developing a writing package with student graphing of fluency. Education and Treatment of Children, 25(2), 249267.

Kewal Ramani, A., Gilbertson, L., Fox, M., \& Provasnik, S. (2007) Status and trends in the education of racial and ethnic minorities (NCES Publication No. 2007039). Washington, DC: U.S. Department of Education, National Center for Education Statistics, Institute of Education Sciences.

Kim, A., Vaughn, S., Wanzek, J., \& Wei, S. (2004). Graphic organizers and their effects on the reading comprehension of students with LD: A synthesis of research. Journal of Learning Disabilities, 37(2), 105-118.

Kunka, J. L., Harris, M., Bishop, K., Kopp, B., Mooney, M., Neyhart D., et al. (2007). The writing process presentation. The Owl at Purdue. Retrieved July 8, 2008, from http://owl.english.purdue.edu/owl/resource/701/01/

LD Online. (2008) Glossary: Scaffolding. Retrieved May 23, 2009, from http://www.ldonline.org/glossary?theme=print\&letter $=\mathrm{S}$

Learning Express. (2003). 501 Writing Prompts. New York: Author. 
Lin, S. Strickland, J., Ray, B., \& Denner, P. (2004). Computer-based concept mapping as a prewriting strategy for middle school students. Meridian Middle School Computer Technologies Journal. Retrieved June 18, 2008, from www.ncsu.edu/meridian/sum2004/cbconceptmapping

Lorber, M. (2004). Instructional computer technology and student learning: An investigation into using inspiration(TM) software to improve eighth grade students' ability to write. Ann Arbor, MI: ProQuest Information and Learning Company (UMI 3158289).

Martin, J. A. (2008, October 1). Mini-notebooks mania, part 2: The benefits and drawbacks to mini-notebooks, plus some buying tips. PCWorld. Retrieved July 6 , 2009, from http://www.pcworld.com/printable/article/id,151346/printable.html

Maxwell, R. J. (1996). Writing across the curriculum. Needham, MA: Allyn and Bacon.

Mayes, S. D., \& Calhoun, S. L. (2005). Frequency of reading, math, and writing disabilities in children with clinical disorders. Learning and Individual Differences, 16(2), 145-157.

McCormick, C. B. (2003). Metacognition and learning. In I. B. Weiner (Series Ed.), W. M. Reynolds \& G. E. Miller (Eds.), Handbook of psychology: Vol. 7 Educational Psychology (pp. 125-148). Hoboken, NJ: John Wiley \& Sons.

Meyer, D. J. (1995). The effects of graphic organizers on the creative writing of third grade students. Union, NJ: Kean College of New Jersey. (ERIC Document Reproduction Service No. ED 380803)

Miller, J. L. (2000). Written expression disorder. atHealth.com. Retrieved August 17, 2008, from http://www.athealth.com/Consumer/Disorders/writtenexp.html

Monroe, B. W., \& Troia, G. A. (2006). Teaching writing strategies to middle school students with disabilities. The Journal of Educational Research, 100(1), 21-33.

Montgomery, J.K., \& Kahn, N.T. (2007). Ten steps to writing better essays. Greenville, SC: Super Duper Publications.

Moskal, B. M. (2000). Scoring rubrics: what, when and how? Practical Assessment, Research \& Evaluation, 7(3). Retrieved July 9, 2008 from http://PAREonline.net/getvn.asp?v=7\&n=3

Myles, J. (2002). Second language writing and research: The writing process and error analysis in student texts. Teaching English as a Second or Language- EJ, 6(2), 120. 
National Center for Education Statistics (NCES). (2006). Digest of education statistics, 2005 (NCES Publication No. 2006-030). Washington, DC: U.S. Department of Education.

National Center for Educational Statistics (NCES). (2007). Digest of educational statistics, 2006 (NCES Publication No. 2007-017). Washington, DC: U.S. Department of Education.

National Council for Teachers of English (NCTE) (2001). Statement on second language writing and writers. Retrieved June 21, 2008, from http://www.ncte.org/cccc/resources/positions/123794.htm

National Writing Project (2003). National Writing Project Statement on the 2002 NAEP Writing Report Card. Berkeley, CA: University of California.

Nesbit, J. C., \& Adesope, O. O. (2006). Learning with concept and knowledge maps: A meta-analysis. Review of Educational Research, 76(3), 413-448.

Rossitto, C. (2004). The writing process and writing technology: A pre-study for the Scribani Project. (Royal Institute of Technology and Stockholm University Technical Report No. TRITA-NA-P0404, IPLab-219) Retrieved August 17, 2008, from ftp://ftp.nada.kth.se/IPLab/TechReports/IPLab-219.pdf

Salahu-Din, D., Persky, H., \& Miller, J. (2008). The Nation's Report Card: Writing 2007 (NCES Publication No. 2008-468). Washington, DC: U.S. Department of Education, National Center for Education Statistics, Institute of Education Sciences.

Scott, B.J., \& Vitale, M.R. (2003). Teaching the writing process to students with LD. Interventions in Schools and Clinic, 38(4), 220-226.

Sitko, M. C., Laine, C. J., \& Sitko, C. (2005). Writing tools: Technology and strategies for struggling writers. In D. Edyburn, K. Higgins, \& R. Boone (Eds.), Handbook of special education technology research and practice (pp. 355-377). Whitefish Bay, WI: Knowledge by Design.

Steele, K. (2007). Definitions/ purposes for the modes of writing. Retrieved May 21, 2009, from http://www.kimskorner4teachertalk.com/writing/modes/definitions.html

Sturm, J. M., \& Rankin-Erickson, J. L. (2002). Effects of hand-drawn and computergenerated concept mapping on the expository writing of middle school students with learning disabilities. Learning Disabilities: Research \& Practice, 17(2), 124139. 
The Access Center. (2007). Using mnemonic instruction to facilitate access to the general education curriculum. LD Online, Article 15577. Retrieved August 17, 2008, from http://www.ldonline.org/article/15577

The Psychological Corporation, (2001). Wechsler Individual Achievement Test-Second Edition Abbreviated (WIAT_II). Retrieved June 2, 2009, from Mental Measurements Yearbook database.

Troia, G. (2003). Accessing skills towards successful writing development. The Access Center: Improving Outcomes for All Students K-8. Retrieved July 16, 2008, from http://www.k8accesscenter.org/index.php/category/language-arts/writing/

University of Iowa. College of Education. IOWA Testing Programs: IOWA Writing Assessment. Retrieved April 12, 2008, from http://www.education.uiowa.edu/itp/other_pgms/writing.htm

U.S. Census Bureau. 2000 Census of Population, Public Law 94-171. (Redistricting Data File). Available at http://quickfacts.census.gov/qfd/states/00000.html

U.S. Department of Education, Office of Special Education and Rehabilitative Services. (2002). A new era: Revitalizing special education for children and their families. Washington, DC: U.S. Department of Education.

Wilder, H., \& Mongillo, G. (2007). Improving expository writing skills of preservice teachers in an online environment. Contemporary Issues in Technology and Teacher Education, 7(1), 476-489.

Williams, J. A. (2001). Classroom conversations: Opportunities to learn for ESL students in mainstream classrooms. The Reading Teacher, 54(8), 750-757.

Willis, A. I. (2000). Critical issue: Addressing literacy needs in culturally and linguistically diverse classrooms. North Central Regional Educational Laboratory. Retrieved June 19, 2008, from http://www.ncrel.org/sdrs/areas/issues/content/cntareas/reading/li400.htm\#contact $\underline{\mathrm{S}}$

Woodcock, R., McGrew, K., Mather, N., \& Schrank, F. (1977, 1977-2003). WoodcockJohnson(r) III Diagnostic Supplement to the Tests of Cognitive Abilities. Retrieved June 2, 2009, from Mental Measurements Yearbook database.

Wong, B. Y. L. (2000). Writing strategies instruction for expository essays for adolescents with and without learning disabilities. Topics in Language Disorders, 20(4), 29-44. 
APPENDIX A

INSTITUTIONAL REVIEW BOARD APPROVAL 


\section{MEMORANDUM}

To: $\quad$ Caridad Unzueta

CC: Dr. Patricia Barbetta

From: Chris Grayson, CIM, Asst. Director of Research Compliance

Date: December 12, 2008

Propasal Title: The Use of Computer Graphic Organizer for Persuasive Writing by Hispanic Students with Specific Learning Disabilities.

Approval \# $120908-00$

Your study was deemed Exempt by the Institutional Review Board at Florida International University on Deetaber 9, 2008.

As a requirement of IRB approval you are required to:

1) Submit a completion report (Form B-2) upon completion of your project in order for the file to be closed.

2) Submit a proposal and receive approval for any additions or changes in the procedures involving human subjects.

3) Provide immediate written notification to the IRB of every serious or unusual or unanticipated adverse event as well as problems with the rights or welfare of the human subjects. You must confirm the receipt of serious AE reports with the IRB office.

Special Conditions: N/A

Please note your approval number is indicated above. For further information, you may contact the IRB Coordinator by email at ibiacuc@fiucdu or visit the ORI - Human Subjects website at http://ori.fiu.edu/IRB.html. 
APPENDIX B

PARENT/ GUARDIAN LETTER OF INFORMED CONSENT 


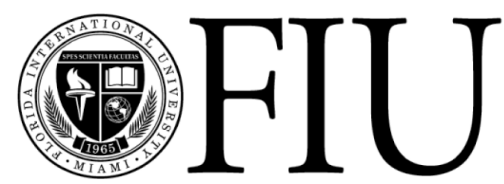

FLORIDA INTERNATIONAL UNIVERSITY

Miami's public research university

\section{CONSENT TO PARTICIPATE IN A RESEARCH STUDY}

\section{Title: THE USE OF COMPUTER GRAPHIC ORGANIZER FOR PERSUASIVE WRITING BY HISPANIC STUDENTS WITH SPECIFIC LEARNING DISABILITIES}

Your child is being considered as a candidate for a research study. The investigator of this study is Caridad H. Unzueta and she is a doctoral candidate at FIU. The study will include approximately four children with specific learning disabilities in written expression. The study will require about 1 hour of your child's time daily for approximately 6 to 8 weeks. The study investigates the use of a writing strategy to help improve persuasive writing. Your child will also receive a consent form explaining the study.

If you permit your child to be a part of the study, your child will be asked to stay after school for approximately 1 hour daily. During this time, your child will first be taught how to write a persuasive essay and then be asked to write several persuasive essays. The researcher will be collecting data on the various aspects of the written essay including the overall organization of the essay, quality, and quantity of words and sentences used. Upon analyses of these essays, your child will then be taught how to use a computer graphic organizer to write his or her essays. Your child will then be asked to write several more essays using this writing strategy.

The data collected will be identified by a pseudonym only and not your child's name. All of the information is private and will not be shared with anyone unless required by law. The data will be presented in a graph like table. The results will be presented as part of a dissertation and may appear in a paper as well.

You and your child may ask questions regarding the study at any time. Participation in this study is strictly voluntary and will not affect your child's academic courses. You may withdraw your child from the study at any time if you feel in any way uncomfortable. There is no cost to you for your child's participation in the study. This study will provide him or her with additional writing instruction and support.

If you would like to know more about this research after it is finished, you can contact Caridad Unzueta at 305-4084882. If you feel that you or your child were mistreated or you have questions about your rights as a volunteer in this research study you may contact Dr. Patricia Price, the Chairperson of the FIU Institutional Review Board at 305-3482618 or $305-348-2494$.

Thank you for your time.

Caridad H. Unzueta

Florida International University

This study has been explained to me. All of my questions have been answered to my liking. I am aware of my child and my rights and I agree to be in the study. I give permission for my child to be in the study.

Signature of Participant

Date

I have explained the research procedure, subject rights and answered questions asked by the participant. I have offered him/her a copy of this informed consent form.

Signature of Witness

Date

University Park • Miami, Florida 33199 
APPENDIX C

ASSENT FORM FOR PARTICIPANT 


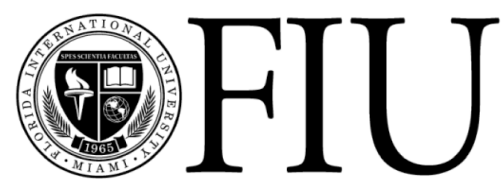

FLORIDA INTERNATIONAL UNIVERSITY

Miami's public research university

\section{ASSENT TO PARTICIPATE IN A RESEARCH STUDY \\ Title: THE USE OF COMPUTER GRAPHIC ORGANIZER FOR PERSUASIVE WRITING BY HISPANIC STUDENTS WITH SPECIFIC LEARNING DISABILITIES}

My name is Caridad H. Unzueta and I am a doctoral candidate at Florida International University. You are being asked to participate in a research study. The study will investigate the use of a computer graphic organizer to help you write persuasive essays.

I will need to get permission from your parent before you help with the study. If you decide to help, you will go to the computer lab four (4) times a week.

1) I will teach you how to write a persuasive essay.

2) You will be asked to write several persuasive essays.

3) I will collect data from your essays.

4) I will teach you how to use the computer graphic organizer to write your persuasive essay.

5) You will then be asked to write several more persuasive essays using the computer graphic organizers.

6) I will collect data again from your essays.

The activity should take less than an hour to complete. There is no charge or payment for your help. Using the computer graphic organizer during your participation will not harm you in any way. It can only help make your writing better. Your help with this project will not help or hurt your school grades. I only want you to try your best. You or your parent may ask to stop participating at any time.

No one will know your writing scores or information about you. Only I will know which scores are yours. I will write about them in my research paper using a different name.

If you have questions you may ask at any time. If you have questions about the study, you or your parent can call me, Caridad H. Unzueta, at 305-408-4882. If you or your parent feels like you were not treated fairly during the study or you have questions regarding your rights as a volunteer in this research study you may call Dr. Patricia Price, the Chairperson of the Institutional Review Board at 305-348-2618 or 305-3482494.

If you would like to be in the study, sign below. You will get a copy of this form.

$\frac{\text { Sign Here }}{\text { Investigator: Caridad H. Unzueta }}$

$\frac{\text { Date }}{\text { Date }}$

University Park • Miami, Florida 33199 
APPENDIX D

TECHNOLOGY SKILLS ASSESSMENT SAMPLE ESSAY AND INSTRUCTIONS

FOR STUDENT 


\section{Technology Skills Assessment Essay and Instructions}

\section{Directions:}

1. Open a new Word document.

2. Save the Word document as Test 1 on the hard drive.

3. Copy the following paragraph into the Word page.

The purpose of a persuasive essay is to change a reader's opinions on a topic. A persuasive essay needs planning. Planning includes choosing, researching, and outlining a topic. The first step for writing a persuasive essay is to decide what you are trying to persuade someone to believe. The next step is to collect information to support your arguments and organize them in a graphic organizer. Afterwards an outline will help organize the flow of the sentences and of the paragraphs. A draft is then made from this outline. Once the draft is complete, the editing and rewriting begins. Writing a persuasive essay.

4. Indent the first sentence, so that it looks like a paragraph.

5. Highlight the whole paragraph and double space it.

6. Change the margins of the whole document to be 1" all around.

7. Make the last sentence Bold.

8. Cut the last sentence and move it to the top of the paragraph.

9. Make this sentence the title therefore hit enter after it to separate it from the paragraph.

10. Center the title.

11. Save the work onto your flash drive.

12. Print the paragraph and write your name on it. 


\section{APPENDIX E}

TECHNOLOGY SKILLS ASSESSMENT CHECKLIST 


\section{Technology Skills Assessment Checklist}

Participant:

Date:

Please check off if the participant is able to accomplish the following tasks:

1. Open a new Word document.

2. Save the Word document.

3. Copy text into a document.

4. Indent the first sentence using a tab.

5. Highlight the whole paragraph

6. Double space a paragraph.

7. Change the margins.

8. Use the Bold feature.

9. Use the cut and paste features.

10. Use the Center the feature.

11. Save the work.

12. Print a document 
APPENDIX F

WRITING PROMPTS 
Writing Prompts *Adapted and modified from Learning Express (2003).

1. Many people believe that television violence has a negative effect on society because it promotes violence. Do you agree or disagree? Use specific reasons and examples to support your response.

2. According to some people, children should not be allowed to get a driver's license until the age of 18. Explain what you think and why.

3. In order to save money, your principal is thinking about canceling all field trips for the remainder of the year. Write an essay persuading him or her to allow students to continue attending field trips. Use specific reasons and examples to support your response.

4. Take a position on whether a student should or should not be issued a driver's license unless he has graduated from high school. State your position and explain why a student should or should not be issued a driver's license unless he has graduated from high school.

5. In order to save money, your principal is thinking about canceling all sports for the remainder of the year. Write an essay persuading him or her to allow students to continue participating in sports. Use specific reasons and examples to support your response.

6. Take a position on whether middle school students should have homework assignments on weekends.

7. Many people volunteer their time to help others, either through non-profit organizations, churches, or other charitable venues. Write an essay convincing readers to find a charity and volunteer their time.

8. We all have favorite activities that we enjoy. Write an essay convincing readers to try the activity that you enjoy most.

9. Think about your favorite sport. Convince your friend that this is the right sport for him or her to join.

10. Research shows that the average American watches as much as six hours of television each day. Do you think this is too much? Write an essay convincing readers to spend less time in front of the TV?

11. Many junior high and high schools around the country now require students to spend a certain number of hours each term doing volunteer work or community service. Some people believe this is an excellent idea that promotes good citizenship and cultivates compassion. Others feel that forced volunteerism is not volunteerism at all. How do you feel about this issue? Use specific reasons and examples to support your position.

12. Think of your favorite place to eat. Write an essay convincing your school to order food from this place for the class party.

13. Most states allow people to get a driver's license at the age of 16. Some people feel that 16 is much too young for the responsibility that comes with driving a car and that teenagers should not be allowed to drive until the age of 18. In your opinion, at what age should people be allowed to drive and why?

14. Many people believe that teenage children should not own cell phones. How do you feel about this issue? State your position and explain your reasons with specific examples. 
15. Write an essay convincing readers to break a specific habit that is harmful to their physical, emotional, or financial health.

16. Have you ever traveled to a place that you found very meaningful and rewarding? Write an essay that persuades others to visit this important place.

17. Some people believe that certain television programs are good to watch. State one such program and convince the reader that they should watch this program.

18. Many students believe that homework is not necessary and should be eliminated. Others believe that it helps them learn. Should homework be eliminated? Why or why not? State your position and support it with specific reasons and examples.

19. Think of your favorite television program. Convince a friend that he or she should be watching this show.

20. Good habits improve our physical, emotional, and/ or financial health. Select one of your good habits and write an essay persuading readers to make that habit part of their lives.

21. What is your all-time favorite book and why? Write an essay persuading readers to read this book.

22. What is your all-time favorite movie and why? Write an essay persuading readers to watch this film.

23. Today, there are more and more reality shows on television. Do these shows make good television? Why or why not? Explain your answer using specific reasons and examples.

24. Take a position on whether students should or should not be allowed to take calculators into the math classrooms. State your position and explain why students should or should not be allowed to take calculators into the math classroom.

25. Is "an eye for an eye" a good basis for determining an appropriate punishment? Why or why not? Use specific reasons and examples to explain your position.

26. Take a position on whether adolescents should or should not be allowed to get a tattoo. State your position and explain why adolescents should or should not be allowed to get a tattoo.

27. Many cities suffer from serious air and noise pollution- as well as endless traffic jams- because of too many cars. Some people feel that cities with extensive public transportation systems should ban passenger cars and force people to walk, bike, or use public transportation. Do you think this is a good idea? Why or why not?

28. On today's talk shows, guests and audience members often argue heatedly with each other, and on more than one occasion, guest and audience members have been hurt. Do today's talk shows go too far? Explain your answer.

29. Take a position on whether parents should or should not limit the amount of daily time spent on the internet. State your position and explain why parents should or should not limit the amount of daily time spent on the internet.

30. Have you ever done something that you know improved your life or the lives of others? Write an essay that convinces readers to take action for the better of themselves or someone else.

31. Carpooling, recycling, and planting trees are all activities that are good for the environment. Write an essay convincing readers to actively participate in one of these activities. 
32. The Internet includes many websites with images and content that are inappropriate. Should websites like these be censored by parents? Why or why not? State your position and support it with specific reasons and examples.

33. Some people prefer to live in the quiet of the country; others prefer the hustle and bustle of the city. Which do you think is the better choice? State your position and support it with specific reasons and examples.

34. Is there a book that you feel should be required reading for everyone? Write an essay persuading your audience to read this book?

35. Some people go right on to college after high school; others take a year or more off to work or travel. Which do you think is the better choice? State your position and support it with specific reasons and examples.

36. Today's top professional athletes often have salaries and bonuses in the tens of millions of dollars. Do you think these athletes deserve such high compensation? Why or why not? Explain your position and use specific reasons and examples.

37. Many parents do not allow their children to play with toy guns. In your opinion, is this a wise decision? Explain what you think parents should do about toy guns and why.

38. Some people think of the United States as a nation of "couch potatoes." Write an essay persuading readers to be more physically active.

39. Write a persuasive essay trying to convince your principal to allow students to use laptops in school. Use specific reasons and examples to explain your answer.

40. Some people believe that students aren't learning enough in school. Should classes be more difficult or are they at the right level now? Explain your answer using specific reasons and examples.

41. Sometimes parents or adults do not tell children that a loved one is sick or dying for fear that they will not be able to handle the news. Do you agree with this belief? Why or why not?

42. Some people fish to eat what they catch; others fish simply for the "sport," returning the fish to the water after they've caught it. Many animal rights activists argue that sport fishing is cruel and should be abolished. How do you feel about this issue? State your position and support it with specific reasons and examples.

43. Some people think that school cafeterias should be required to provide low-fat and/or vegetarian lunch options to accommodate the eating habits of all students. Do you agree or disagree? Explain your position and use specific reasons and examples as support.

44. Elementary and secondary schools around the country are beginning to actively address the problem of bullies. In your opinion, is bullying an issue that should be addressed by schools or left to parents? Use specific reasons and examples to support your position.

45. Most private schools require students to wear uniforms. Should public school students wear uniforms too? Argue for or against school uniforms for public school students. Use specific reasons and examples to support your position.

46. Do you think that the movie and/or TV ratings systems are effective or useful? Use specific reasons and examples to support your position.

47. Many people believe that honesty is the best policy. In your opinion, is it ever okay to lie? Explain your answer using specific reasons and examples. 
48. Students in your school have been leaving the cafeteria in a mess. In order to solve this problem, your principal asked students to take better care of the cafeteria, but the problem continued. Your principal's reaction is to cancel all extracurricular activities until the problem is resolved. Do you agree or disagree with his reaction? Use specific reasons and examples to support your position.

49. Your school just received a large sum of money as a gift, how do you think that money should be spent? Write an essay convincing school officials to allocate the money in the way you think is best for the school.

50. Many people feel that students are too competitive. Do you agree? If so, is this a good thing or a bad thing? Use specific reasons and examples to support your answer.

51. In our increasingly global society, many people feel that all students should be required to learn a foreign language before graduating from high school. Do you agree? Why or why not? Explain your position using specific reasons and examples.

52. Should people be allowed to drive while talking on a cell phone? Use specific reasons and examples to explain your answer.

53. The network that runs your favorite television show has suddenly decided to cancel it. Write a letter convincing the station to continue running the show.

54. Most students enjoy the long stretch of summer vacation, but some parents and educators feel that two and a half months is too long a break from school. Some argue that students and families would be better served if the school year were extended through July, with a three or four-week break in August, a longer winter break, and a week off each in the spring and fall. Should the school year be extended or kept the way it is? Why or why not? Explain your answer.

55. Should a parent limit the amount of Television and video games a child watches or plays? Take a position and explain your answer using specific reasons and examples.

56. Your principal has asked you to come up with a lunch menu for the school lunch. What would you serve and why? Use specific reasons and examples to support your position.

57. Students who don't want to write papers can find dozens of sites on the Internet that offer essays for sale. Do you think this is a good moral business, or should these sites be shut down? Use specific reasons and examples to support your answer.

58. Do you think the high school entrance exam is an accurate measure of a student's abilities to a high school? Support your position with specific examples.

59. Sometimes people stay quiet rather than saying the whole truth. Is not speaking considered lying? Why or why not? Explain your answer.

60. Many students complain about having to learn history. Why do we need knowledge of the past? Write an essay convincing them that learning about the past is important.

61. Some people rather not speak up when they see another person being bullied for fear of being bullied as well. Do you agree with this? Why or why not?

62. Many students believe that being late for school is alright. Do you agree with this? Why or why not? Support your position. 
APPENDIX G

TREATMENT FIDELITY PROCEDURE SHEET AND CHECKLIST 


\section{Treatment Fidelity Procedure Sheet and Checklist}

Completed by:

Date:

Place a check mark next to the statement if the behavior is observed.

General Study Procedures

1. Open classroom.

2. Turn on lights and AC.

3. Turn on the teacher computer and four Dell laptops.

4. Launch Microsoft ${ }^{\circledR}$ Word 2007 on all the laptops and have a new document opened and labeled with the participant's name.

5. Greet participants and provide juice and chips for them.

Persuasive Writing Instructions (Lesson might take more than 1 day)

1. Follow all of the General Study Procedures.

2. State: "Today I will teach you what persuasive writing is and the components of a persuasive essay. I will use a Powerpoint presentation, of which you will be given copies, to explain the objective of a persuasive essay and its different parts."

3. Pass out the handouts.

4. Open the Powerpoint presentation and teach the lesson.

5. State: "Now we will see an example of a good persuasive essay and an example of poorly written essay. Together we will score the essays using an analytical scoring guide for persuasive writing."

6. Pass out scoring rubric and read through it with the participants.

7. Open good essay on Microsoft® Word.

8. Read essay together.

9. Look for the arguments and supporting details.

10. Score essay together using the rubric.

11. Open poor essay on Microsoft ${ }^{\circledR}$ Word. 
12. Read essay together.

13. Look for the arguments and supporting details.

14. Have each participant score essay individually and then have them share.

15. Give students a writing prompt.

16. Have student practice writing a persuasive essay.

17. Using the rubric, have the students score their own essays.

18. Save the essays onto the thumb drive and score the essays using the rubric.

19. If the participants are able to compose a persuasive essay that stated arguments and supporting details and takes a convincing stand on a position, then move on to baseline. Otherwise explain the parts of persuasive writing and have the student compose another essay using a writing prompt.

Baseline Procedures and Intervention Procedures

20. Follow all of the steps of the General Study Procedures.

21. Give each participant who is still on baseline, two sheets of unlined paper and two sharpened number 2 pencils.

22. Open Inspiration ${ }^{\mathrm{TM}}$ and the persuasive template for the participants on intervention.

23. State: "Today, you will be given a writing prompt and asked to compose a persuasive essay on a prompt. The writing prompt is [read from prompt]. You will have a total of 40 minutes to write your essay. You must state your position, either you agree or disagree with the prompt. Remember the mnemonic TREE as you write your essays. T stands for Tell your position, $\mathrm{R}$ stands for the three reasons, E tells you to end or conclude your essay and the final E stands for examining or editing your writing. Those of you trained with Inspiration must use Inspiration for any planning or prewriting. Those not trained may use the paper and pencil for any planning or prewriting. All final drafts must be typed using Microsoft $\AA$ Word. You will be given up to 15 minutes for your planning. After 15 minutes you will be asked to move on to the writing. You do not need to wait to move on, simply raise your hand and inform me. After 20 minutes you will be asked to begin your editing. Are there any questions? You may begin." 
24. After 15 minutes remind the students to move on to the writing stage (if they have not done so).

25. After 20 more minutes remind the students to move on to the editing stage (if they have not done so).

26. After 5 more minutes ask the participants to stop if they have not done so. Save all of their essays on the thumb drive and all planning work done either by hand or on Inspiration.

Intervention Training of Inspiration ${ }^{\mathrm{TM}} 8.0$

27. As soon as a participant is ready to get trained on the computer graphic organizer, Inspiration ${ }^{\mathrm{TM}} 8.0$, he or she will be given training on the program during the trainer's planning time.

28. The program Inspiration ${ }^{\mathrm{TM}}$ will be opened to the persuasive writing template.

29. The participant will be taught how to create a main cluster, add and link clusters to it. He or she will also learn how to change the look of the clusters, font and colors.

30. After the participant has learned how to create clusters, the outline mode will be taught. Here the participant will learn how to move and reorganize sentences and the order of paragraphs.

31. The participant will then be taught how to transfer the outline from Inspiration $^{\mathrm{TM}} 8.0$ to Microsoft巴 Word. In Microsoft ${ }^{\circledR}$ Word the participant will then learn how to convert the outline into paragraphs to finish the essay.

Note any deviations or comments here. 
APPENDIX H

WRITING SAMPLE SCORING SHEET 


\section{Scoring Sheet}

Participant:

Date:

Phase:

Session \#:

Minutes Planning:

Minutes Writing and Editing:

Start Time:

End of Writing Time:

End of Planning:

End of Editing Time:

\section{Arguments and Supporting Details}

Arguments will be defined as a series of statements that establish a position to the premise (Andrews, 1995). An argument is composed of supporting details that help give logical support or rationale to the argument. Supporting details will be defined as the number of statements containing facts, logical support, or examples that support the writer's arguments and point of view.

During Planning Stage:
Arguments
Supporting Details

\begin{tabular}{|l|l|}
\hline & \\
\hline & \\
\hline & \\
\hline & \\
\hline & \\
\hline & \\
\hline & \\
\hline & \\
\hline
\end{tabular}


Total number of arguments: Total number of supporting details:

Present in the written essay.

Arguments

Supporting Details

\begin{tabular}{|l|l|}
\hline & \\
\hline & \\
\hline & \\
\hline & \\
\hline & \\
\hline & \\
\hline & \\
\hline & \\
\hline & \\
\hline
\end{tabular}

Total number of arguments: Total number or supporting details:

Total number of arguments present in planning and written essay:

Total number of supporting details present in planning and written essay:

\section{Writing Fluency}

The writing fluency is measured by the number of written words including misspelled or garbled words in the written essay.

Total number of words in the essay: 


\section{Syntax}

A T-unit is the shortest grammatically allowed sentence without creating any fragments between $\mathrm{T}$-units. It must contain a subject and a predicate. It also contains any dependent clause that would be a fragment if not attached to the sentence.

Read the essay. Separate the T-units by creating a slash after each complete T-unit. Count the total number of slashes.

Total number of T-units:

Length of each T-unit is the number of words in the T-unit. Record each one below.

\begin{tabular}{|l|l|l|l|l|l|l|l|l|}
\hline T-unit & Length & & T-unit & Length & T-unit & Length & T-unit & Length \\
\hline 1 & & 9 & & 17 & & 25 & \\
\hline 2 & & 10 & & 18 & & 26 & \\
\hline 3 & & 11 & & 19 & & 27 & \\
\hline 4 & & 12 & & 20 & & 28 & \\
\hline 5 & & 13 & & 21 & & 29 & \\
\hline 6 & & 14 & & 22 & & 30 & \\
\hline 7 & & 15 & & 23 & & 31 & \\
\hline 8 & & 16 & & 24 & & 32 & \\
\hline
\end{tabular}

Average length of the T-unit (total number of words divided by total number of Tunits):

\section{Overall Organization}

The Analytic Trait-Scoring Rubric (adapted from Monroe \& Trioa, 2006) allows the rater to score each organization aspect of the essay individually. Circle the appropriate score for each trait below.

\section{Premise/ Argument/Content}

6 Exceptionally clear, focused, and interesting: Writing holds the reader's attention throughout. Main premise and arguments stand out and are developed by strong support and rich details suitable to the audience. 
5 Clear, focused, and interesting. Writing holds the reader's attention. Main premise and arguments stand out and are developed by supporting details suitable to the audience.

4 Clear and focused: Reader can easily understand the main premise. Supporting details are present, although it may be limited or rather general.

3 Reader can understand main premise and arguments, although they may be overly broad or simplistic. Supporting details is often limited, insubstantial, overly general, or occasionally off topic.

2 Main premise and arguments are somewhat unclear or development is attempted but minimal.

1 Writing lacks a central premise. Paper is too short to develop arguments.

\section{Organization}

6 Organization enhances the central premise and its development. Order and structure are compelling and move the reader through the text easily.

5 Organization enhances the central premise and its development. Order and structure move the reader through the text.

4 Organization is clear and coherent. Order and structure are present but formulaic.

3 Attempt made to organize writing, however, the overall structure is inconsistent or skeletal.

2 Lacks structure. An occasional organizational device is discernible, however, the writing is either difficult to follow or the piece is simply too short to demonstrate organizational skills.

1 Writing lacks coherence. Organization seems haphazard and disjointed. Reader is confused.

\section{Sentence Fluency}

6 Writing has an effective flow and rhythm. Sentences show a high degree of craftsmanship, with consistently strong and varied structure that makes expressive oral reading easy and enjoyable.

5 Writing has an easy flow and rhythm. Sentences are carefully crafted, with strong and varied structure that makes expressive oral reading easy and enjoyable.

4 Writing flows, however, connections between phrases or sentences may be less than fluid. Sentence patterns are somewhat varied, contributing to ease in oral reading.

3 Writing is mechanical rather than fluid. Occasional awkward constructions may force rereading.

2 Writing tends to be either choppy or rambling. Awkward constructions often force rereading.

1 Writing is difficult to follow. Sentences tend to be incomplete, rambling, or very awkward.

\section{Word Choice}

6 Word choice is very well suited for the piece. The vocabulary is exceptionally clear and precise. Lively and memorable words paint a strong image in the reader's mind.

5 Word choice is well suited for the piece. The vocabulary is clear and precise. Some lively and memorable words help paint a strong image in the reader's mind. 
4 Word choice is adequate for the piece. The vocabulary is mostly clear and concise, but economy of expression could be improved. Some well-chosen words help the reader paint a mental image.

3 Word choice lacks precision, although it is generally acceptable. Economy of expression could be greatly improved. The reader must struggle to create a mental image because so many words lack vividness.

2 Word choice is generally poor. Many words lack explicitness or are used incorrectly. Some redundancy is evident. A mental image is almost impossible to create given the vagueness of the chosen vocabulary.

1 Word choice is very poor and may be indicative of a limited vocabulary. The chosen words are vague or are used incorrectly. Much redundancy is evident. The reader is confused and unable to paint a mental image.

\section{Conventions}

6 Writing demonstrates exceptionally strong control of standard writing conventions (i.e., spelling, capitalization, and punctuation) and uses them effectively to enhance communication. Paper is free from errors or they are very minor.

5 Writing demonstrates strong control of standard writing conventions and uses them effectively to enhance communication. Errors are few and noticeable only if reader searches for them.

4 Writing demonstrates control of standard writing conventions. Minor errors, while perhaps noticeable, do not impede readability.

3 Writing demonstrates limited control of standard writing conventions. Errors impede readability.

2 Writing demonstrates little control of standard writing conventions. Frequent, significant errors impede readability.

1 Numerous errors in standard writing conventions make text very difficult to read. Severity and frequency of errors are overwhelming. Reader finds it difficult to focus on message and must reread.

Sum of Score:

Average score in writing from writing rubric:

(Sum of scores divided by 5) 
APPENDIX I

SAMPLE DATA LOGS 


\section{Arguments and Supporting Details}

Participant:

Rater:

$A=$ Arguments $\quad S D=$ Supporting Details

\begin{tabular}{|c|c|c|c|c|c|c|c|}
\hline \multirow[t]{2}{*}{ Date } & \multirow{2}{*}{$\begin{array}{l}\text { Writing } \\
\text { Prompt } \\
\quad \#\end{array}$} & \multicolumn{2}{|c|}{ Planning } & \multicolumn{2}{|c|}{ Written Essay } & \multicolumn{2}{|c|}{ Planning to Essay } \\
\hline & & $\begin{array}{c}\text { \# of } \\
\text { Arguments }\end{array}$ & $\begin{array}{c}\text { \# of } \\
\text { Supporting } \\
\text { Details }\end{array}$ & $\begin{array}{c}\text { \# of } \\
\text { Arguments } \\
\end{array}$ & $\begin{array}{c}\text { \# of } \\
\text { Supporting } \\
\text { Details }\end{array}$ & $\begin{array}{c}\text { \# of } \\
\text { Arguments }\end{array}$ & $\begin{array}{c}\text { \# of } \\
\text { Supporting } \\
\text { Details }\end{array}$ \\
\hline & & & & & & & \\
\hline & & & & & & & \\
\hline & & & & & & & \\
\hline & & & & & & & \\
\hline & & & & & & & \\
\hline & & & & & & & \\
\hline & & & & & & & \\
\hline & & & & & & & \\
\hline & & & & & & & \\
\hline & & & & & & & \\
\hline & & & & & & & \\
\hline & & & & & & & \\
\hline & & & & & & & \\
\hline & & & & & & & \\
\hline & & & & & & & \\
\hline & & & & & & & \\
\hline & & & & & & & \\
\hline & & & & & & & \\
\hline & & & & & & & \\
\hline & & & & & & & \\
\hline
\end{tabular}


Writing Fluency

\section{Participant:}

Rater:

\begin{tabular}{|c|c|c|c|}
\hline Date & $\begin{array}{l}\text { Writing } \\
\text { Prompt \# }\end{array}$ & $\begin{array}{l}\text { Total } \\
\text { \# of Words }\end{array}$ & $\begin{array}{l}\text { Fluency } \\
\text { Rate }\end{array}$ \\
\hline & & & \\
\hline & & & \\
\hline & & & \\
\hline & & & \\
\hline & & & \\
\hline & & & \\
\hline & & & \\
\hline & & & \\
\hline & & & \\
\hline & & & \\
\hline & & & \\
\hline & & & \\
\hline & & & \\
\hline & & & \\
\hline & & & \\
\hline & & & \\
\hline & & & \\
\hline & & & \\
\hline & & & \\
\hline & & & \\
\hline
\end{tabular}




\section{Syntax Log}

Participant:

Rater:

\begin{tabular}{|c|c|c|c|}
\hline Date & $\begin{array}{l}\text { Writing } \\
\text { Prompt \# }\end{array}$ & $\begin{array}{l}\text { Total } \\
\text { \# of T-Units }\end{array}$ & $\begin{array}{l}\text { Average \# of } \\
\text { Words in T-unit }\end{array}$ \\
\hline & & & \\
\hline & & & \\
\hline & & & \\
\hline & & & \\
\hline & & & \\
\hline & & & \\
\hline & & & \\
\hline & & & \\
\hline & & & \\
\hline & & & \\
\hline & & & \\
\hline & & & \\
\hline & & & \\
\hline & & & \\
\hline & & & \\
\hline & & & \\
\hline & & & \\
\hline & & & \\
\hline & & & \\
\hline & & & \\
\hline
\end{tabular}




\section{Overall Organization}

Participant:

Rater:

$\mathrm{P}=$ Premise $/$ Argument $\mathrm{O}=$ Organization $\mathrm{S}=$ Sentence Fluency $\mathrm{W}=$ Word Choice $\mathrm{C}=$ Conventions Rating Scale is from 1 to 6 .

\begin{tabular}{|c|c|c|c|c|c|c|c|}
\hline Date & $\begin{array}{l}\text { Writing } \\
\text { Prompt \# }\end{array}$ & $P$ & O & $S$ & W & C & $\begin{array}{l}\text { Average } \\
\text { Score }\end{array}$ \\
\hline & & & & & & & \\
\hline & & & & & & & \\
\hline & & & & & & & \\
\hline & & & & & & & \\
\hline & & & & & & & \\
\hline & & & & & & & \\
\hline & & & & & & & \\
\hline & & & & & & & \\
\hline & & & & & & & \\
\hline & & & & & & & \\
\hline & & & & & & & \\
\hline & & & & & & & \\
\hline & & & & & & & \\
\hline & & & & & & & \\
\hline & & & & & & & \\
\hline & & & & & & & \\
\hline & & & & & & & \\
\hline & & & & & & & \\
\hline & & & & & & & \\
\hline & & & & & & & \\
\hline
\end{tabular}


APPENDIX J

INTERRATER RELIABILITY FORM 
Inter-Observer Agreement (IOA) Form

Participant:

Prompt \#:

Session Date:

Directions: This sheet compares the data collected by the researcher with the data collected by the second observer. Using the data sheets independently completed by the researcher and the observer, do a comparison of their marks in each of the following three categories.

\section{Arguments and Supporting Details}

Arguments and Supporting Details in Planning Stage

\# of Arguments agreed upon:

\# of Arguments in disagreement:

\# of Supporting Details agreed upon:

\# of Supporting Details in disagreement:

Arguments and Supporting Details in Written Essay

\# of Arguments agreed upon:

\# of Arguments in disagreement:

\# of Supporting Details agreed upon:

\# of Supporting Details in disagreement:

Arguments and Supporting Details in Planning that appear in Written Essay

\# of Arguments agreed upon:

\# of Arguments in disagreement:

\# of Supporting Details agreed upon:

\# of Supporting Details in disagreement:

Total \# of Agreements $\div$ \# Total \# of Disagreements with Agreements $x$ $100=$ $\%$ IOA 


\section{Writing Fluency}

\# of words from rater 1:

\# of words from rater 2 :

Smaller \# of the 2 $\div$ greater $\times 100=$ $\% \mathrm{IOA}$

\section{Syntax}

\# of T-units from rater 1:

\# of T-units from rater 2:

Smaller \# of the 2 $\div$ greater $\times 100=$ $\%$ IOA

\section{Organization}

Total Score from Rater 1:

Total Score from Rater 2:

Smaller \# of the 2 $\div$ greater $\times 100=$ $\%$ IOA 
APPENDIX K

PERSUASIVE WRITING GRAPHIC ORGANIZER TEMPLATE 
Persuasive Writing Template

*adapted and modified from Inspiration ${ }^{\mathrm{TM}} 8.0$ Templates

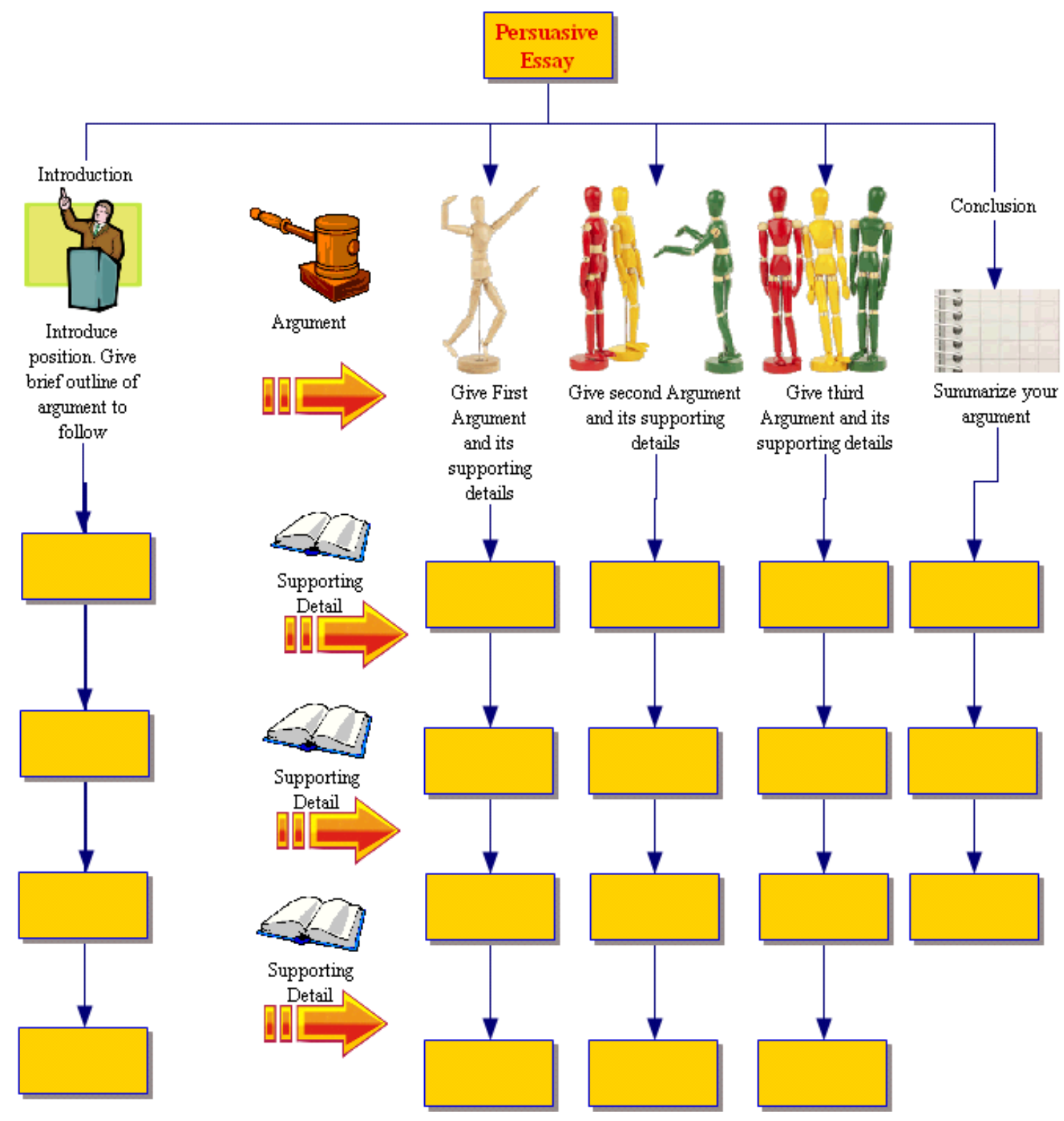


APPENDIX M

PERSUASIVE WRITING POWERPOINT OUTLINE 


\title{
Outline of Presentation \\ Persuasive Writing
}

\author{
Persuasive Essays \\ \# Is a written essay in which a writer presents a case for or against a particular \\ position. \\ * Each logical supporting argument, powerful image, or striking verbal phrase is \\ a step towards persuading your audience to your cause. \\ Persuasive Essays \\ \# Deal with an issue that has more than one side \\ * Has a clear organization that builds toward a conclusion. \\ * States clearly the writer's position or premise. \\ \# Includes arguments supporting the writer's position: statistics, expert \\ opinions, and personal observations \\ * Uses powerful images verbal or pictorial

\section{Audience and Purpose} \\ * Audience: Whom you want to convince \\ \# Purpose: To convince the reader to your cause.

\section{Providing Support} \\ * Logical Arguments- Take your readers step-by-step through your argument \\ and present accurate evidence to earn their trust \\ * Appeal to basic values- Call on ideas that all readers support \\ Appeal to emotions- May take form of a brief story or vivid image \\ * Repetition and parallelism- The use of sentences with identical forms \\ strengthen your presentation

\section{How to structure the essay: TREE} \\ \# Tell: State what your position is and where you stand. \\ * Reasons: Provide at least three reasons (arguments) with supporting \\ statements (each one should be a paragraph). \\ * End: Conclude your essay by restating your position \\ * Edit: Check your essay, not only for grammar but for organization \\ Example 1: (adapted from Hoover, et al., 1995)
}

One day my class earned some money. And we have to decide how to spend it and I think I got an idea. I think we should give it to the school because can buy materials for the clases or they could put more equipment for gym. Or we could give it to the neighborhood and they could buy like plants to put around the streets and stuff. I think that because the buget the school do not have the money to buy that stuff but if some classes could raise some money that would be great! So see hear I have a great way to spend the money

Example 2: (adapted from Hoover, et al., 1995)

I think that the extra money should be used to build a new, larger gym at our school. The gym we have right now is much too small, and has no bleachers. Because of this, few people get to cheer on or basketball teams. There is only a couple of feet 
between the walls of the gym and the out- of-bounds line, so spectators are sometimes interfering with play. Also, if more spectators came, the school would get more money from admission fees and food or drinks that are sold.

A new gym would also help with our PE classes. As it is, the gym is very crowded when a whole grade is inside for PE. A larger gym would make PE more enjoyable on rainy days when we have to stay inside because of more room for us to play. It would be safer, too, since we wouldn't be running into each other and tripping over somebody else's feet. This way, there would be a lot less risk of someone getting injured.

A bigger gym would make the athletic program at our school better. The basketball players could practice in a regular size gym, and perform better when they are at another school to play a game. With new equipment, everybody could do something that they enjoy, instead of being bored with PE or not participating. People in my school could stay in shape, and enjoy doing it.

The gym is not in as good shape as it should be. The basketball backboards have been around a while and are not in great shape. The floor is slippery, and the stage at one end of the gym gets in the way. People often knock balls up there, and have to delay whatever game they're playing to get the ball.

A new longer gym could make the school safer, look better for the school, and would make PE more enjoyable. 
APPENDIX M

PERSUASIVE WRITING COMPONENTS ASSESSMENT 


\section{Persuasive Writing Components Assessment}

Participant:

Student was able to successfully:

1. Locate the premise statement of the essay.

2. Locate at least 3 arguments supporting the premise.

3. Locate at least 1 supporting detail for each argument found.

4. Locate the conclusion paragraph. 
VITA

CARIDAD H. UNZUETA

1993-1996

Work Study

Computing Facilities

University of Miami

Coral Gables, Florida

1996

B.S., Mathematics

University of Miami

Coral Gables, Florida

1997-1998

Mathematics Teacher

La Salle High School

Coconut Grove, Florida

1998-2000

Mathematics Department Chair

Archbishop Coleman F. Carroll High School

Miami, Florida

1999

M.S., Mathematics Education

Florida International University

Miami, Florida

2000-2007

Academic Dean

Archbishop Coleman F. Carroll High School

Miami, Florida

2003

Ed. S., Educational Leadership

Florida International University

Miami, Florida

\section{PUBLICATIONS AND PRESENTATIONS}

Unzueta, C. H. (2006). The impact of note-taking strategies on comprehension of high school students with specific learning disabilities. In A. Nevin (Ed.) Reviews of single subject research designs: applications to special education and school psychology, Miami, FL: Florida International University. (ERIC Document Reproduction Service No., ED491545)

Moores-Abdool, W., \& Unzueta, C. H. (2007, October). Response-to-Intervention: Current Research-Based Interventions. Poster session presented at the annual meeting of the Florida Council for Exceptional Children, Fort Lauderdale, FL. 
Moores-Abdool, W., Vazquez-Donet, D., \& Unzueta, C. H. (2007, November). Chronicles of Change: A brief history of Specific Learning Disabilities. Poster session presented at the annual meeting of the Teacher Education Division Conference Council for Exceptional Children, Milwaukee, WI.

Valle-Riesta, D.M., Anderson, L., Carithers, S., Guzman-Cordero, I., Heineken, D., Hernandez, H., Robin, S., Ugalde, C., \& Unzueta, C. H. (2007, October). Exercising leadership and engaging in reflective thought with master's level special education teachers. Seminar presented at the annual meeting of the Florida Council for Exceptional Children, Fort Lauderdale, FL.

Moores-Abdool, W., Unzueta, C.H., Vazquez-Donet, D., \& Bijlsma, E. (2008). Discrepancy dinosaurs and the evolution of Specific Learning Disability Assessment. Journal of Scholarship Teaching and Learning, 8(2), 77-83.

Unzueta, C. H. (2008). "Like a family": Perspectives of doctoral students from traditionally under-represented populations on cohorts. Proceedings of the College of Education Research Conference at Florida International University, USA, 151-157, Available from http://coeweb.fiu.edu/Research_Conference/Proceedings.html

Unzueta, C. H. (2008). Using a bilingual reading strategy to reduce SLD numbers. Proceedings of the College of Education Research Conference at Florida International University, USA, 158-161. Available from http://coeweb.fiu.edu/Research_Conference/Proceedings.html

Unzueta, C. H., Moores-Abdool, W., \& Vazquez-Donet, D. (2008). A different slant on cohorts: Perceptions of professors and special education doctoral students. Miami, FL: American Educational Research Association Conference. (ERIC Document Reproduction Service No. ED500897)

Barbetta, P., Silio, M., Unzueta, C. H., \& Bijlsma, E. (2008, October). Computer graphic organizers, word prediction, and text-to-speech: Useful technologies for the writing process. Seminar presented at the annual meeting of the Florida Council for Exceptional Children, Sarasota, FL.

Unzueta, C. H., Moores-Abdool, W., \& Vazquez-Donet, D. (in press). Perceptions of special education professors and culturally linguistically diverse doctoral students on cohorts. Teacher Education Special Education Journal. 